

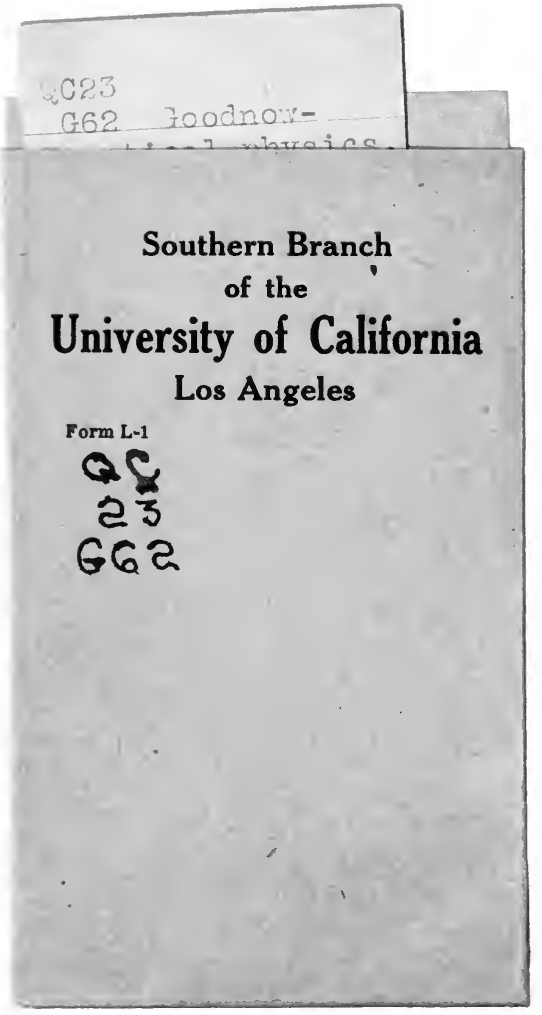


This book is DLE on last date stamped below JAN \&4 1927 oW

MAY \& 91956 




\section{B O O K S \\ BY \\ MINNIE GOODNOW, R. N.}

\section{First-Year Nursing}

$12 \mathrm{mo}$ of 351 pages, illustrated. Cloth, $\$ 1.75$ net. Sccond Edition.

\section{Outlines of Nursing History}

12 mo of 370 pages, with 88 illustrations.

Cloth, $\$ 2.00$ net.

\section{War Nursing}

$12 \mathrm{mo}$ of 172 pages, illustrated. Cloth, $\$ 1.50$ net.

Practical Physics for Nurses 12 mo of 203 pages, with 100 illustrations. Just Ready. 


\title{
PRACTICAL PHYSICS FOR NURSES
}

\author{
By \\ MINNIE GOODNOW, R. N.
}

Author of "First-Year Nursing," "Outlines of Nursing History," "War Nursing," "Ten Lessons in Chemistry for Nurses," and "The Nursing of Children"; formerly Directress of Nurses, Milwaukee County Hospital; formerly Superintendent of the Woman's Hospital, Denver, and of the Bronson? Hospital, Kalamazoo; Specialist in Hospital Equipment

WITH 100 ILLUSTRATIONS

PHILADELPHIA AND LONDON

W. B. SAUNDERS COMPANY 1919

38427 
Copyright, 1919, by W. B. Saunders Company

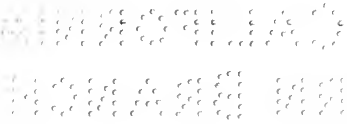

PRINTED IN AMERICA

PRES8 OF

W. B. SAUNDERS COMPAKY

PHILADELPHIA 


\section{$Q C 23$
$G 62$}

\section{FOREWORD}

THE criticism is often made that nurses are not intelligent about the handling of ordinary household and hospital appliances, and that they make no attempt

$M$ to understand the workings of plumbing, heating and $\checkmark$ ventilating apparatus, surgical instruments and appa- ratus, etc.

The fault lies not so much in the nurse herself, nor in any lack of inclination to learn, as it does in the fact that she has not been taught the laws which govern 6 some of the simplest activities of life. Very many - nurses are not high-school graduates, and of those who are, not all have studied physics, nor know how to apply their knowledge to nursing.

Both Physics and Chemistry are of great importance to a nurse, because they are, at bottom, sciences of common life. The human anatomy is built in accordance with the laws of physics, and its movements are governed by them. It is necessary, therefore, if a nurse is to do intelligent work, that she should know some of the existing laws of physics, and how her pątients, her hospital environment, and all her work are controlled by them.

This subject has been a much-neglected one in hospital training-schools, chiefly because there was no text-book concerning it which was suited to nurses. 
The following lessons have been prepared in the endeavor to give briefly some of the more important laws of physics, especially those which apply to daily life and to a nurse's work. No effort has been made to cover the whole subject, but only to select from it some of the principles which apply most obviously and directly to hospital life and to nursing. There are many laws of physics not even mentioned in the following pages.

The apparatus and supplies for the illustrative experiments are of the simplest sort. Most hospitals will already have them in stock.

The author wishes to acknowledge her indebtedness to Mr. William H. Smiley, educator, and to Dr. Horace Greeley Wetherill, surgeon, for careful and invaluable criticism of the manuscript, and to Miss Kinsey for correction.

September, 1919.

Minnie Goodnow, R. N. 


\section{CONTENTS}

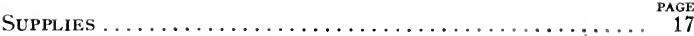

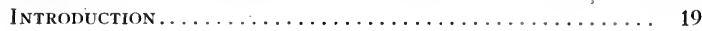

CHAPTER I

Matter. Its Composition .................... 21

CHAPTER II

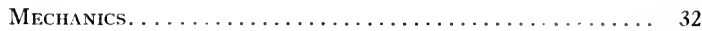

CHAPTER III

Mechanics (Continued) $\ldots \ldots \ldots \ldots \ldots \ldots \ldots \ldots \ldots \ldots, 41$

CHAPTER IV

HYdraulics.......................... 60

CHAPTER V

Pneumatics.............................. 73

CHAPTER VI

Pneumatics (Continued) ..................... 85

CHAPTER VII

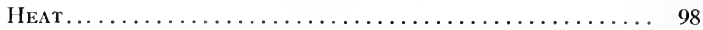

CHAPTER VIII

Heat (Continued) . . . . . . . . . . . . . . . . . 115

CHAPTER IX

SOUnd.............................. 130

CHAPTER $\mathrm{X}$

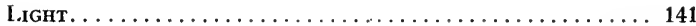


Electricity. . . . . . . . . . . . . 163

\section{CHAPTER XII}

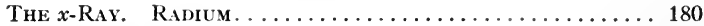

\section{CHAPTER XIII}

Questions for Review of Principles and Original Thinking 190

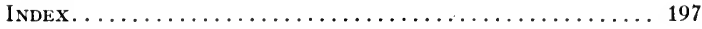




\section{PRACTICAL PHYSICS FOR NURSES}

\section{SUPPLIES}

THE following will be sufficient to enable one to make the experiments suggested in this book:

Two quart flasks.

Several large corks, one which shall fit flask, being perforated for two tubes.

Glass tubing, pieces 6 to 18 inches long, two sizes; one piece bent into a $\mathrm{U}$-shape.

Rubber tubing, a few short pieces to fit glass tubing.

One dozen test-tubes, with holder.

A few microscope slides.

Two bath thermometers, or other unmounted thermometers.

One thermometer with scale to $25^{\circ} \mathrm{F}$.

A glass prism.

A square bottle.

Two lamp chimneys.

Small quantities of sulphuric acid, copper sulphate, alum, sugar, touch-paper.

\section{APPARATUS}

If possible, bring into class or arrange to have class see the following:

Axis-traction forceps.

Bulb syringe.

Electric cautery.

Electric battery or cell, wet form.

Electric toaster.

Glass dressing syringe.

Glass irrigator, with uterine point. 
Head-mirror.

Hypodermic syringe.

Laryngoscope.

Microscope.

Obstetric chart, showing progress through pelvis.

Rectal dilators.

Reading glass.

Stomach-tube.

Sphygmomanometer.

Urine centrifuge.

Urinometer.

Uterine dilator.

$x$-Ray apparatus. 


\section{INTRODUCTION}

Physics is the science of every-day life, and relates to most of our ordinary activities. The wind and weather, our houses and their contents, all work and play, all personal and commercial activities involve the laws of physics.

We find ourselves annoyed or defeated because things "won't work" as we wish them to. Usually the reason is that we are attempting to make them act in opposition to the laws of nature; we do this because we do not know what those laws are, nor to what extent they govern the world. A very elementary knowledge of these common laws will not only help us to do our daily tasks . with greater ease, but will make them vastly more interesting and meaningful.

A knowledge of physics is essential not only to the skilful use of hospital and nursing appliances and equipment, but to an understanding of the structure and functions of the human body. Dr. John C. Draper says: "There is not a tissue, organ, nor function of the body the proper comprehension of which does not involve a knowledge of the laws of physics. There is hardly a principle of physics which does not apply to the human body."

The bony structure, the attachment of muscles, the 
working of the heart, blood-vessels and respiratory organs, the acts of seeing and hearing, etc., all depend upon the laws of physics; while apparatus and appliances for the treatment of disease can hardly be used intelligently or effectively without a comprehension of these same laws.

Physics, in its logical limits, is an abstruse and difficult subject. The fundamental principles are, however, extremely simple and can be understood even by untrained minds. The mere committing to memory of some of its laws will serve to elucidate, throughout one's life, many appliances and occurrences.

It is recommended that all the experiments given, however simple or familiar, be actually made in class, so that the full force of their meaning and application may come at the psychologic moment. 


\section{CHAPTER I}

\section{MATTER. ITS COMPOSITION}

MAN has always been eager to know of what things were made, and why inanimate objects act as they do. Physics and Chemistry are the two sciences which have been developed in this search for knoweldge. Chemistry is, in reality, a branch of Physics.

Physics is the science of matter, its properties, changes, and motions.

Matter is anything which we can see, feel, or handle; anything which occupies space.

Simple and Complex Substances.-Some substances, or portions of matter, are simple; some are complex.

Wood, for example, is a complex substance. If, in attempting to find out of what it is made, we divide it into minute pieces, we spoil or destroy it and cannot make it into wood again. If we heat it, we also destroy it.

Iron, on the other hand, is a simple substance. If we divide it into ever so fine particles, we can still identify it as iron; if we heat it ever so hot, as soon as it cools it is plainly iron; we have not spoiled nor destroyed it by what we have done to it.

The Ultimate Composition of Matter.-With even the 
simplest substance, after we have divided it into the smallest particles possible, we have not found out its real composition. We imagine that if we were able to divide it still further we might get at this knowledge. We find that scientists have been able, in what seem rather roundabout ways, but which are none the less exact, to accomplish this.

Scientists have agreed that all matter is made up of tiny particles, called molecules, ${ }^{1}$ which in a simple substance like iron are all alike.

It is agreed that molecules are composed of still smaller particles, called atoms, which may or may not be alike, but which together form a definite substance, either simple or complex. There may be few or many atoms in a molecule, the number varying from two to fifty or more. .

The assumption that matter is composed of molecules, which are themselves composed of atoms, is called the Atomic Theory. While merely a theory which it is not possible to prove, it so well accounts for everything which man has observed that it is generally accepted as fact.

A particle is the smallest subdivision of matter that can be obtained by mechanical means.

A molecule is the smallest portion of matter which can exist alone.

${ }^{1}$ It is estimated that there are 2,000,000,000,000,000,000,000,000 molecules in a drop. 
An atom is the smallest portion of matter which can exist in combination.

Much modern research has been directed toward discovering the make-up of atoms; the electron theory has been formulated, and is by some scientists regarded as proved. This theory holds that each atom is composed of many infinitely small particles, which are called corpuscles. All of these corpuscles are electrically charged, part of them being positive and part negative; such being the case, they mutually attract one another and hold together to form the atom. Heat or other forces may loosen the attraction, so that some of the negatively electrified corpuscles may fall off, in which case they promptly attach themselves to some other atom. In certain substances which we call "radio-active" (See Chapter XII) corpuscles are more or less constantly and forcibly being expelled from the atom.

Physics concerns itself with molecules. Chemistry concerns itself with atoms, and deals with the minute structures and change of matter.

Chemical and Physical Changes.-If we heat water to the boiling-point, it changes into steam. If we subject it to sufficient cold, it changes into ice. These are changes in form only. They are called physical changes.

If we heat sugar, it melts, bubbles, boils, turns brown, gives off smoke, and finally becomes a charred, black mass, which is plainly no longer sugar. 
Experiment.-Take a small tin plate or dish, grasp it with forceps, place on it a small amount of white sugar, and hold it over a gas, alcohol, or other flame. Note the various changes which take place as the heating progresses, and the resulting black mass, which is almost pure carbon. This is a change in composition. It is called a chemical change.

A physical change is a change in the form of a substance.

A chemical change is a change in the composition of a substance.

\section{PROPERTIES OF MATTER}

The molecules of any substance, no matter how compact it seems to be, do not touch each other. In hard, firm substances they are close together; in soft or loose substances, further apart; but they are always slightly separated, the distance between being very little, yet enough to admit of motion. (See Heat.)

The force which holds molecules in place or together is called cohesion.

The force which holds atoms together is called chemical affinity.

Cohesion holds molecules of the same sort together, as iron to iron. It is cohesion which makes an iron bar or a piece of wood firm and strong.

Adhesion is the force which holds molecules of unlike substances together; for example, grease or dirt adheres to a utensil.

Experiment.-Press two plates of glass (microscope slides or window glass) together. You will find it somewhat difficult to separate them; it is most easily done by sliding, which separates them particle by particle. Wet the surface with water or oil and again press together; they will separate with still greater difficulty. The water or oil has greater adhesion than the glass. 
Reduce the force of cohesion and you increase the force of adhesion. Water or oil has less cohesion than glass - $i$. e., is less firmly held together-and therefore adheres more closely to the solid object. Grind rock salt to powder and it dissolves more readily; the cohesion in the large lump being broken up, adhesion between the salt and water, unlike substances, takes place more easily.

Some of the properties, or inherent qualities, of matter are as follows:

\section{GENERAL PROPERTIES}

Extension is self-evident. Divisibility is also selfevident.

Mobility.-It is readily apparent that all substances are movable if sufficient force is applied.

Impenetrability.-One thing cannot occupy the same space as another at the same time. In instances where it seems to occur, as when a sponge is placed in water, it is merely that the molecules of one substance are between those of the other; the water, in this case, fits around the sponge, but is not occupying the same space.

Experiment.-Fit a funnel tightly into the mouth of a bottle, so that no air can pass around the stem of the funnel. Pour water into the funnel; only a little of it runs into the bottle, though the latter is apparently empty. Why? Because the bottle is already full of air. Loosen the funnel so that the air in the bottle can escape, and the water readily runs in. Difficulty in filling a hotwater bag arises when so large a stream of water is used that it blocks the exit of the air; a smaller stream overcomes the difficulty. 
Inertia is a quality which all matter possesses to a marked degree. It is the property which makes matter, when let alone, continue to do what it is doing. If it is moving, it tends to keep on. If it is at rest, it tends to remain so. When we attempt to move an object, we feel the resistance of its inertia; when we attempt to stop a moving object, we also feel the resistance of inertia. A railroad train, for example, is difficult to either start or stop because of its inertia. A ball thrown from the hands stops only because of the pull of gravity and the resistance of the air; it tends to go on.

Experiment.-Place a card on the end of the finger, and a coin on the card. Strike the card lightly out of its place. The coin will remain, because of its inertia.

Porosity.-If we accept the molecular theory, all matter is porous. We usually apply the term, however, only to substances in which the quality is marked.

Experiment.-Take a quantity of loose absorbent cotton, and put it piece by piece into a small tumblerful of alcohol; nearly a quart can be put into the alcohol before the tumbler overflows. This is due to the porosity of both alcohol and cotton. Examine the stone filter from a water-sterilizing apparatus; one would say that it is not porous at all, yet water goes through it if under pressure.

Porosity involves compressibility. All substances are compressible, but in varying degrees; it is merely a question of applying sufficient force to drive the molecules closer together. Air and all gases are readily compressible. Some solids are. Liquids are hardly compressible at all. 
Elasticity is a quality which substances possess in varying degrees. Some return to their original shape and size when compressed, some do to an extent, some not at all. Some substances are rapidly elastic, some slowly.

\section{SPECIFIC QUALITIES}

There are numerous special qualities, those possessed only by certain substances.

Hardness occurs in varying degrees. Lead and wood seem hard, but may be easily cut. The diamond is the hardest known substance.

Opacity, the quality which prevents light from passing through a substance, and transparency, the quality which permits its passage, are important qualities which vary greatly in different sorts of matter.

Tenacity, that is, the ability to keep its particles together, varies greatly in different substances. Its opposite is brittleness. Important manifestations of tenacity are: malleability, the quality which permits a substance to be hammered into thin sheets, and ductility, the quality which permits it to be drawn out into fine threads. For example, gold may be beaten into sheets $\frac{1}{4000000}$ inch in thickness, or so thin that 1 ounce will cover 100 square feet. Platinum is extremely ductile, but the finest thread we know is that of the spider's web; this is used in some scientific apparatus (the microscope, surveying instruments) because no artificial thread is so fine. 
Tendency to crystallize is a property of nearly all solid substances. Under favorable circumstances most substances tend to arrange themselves in the form of crystals.

Experiment.-Make a tumblerful of a saturated solution of alum, hot. Hang in it a circle of wire or stiff string and leave it overnight or longer; the circle will be covered with crystals.

When water crystallizes, in freezing, the crystals require more room than the liquid and insist upon expanding; this is the reason that water-pipes burst when they freeze.

\section{FORMS OF MATTER}

Original Forms of Matter.-Matter exists normally in three forms: solid, liquid, and gas.

These forms are due to the weakness or strength of the force of cohesion between their molecules. Solids have their molecules close together and are held firmly; in liquids the molecules are farther apart and are held loosely; in gases they are still farther apart and tend to recede from each other.

We think of these three forms as characteristic of certain substances themselves, whereas, in reality, they depend entirely upon temperature.

Change of Form.-Water is the best example of a substance which can be converted into the form of a solid, liquid, or gas. The same changes are possible in all substances, but with many the change is difficult to accomplish, and in some cases we have not yet learned how to do it without damage. For example, iron can be liquefied by applying a very high temperature; it may 
also be vaporized, but it takes an incredible degree of heat to accomplish it. Sugar is an example of a solid substance which, if carefully heated, may be changed to a liquid. Air, which we think of as a gas, can be made liquid by an extreme degree of cold; and it has even been changed into a solid mass by still greater cold.

Diffusion.-Solids may be diffused-i.e., the molecules driven farther apart-(1) by melting; (2) by solution; (3) by dialysis.

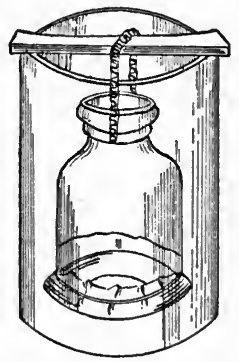

Fig. 1.-Dialyzer (Bliss and Olive).

In dialysis, the given mixture is placed in a small jar having a parchment paper bottom; this is set into a jar of pure water. Any crystalloid substance will soak out through the parchment into the water, where its presence may be discovered by chemical tests. This method is used for examining stomach contents in cases of suspected poisoning. It is not applicable to colloid substances. 


\section{BRANCHES OF PHYSICS}

Mechanics is the branch of physics which deals with solid bodies and the laws that govern them.

Hydraulics is the branch which deals with liquids and the laws that govern them.

Pneumatics is the branch which deals with gases and the laws that govern them.

All three of these branches of science apply to daily life, to the human body, and to nursing.

\section{SUMMARY}

Physics is the science of every-day life. It treats of matter, its properties, changes, and motions. A knowledge of it is necessary in order to deal satisfactorily with household or hospital appliances; and for a correct understanding of the human body and its functions.

Substances are simple or complex, $i$. e., composed of one or several elements.

The Atomic Theory has been accepted because it accounts for all natural phenomena. It assumes that all matter is composed of molecules (the smallest portions of matter that can exist alone), which are themselves composed of atoms (the smallest portions of matter that can exist in combination). Physics concerns itself with molecules. Chemistry, a branch of physics, concerns itself with atoms.

A physical change is the change in the form of a substance. 
A chemical change is the change in the composition of a substance.

Neither atoms nor molecules are in actual contact with each other. Atoms are held together by chemical affinity; molecules of the same sort by cohesion; molecules of different sorts by adhesion.

The general properties or characteristics of matter are extension, divisibility, mobility, inertia, porosity, compressibility, etc.

Some of the specific properties of matter are hardness, opacity, transparency, tenacity, brittleness, tendency to crystallize, etc.

Matter exists in three forms-solid, liquid, and gas. These forms are due to the strength or weakness of cohesion between their molecules. This depends upon their temperature, which is a relative matter. As a rule, low temperatures cause matter to solidify, high temperatures cause it to liquefy, still higher cause it to become gaseous.

Mechanics is the science of solids. Hydraulics is the science of liquids. Pneumatics, the science of gases. 


\section{CHAPTER II}

\section{MECHANICS}

\section{LAWS RELATING TO SOLIDS}

Gravity is the force which the earth exerts on all sorts of matter. The earth pulls everything-solids, liquids, or gases - toward its center. This pull is exerted in a straight line, directly to the center of the earth. It is called the "line of direction." The exact direction of this pull is shown by the plumb line used by builders, artists, etc. A building which is "out of plumb" is likely to fall sooner or later, since the foundation may be unable to hold the top against the pull of the earth.

It is this pull of the earth which causes objects to fall when not supported, makes the rain and snow descend, water to run down hill, etc.

Weight.-Another manifestation of the pull of the earth is what we call weight. Since the earth pulls equally on every molecule, it give us a convenient method of finding out the quantity of matter in a mass. Weight may be defined as the measure of the force of gravity upon an object.

We must distinguish clearly between amount of matter, which refers to the number of molecules in it; and volume, which refers to the space it occupies. There is the same amount of matter in a pound of lead and a 
pound of feathers, but there is a very great difference in the volume of the two. Weight indicates the amount of matter, but has no relation to volume.

The specific gravity, or specific weight, of any substance is its weight as compared with an equal volume of some substance taken as a standard. In the case of solids and liquids water is used as the standard (distilled water at a temperature of $4^{\circ} \mathrm{C}$.); with gases, hydrogen gas at $0^{\circ} \mathrm{C}$. For example, water is called 1.000. Gold is 19.5 (meaning that it is $19 \frac{1}{2}$ times as heavy as an equal volume of water); copper is 8.788 ; coal, 1.270; urine, about 1.020; olive oil, .970; alcohol, .797 ; ether, .734; wood, .580; cork, .240, and so on.

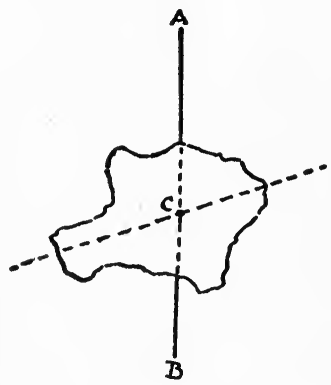

Fig. 2.-Center of gravity.

The Center of Gravity of an object is the point on which it will just balance itself, no matter in what position it is placed. It is, to state it differently, the weight center of the object. 
Equilibrium is poise or balance between two or more forces. It causes a body to remain stable when there are forces tending to move it.

The stability of an object depends upon the relation of its center of gravity to its base. A large base or a low-down center of gravity gives a greater stability.

There are three sorts of equilibrium: (a) Stable when a body has a broad or heavy base and a low center of

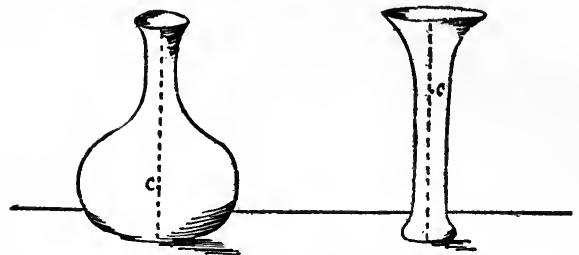

Fig. 3.-Stable and unstable equilibrium.

gravity. Examples, a cone or pyramid, a chair with four spreading legs, a quadruped. (b) Unstable, when a slight force will push an object over, that is, when its center of gravity is high up or falls toward one side of the base. Examples, a book standing on edge, a biped; extreme examples, a person standing on one leg, a tight-rope walker. (c) Neutral, when a slight force would not act upon it, nor change its center of gravity. Example, a three-legged stool, which stands well until a heavy weight is put upon one side of it, bringing the center of gravity outside of the base.

Standing and Walking.--Learning to stand or walk is 
difficult because in the human body the center of gravity is high up from the ground (in the abdomen), and the base (the space enclosed by the feet) is small in proportion. Standing is the process of maintaining oneself in equilibrium on a small base. Walking is a process of alternately falling forward and saving oneself, the center of gravity being thrown first over one foot, then over the other. When one carries a load on his back he bends forward so as to have the center of gravity well inside his base; in carrying a weight in the hand he bends to one side for the same reason.

Both standing and walking are accomplished by the combined action of many muscles, corresponding sets on each side pulling against each other to stiffen the framework and maintain it erect, while other muscles are moving a portion or the whole. The processes are exceedingly complex, and it is not surprising that it takes some months to acquire them.

In using a cane or crutches one enlarges his base, thereby making his equilibrium more stable.

\section{ENERGY. WORK}

Whenever anything happens, or is done, there is some driving force behind it. This driving force is what we call energy. There are various sorts of energy, heat being the commonest; others are light energy, sound energy, muscular energy, electric energy, chemical energy, etc. All these bring about changes in matter. 
One form of energy may be changed into another, as chemical action may produce heat, motion may produce heat, electricity may produce light, etc. All sorts of methods and appliances have been devised to accomplish such changes.

Energy is Indestructible.-It may change from one form to another, but none of it is lost. When it disappears at one spot, it reappears at another. This is called the law of conservation of energy. Examples: coal (stored-up energy derived primarily from the sun) is burned, producing heat, which in its turn produces steam, which in its turn produces motion, which may be utilized in various ways; energy used in winding a clock reappears in the movements of the clock; electricity may be converted into sound by means of the mechanism of a bell. Many examples will occur to anyone.

Work.-Whenever any of the forms of energy manifest themselves, work is done.

Whenever work is done, it means that an opposition of some sort, a resistance, is overcome, and some change in condition results. This change may be motion or any other form of action.

\section{WORK AND MOTION}

Whenever force produces motion, work is done. This amount of work is measured by the distance through which a body is moved multiplied by the force which moves it. 
The fundamental laws of motion are those formulated by Sir Isaac Newton. They are as follows:

1. A moving body always follows a straight line, unless it is acted upon by another force which changes its direction. A stone dropped from a height moves in a straight

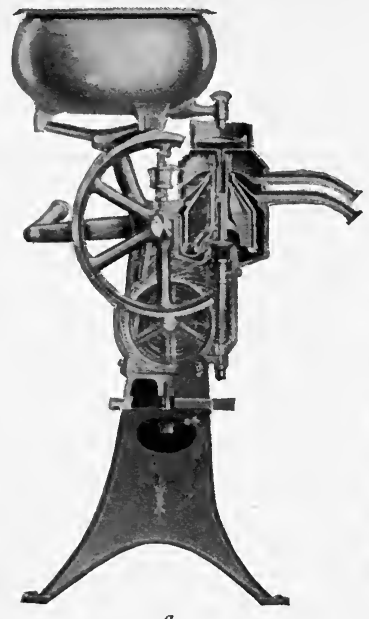

$a$

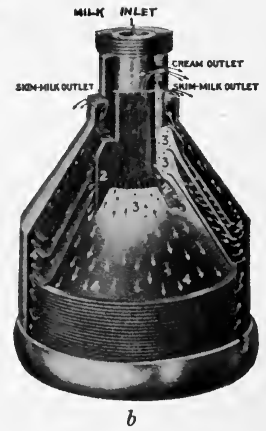

Fig. 4. $-a$, Cream separator; $b$, detail of mechanism.

line because it is acted upon by but one force, that of gravity. A ball thrown from the hand moves in a curve because it is being acted upon by two forces, the muscular energy which started it and the pull of the earth; the resultant of the two forces determines its path. ${ }^{1}$

${ }^{1}$ In neither case do we take into account the resistance of the air. 
Centrifugal Force.--Swing a weight around by a thread; one is conscious that it is trying to fly off in a straight line, but is held by the thread; therefore it moves in a circle; if the thread breaks, it flies in a straight line until pulled toward the earth by gravity. This tendency of a moving body to flee from a fixed center is called centrifugal force (from centrum, center, and fugere, to flee, Latin). The cream separator comes under this law. The milk is whirled rapidly and tends to fly into space, but is held back by the container. Cream and skimmed milk being of different densities, they separate in the whirling, the milk going to the outer part of the container, the cream remaining nearer the center. The urine centrifuge works upon the same principle, the lighter fluid being whirled to the outside, the heavier sediment remaining at the center.

2. Every change in motion is in proportion to the force or forces applied, and takes places. in the straight line in which that force (or forces) act.

3. To every action there is always an equal and opposite reaction. This principle of rebound is important and should be borne constantly in mind. Surprisingly enough, it has a counterpart in the realm of psychology; one notes how depression invariably follows excitement.

\section{MACHINES}

Machines are devices by which work may be done more conveniently or advantageously than without them. Man's hands are unsuited to many processes, so he calls 
things, or combinations of things, to his aid. A pencil is a machine, strictly speaking, because it enables us to do easily what would otherwise be very troublesome.

Machines convert a small force acting through a long distance into a great force acting through a small distance, or vice versa. In the first case we obtain greater power; in the second, we obtain greater exactness.

Machines enable us to do things which without them would be too large for us, too rapid for us, or too exact for us, to accomplish.

The body is sometimes referred to as "the human machine." This is in a sense correct, since many parts of it are constructed like other machines, and portions literally are machines.

The Driving Force.-A machine does not, by itself, literally do the work demanded of it. There must always be a driving force, and it is this which in reality does the work. The machine is that through which the driving force acts.

Our most interesting and useful machines are those in which the power, or driving force, is some other than our own. Some machines are driven by horse power or the energy of other animals; some run by the forces of nature, as wind or water; steam engines use the energy stored up in coal; motor cars utilize that stored in gasoline; electric appliances make use of the power obtained from electricity, which may in its turn be derived from some other source of energy.

Types and Classes of Machines.-Machines are of 
two general types and are divided into six classes. The lever, the wheel and axle, and the pulley are of one type; the inclined plane, the wedge, and the screw are of the other type.

\section{SUMMARY}

Gravity is the force by which the earth pulls everything toward its center. Its action produces weight, which enables us to know the amount of matter in any given mass or object.

Specific gravity is the weight of any given substance compared with water as a standard.

Equilibrium, the balance between two or more forces, may be stable, unstable, or neutral. Man, in walking upright, is in a state of unstable equilibrium, as his base is small and his center of gravity high up.

The driving force behind any action is called energy. There are various forms of energy, light, heat, chemical, muscular, electric, etc. One form of energy may be changed into another, but none is ever lost or destroyed.

Manifestations of energy are called work. This is an overcoming of resistance or some change in condition.

Newton's three laws of motion cover the fundamentals.

Machines are devices by means of which we may accomplish things otherwise too large, too rapid, or too exact for us to do unaided.

Behind the machine there must always be a driving force, such as that supplied by the strength of animals, by water-power, wind, electricity, gasoline, coal, etc.

There are six classes of machines. 


\section{CHAPTER III}

\section{MECHANICS (Continued)}

The lever is the most common and most useful machine; in fact, nearly all machines are, in a sense, varieties of lever or combinations of levers.

A lever is a rigid bar, straight or curved, resting on a fixed point or edge, called the fulcrum. It is used to move weight or overcome resistance. The hand-spike is a common form of the simple lever.

There are three things concerned in the action of a lever: 1. The weight to be lifted or moved. 2. The power which shall move it. 3. The fulcrum, or point upon which the movement is to take place.

There are three classes of levers: In the first class the fulcrum is between the weight and the power. In the second class the weight is between the fulcrum and the power. In the third class the power is between the fulcrum and the weight.

In all cases it is possible to calculate, by mathematical means, the exact power that will be required to move a given weight through a given distance.

In levers of the first class, the fulcrum being between the power and the weight, the weight moves in an opposite direction to that in which the power is applied. Com- 
mon examples are the tack lifter, the can opener, the pump handle, the grocer's scales, etc.

I

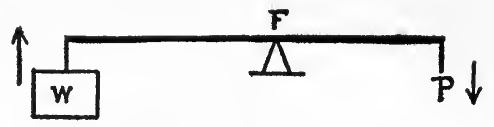

II

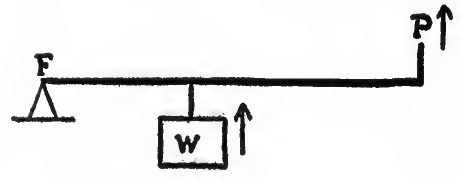

III

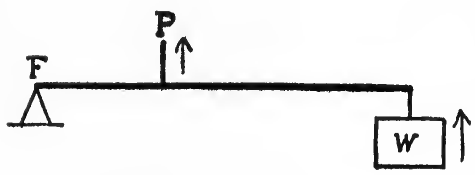

Fig. 5. - The three classes of lever.

Scissors, pliers, artery clamps, etc., are double levers of the first class, the weight being between the blades, 
the power the force applied by the hand, the fulcrum the joint. The bivalve speculum is a double lever, the weight being the walls of the cavity into which it is in-
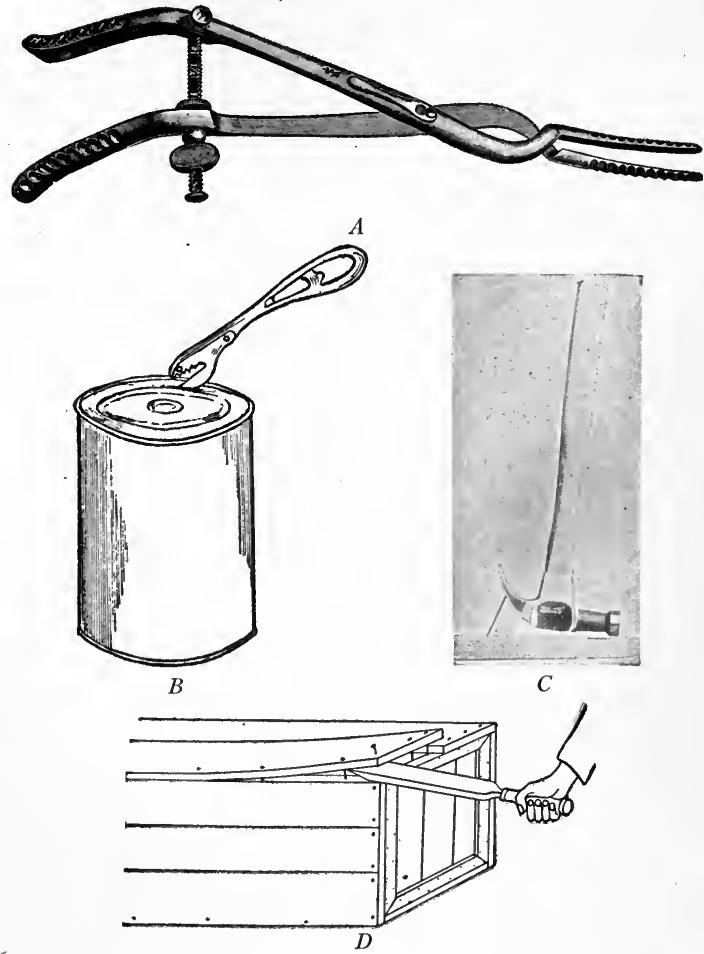

Fig. 6.-Levers of the first class: A, Uterine dilator; B, can opener; C, claw hammer; D, chisel. (Butler, "Household Physics.") 
serted. The long uterine dilator with two handles is also a double lever. (The small, graduated dilators are wedges, not levers.)

If the power arm of the lever is long and the weight arm short, the work is more easily done than if the reverse is the case; the distance an object can be moved in this case is lessened, but force and time are gained.

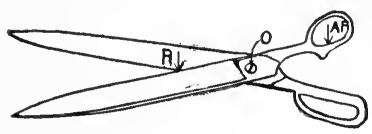

$a$

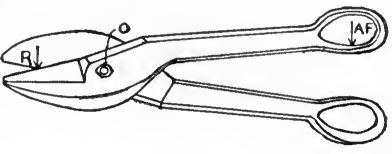

$b$

Fig. 7.-Levers of the first class, with long and short power arms: $a$, Paper-cutting shears; $b$, metal-cutting shears. (Butler, "Household Physics.")

In the large uterine dilator great force is gained because of the excessive length of the handles. It is for this reason that metal-cutting shears have long handles, while scissors for cutting paper have very short handles; the first requires great power; the second, little power but a long sweep.

In the human anatomy there are many portions which can be used as levers of the first class. In grasping an object with the hand, the object is the weight, the finger joints are the fulcrum, the flexor muscles the power. In putting the head back the joint at the top of the spine is the fulcrum, the head is the weight, and the muscles at the back of the neck are the power 
(see Fig. 11). In pushing an object with the foot, the object is the weight, the ankle- or knee-joint is the fulcrum, the leg muscles the power.

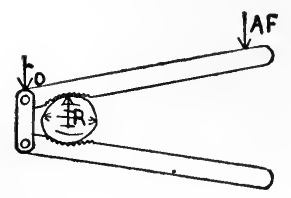

a.

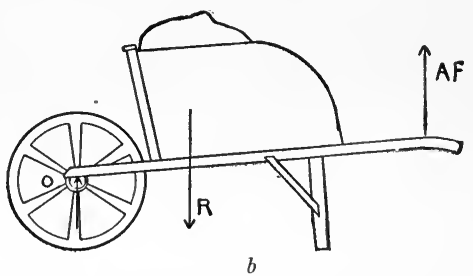

Fig. 8.-Levers of the second class: $a$, Nut-cracker; $b$, wheelbarrow. (Butler, "Household Physics.")

In levers of the second class the weight being between the power and the fulcrum, the weight moves in

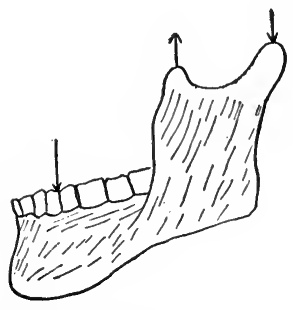

$a$

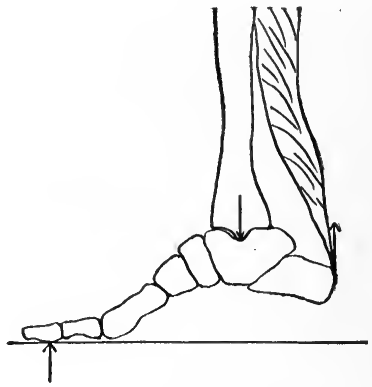

$b$

Fig. 9.-Levers: $a$, Jaw of human being; $b$, foot when we rise on the toes. (Butler, "Household Physics.")

the same direction as that in which the power is applied. The wheelbarrow is a common example. The nut 
cracker and the lemon squeezer are double levers of the second class.
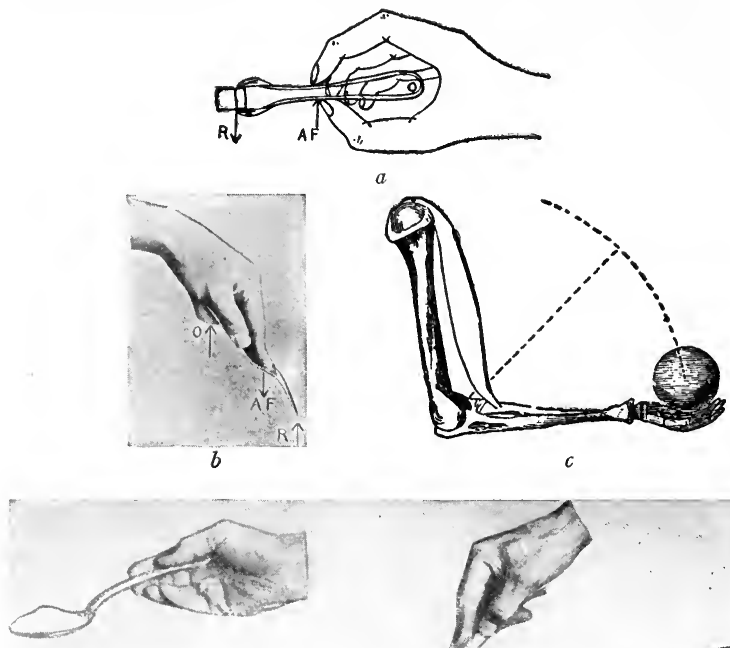

Spoon.
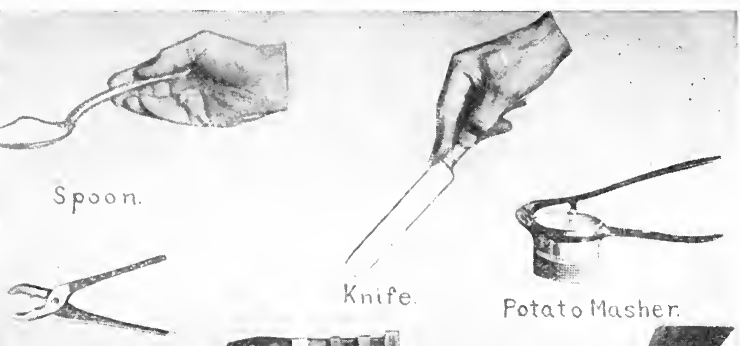

Pliers

Fire Tongs.

Knife

Potato Masher.

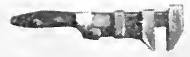

Wrench

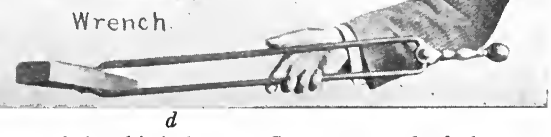

Fig. Io.-Levers of the third class: $a$, Sugar tongs; $b$, fork; $c$, forearm; $d$, spoon, knife, potato masher, pliers, wrench, and fire tongs. (Butler, "Household Physics.") 
In lifting the weight of the body to the tip-toes, the toes form the fulcrum, the calf muscle the power.

In this class of lever also, if the weight is near the fulcrum, and the power arm is long, the work is more easily accomplished.

In levers of the third class the fulcrum is at one end, the weight at the other, the power between them. Common examples are the fork and spoon, as used in eating. Sugar tongs and thumb forceps are double levers of the third class.

It will readily be seen that this form of lever is not of advantage in lifting weights, since the power must always be greater than the weight to be lifted. It is used chiefly when we wish to produce a rapid motion through a considerable distance, or to facilitate small, exact movements.

The flexing of the forearm constitutes a lever of the third class. The weight is the hand and anything it may contain, the fulcrum is the elbow-joint, the power is the biceps muscle, applied at its point of attachment below the elbow. It is clear that this is not designed for the lifting of great weights, but for quick, dextrous movements.

The bending of the head forward is done by a leverage of the third class; the sternomastoid muscle is the power, the sternoclavicular attachment the fulcrum, the head the weight.

Another example is the use of the lower jaw in masti- 
cation. The weight or resistance is the food between the teeth; the fulcrum is the articulation near the ear, the power is the masseter muscle.

Complicated Movements.-Most of the movements of the body are complicated, two or more fulcrums and a number of muscles being brought into play. (This is also true of a great many machines.) We commonly

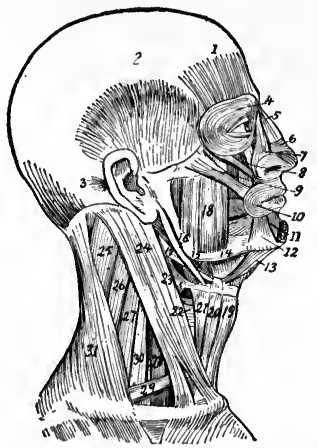

Fig. 11.-Muscles of neck as levers (Dorland's Dictionary).

lift a heavy object by using the muscles of the shoulders and back, somewhat assisted by those of the arm, the elbow and shoulder-joints being the fulcrums, and the action being a combination of lavers of the first and third classes.

An example of a powerful double lever is observed when the body is raised from a squatting position. The knee-joints are the fulcrums, the power is the leg 
muscles. In machinery such an arrangement is called the toggle-joint or Stanhope lever.

\section{OTHER MACHINES}

The crank-and-axle (or wheel-and-axle) is a variety of lever, a sort of continuous lever. Common examples are the coffee-mill, the clothes-wringer, the bread-mixer,
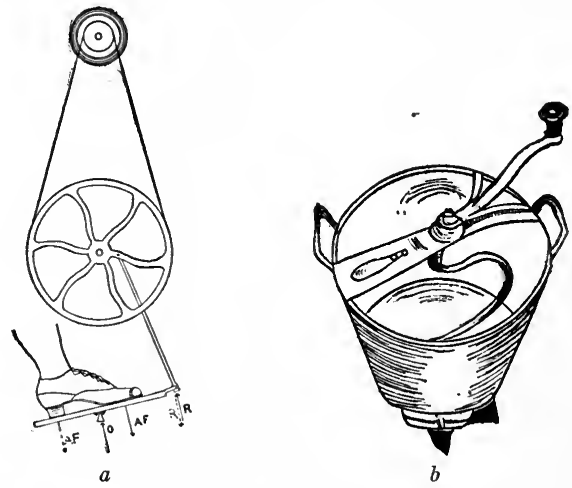

Fig. 12.-The crank and axle: $a$, Treadle of sewing machine; $b$, bread mixer. (Butler, "Household Physics.")

the Dover egg-beater, the ice-cream freezer, etc. The weight is the material to be acted upon or moved, the fulcrum the axle or bearing upon which the movement takes place, the power the muscle of the operator, acting through the wheel or crank.

The driving mechanism of a sewing machine is a 
combination of the wheel-and-axle and a lever (the treadle).

The pulley consists of a grooved wheel called a sheave, set into a frame, the block; the weight to be lifted is attached to one end of a rope which runs over the sheave,

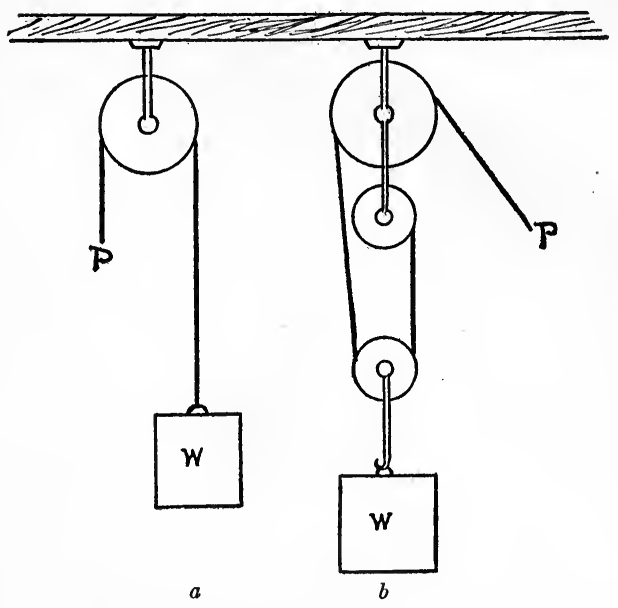

Fig. 13.-The pulley: $a$, Simple; $b$, compound.

the power being applied at the other end of the rope. Adding more sheaves multiplies the power, so that very little force may be needed to move a considerable weight.

The extension apparatus used in fractures of the thigh is a simple pulley, the weight being the body of the patient, the power being the weights attached at 
the foot of the bed. The action is not movement, but merely pull. The superior oblique muscle of the eye is a pulley, also the omohyoid muscle.

The inclined plane needs little explanation, it being obvious that a weight can be pushed or pulled up an incline with much less effort than it can be lifted vertically to the same height.

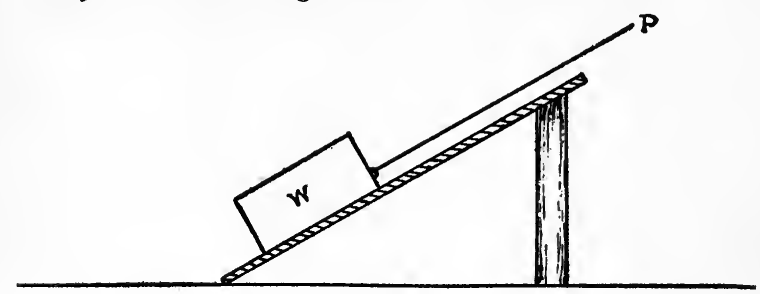

Fig. 14.-The inclined plane.

A series of rules have been formulated by which one may calculate the exact force necessary to move a given weight up an incline of a given angle.

The screw is a curved inclined plane. It is commonly used to increase the pressure of one object upon another, usually with the purpose of holding one or both in place. It is also used to produce a small, very exact adjustment. The adjusting mechanism of the microscope is an example of how a screw changes a long movement into a short, exact one.

The screw-driver is a lever which assists the placing of the screw. In forms of screw like the letter press, the beef-juice press, the meat grinder, the bread slicer, 
etc., the handle is a lever; in the two latter the handle is a modified lever, the crank and axle.

The wedge is a double inclined plane which is forced in between two surfaces or portions of matter in order to separate them or in order to hold them against resistance. The power used is applied in the form of blows rather than as a continuous push. The wedge is a very powerful machine.

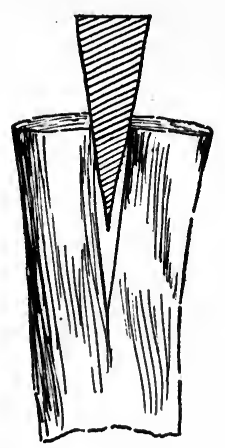

Fig. 15.-The wedge.

Knives are wedges with delicate edges. Rectal dilators and the small uterine dilators are round wedges.

The mechanics of obstetrics is most interesting, though somewhat complicated. The child is the weight, and the tissues of the cervix, the vagina, and perineum the resistance to be overcome. The muscles of the abdominal wall and of the uterus are the power. If the 
woman is on her feet, gravity assists the process. If she is in bed, additional force may be obtained by the pull of her arm and leg muscles against some firm objects.

The child's head, in combination with the sac of amniotic fluid which acts as a cushion to prevent injury to the tissues, acts as a wedge to force the tis-

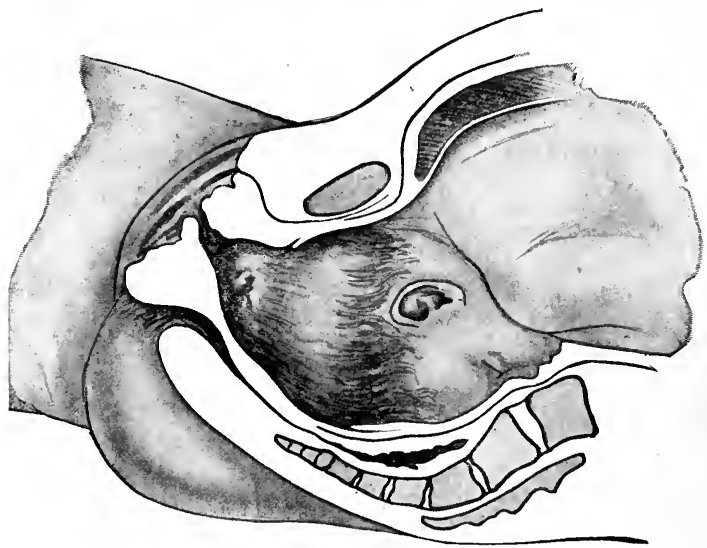

Fig. 16.-Child's head acting as wedge (DeLee).

sues apart. Note how the power is applied intermittently during the pains. The great force employed is appreciated by anyone who has actually delivered a child.

The birth canal is not straight, but much curved, being about one-third of a circle. It is, in effect, a series of inclined planes, which in succession change the direction of the child's progress. 
If the natural forces are not sufficient to produce the necessary progress, the obstetric forceps, a double lever

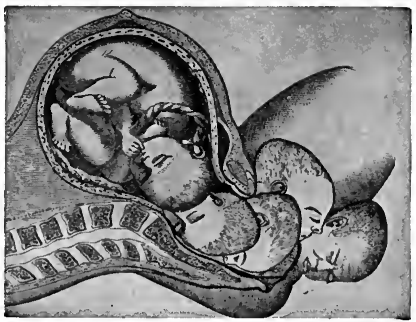

Fig. 17.-Diagram showing the advancement of the head through the pelvis (Leishman).
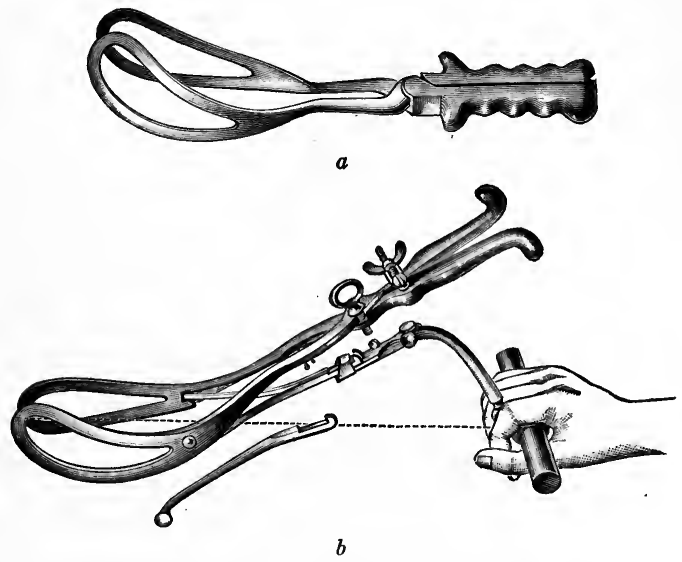

Fig. 18.-Forceps: $a$, Obstetric; $b$, axis-traction.

of the first class, is used to assist the process. With them the obstetrician holds the progress that has been 
made, or aids it by pulling in the direction that the other forces are pushing, and in which the child's head is moving. Since the passage is not straight, the forceps must be curved, and the pull must be made in the direction that the child's head is traveling. "Axistraction" forceps enable the operator to get his pull in the proper direction while the head is still far up and the curve is very great. Watch the direction taken by the handles of the forceps during a delivery and note how great a curve they describe during the descent of the child. At first they point somewhat downward, and at the end of the delivery almost upward.

\section{FRICTION}

When the surface of one body is made to move over that of another, a resistance to the movement is felt. This resistance is friction. If perfectly smooth surfaces could be obtained, there would be little or no friction; but this is impossible. There is always more or less roughness, and therefore some resistance. Roughness increases friction, smoothness reduces it.

Without the action of friction we should find it exceedingly difficult to hold anything in place; everything would tend to slip from our hands or slide away at a touch. Without friction we should be unable to walk or drive, as we should constantly slip. It is an important factor in life.

There are two sorts of friction, rolling and sliding. 
The former gives the least resistance. In machines with which we wish to do work easily we make use of smooth, rolling surfaces, since they move with greater ease.

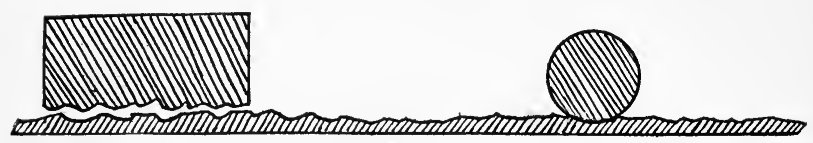

Fig. 19.-Friction. Sliding and rolling.

The so-called ball-bearings, where there are a number of parts which roll over one another, produce a very easy-running joint.

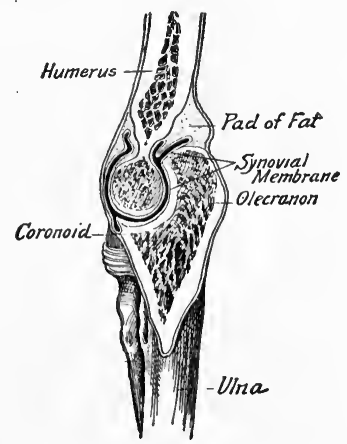

Fig. 20.-Construction of joint (after Toldt).

On the other hand, a brake set to a wheel changes rolling into sliding friction, and so checks the motion. Lubricants reduce friction; it is for this reason that we oil or grease machinery. 
Great friction produces heat (see page 98) which may interfere markedly with the action of a machine.

The human body presents very perfect examples of reduction of friction. The joints are nearly all rolling joints, rather than sliding, thus offering the least resistance to movement, and constitute a great economy of force or power. The cartilages that cover the working portions of the joints are practically perfect in their smoothness; and the synovial fluid is a fine and perfect lubricant, continually renewed. It is when joints are roughened or dried by disease that they work with difficulty.

\section{SUMMARY}

The lever is one of the most used of mechanical devices. There are three essentials to its action-the weight; the power, and the fulcrum or point on which the motion takes place.

There are three classes of levers; they vary according to the relative positions of weight, power, and fulcrum. Examples of each sort.may be found among appliances in every-day use, and in muscular actions taking place in the human body.

Many of the body movements are complicated, being produced by the combined action of many muscles, and involving two or more joints as fulcrums.

The wheel-and-axle is a continuous lever. It is used in many domestic appliances. 
The pulley consists of a sheave set into a block; over this runs a cord attached to both weight and power. A pulley with several sheaves facilitates the moving of a weight.

The inclined plane is another machine which decreases labor in the lifting of weights.

The screw is a curved inclined plane with a rather complex mechanism. It has many applications in domestic and hospital life.

A wedge is a double inclined plane driven by intermittent blows; it is used when great force is needed to separate or hold objects.

Most of our so-called machines are complex combinations of two or more of the simple machines.

An obstetric delivery is essentially a mechanical process. The child's head acts as a wedge to overcome the resistance of the cervical, vaginal, and perineal tissues. The force employed is that of the abdominal and uterine muscles; it may when necessary be aided by the pull of obstetric forceps. The birth canal being curved-practically a series of inclined planes-the shape of the forceps and the direction of the pull must correspond with it.

Friction is the resistance between two surfaces, one of which moves over the other. It is inevitable, since a perfectly smooth surface is impossible to obtain. It is of advantage in holding or placing objects, but is a disadvantage when we wish to move them. Sliding 
friction may be changed to rolling friction, and therefore reduced, by the use of lubricants.

The human body presents many excellent examples of the advantages of the reduction of friction. 


\section{CHAPTER IV}

\section{HYDRAULICS}

\section{LAWS RELATING TO LIQUIDS}

Properties of Liquids.-Liquids tend to keep their molecules together, but not strongly. The force of their cohesion is not enough to overcome the action of gravity; therefore they "run" to the earth unless prevented by other forces.

Different liquids possess different degrees of cohesion. We note this in the varying size of drops of different liquids. Castor oil, for example, coheres rather strongly, and its drops are correspondingly large. Alcohol has less cohesive force, and its drops are smaller. Chloroform drops are very small.

(Sixty drops of water make a dram by measure. Carbolic acid takes 118 drops to make a dram; tincture of aconite, 150 ; ether, 180 ; chloroform, 240.)

Liquids are very much less compressible than solids; in fact, most of them are not compressible to any appreciable extent. This is an important characteristic in their use in practical life.

Water is the most common and the most important liquid. It is therefore used as a standard for measuring the qualities of other fluids. ${ }^{1}$

${ }^{1}$ Specific gravity, or the weight of a substance compared with the same amount of water, as before noted, refers to both liquids and solids. 
Liquids vary greatly in their weight. Note the difference in weight of equal-sized bottles of oil and of sulphuric acid. A cubic foot of cold water weighs 62.42 pounds. In hot water the molecules are farther apart, therefore it requires a little more space and weighs a little less.

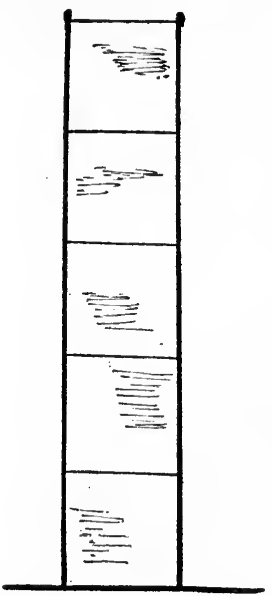

Fig. 21.-Water pressure on bottom of container.

Pressure in Liquids.-If 1 cubic foot of water is placed on top of another, the weight is 124.84 pounds; that is, the pressure upon the bottom of the container is that amount. So, if water is 5 feet deep, the bottom of the container must bear a weight of more than 300 pounds to the square foot. From this one can see that the 
pressure in deep water is very great. It is for this reason-the great pressure-that sea divers cannot

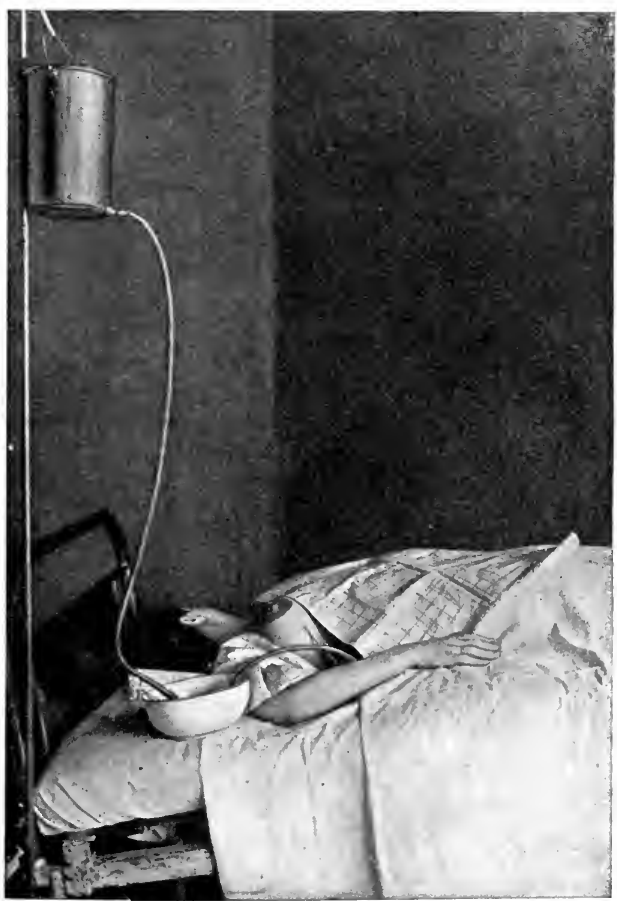

Fig. 22.-Irrigator hung high. The whole column of water makes pressure (DeLee).

go to any great depth; and they must always wear suits of material heavy enough and stiff enough to re- 
sist the weight of the water and keep it from crushing them.

The irrigators which we use in hospital work also illustrate the pressure of fluids. If an irrigator is hung high, there is more water in the tube, $i . e$. , it is deeper,

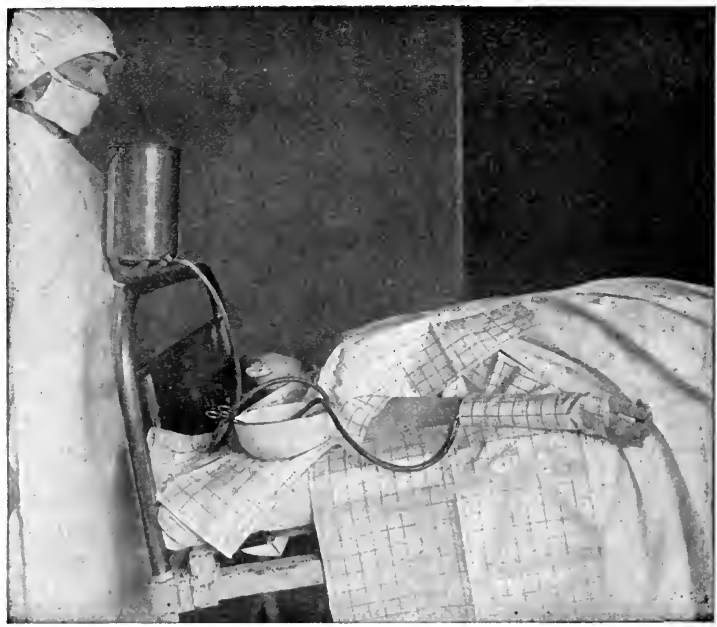

Fig. 23.-Irrigator hung low. There is very little pressure, because the depth of water in irrigator and tube is not great (DeLee).

and the pressure exerted upon its lower part, upon the small surface which is the caliber of the tube, is that of the whole column of water in both irrigator and tubing. If hung low, there is very little pressure, and the water when released finds its escape easily and gently. It 
is, we observe, the depth and not the amount of water which regulates the pressure upon the bottom.

Pascal's law formulates another important. fact. The pressure in a liquid is the same in all directions. Solids press only downward; liquids press sideways and upward as well.

Experiments.-(a) Fill a hot-water bag quite full of water, getting out all the air; lay on the hand; press the top or side of the bag and note that the resistance is as great in one place as in another. (b) Let water run from an irrigator to the tubing of which is attached a uterine tip, one having several holes; note that the water runs with equal force from all of the holes, not more forcibly from the bottom hole, as one would expect.

The discomfort of a patient from a full bladder is due to this law, because the urine is pressing in all directions.

A water-bed is useful because it makes pressure upon the surface of the patient's body equally in all places,

Fig. 24.-Water-bed.

unlike the ordinary bed, which presses harder against the more prominent portions.

It is this law which causes the force of the heart-beat to be distributed evenly throughout the body, so that blood-pressure is the same in all arteries, large or small, far away from or near to the heart.

It is this law which makes the sac of amniotic fluid so 
efficient yet so gentle a dilator in obstetric cases. It presses in every direction at once, yet without possibility of injury to the tissues.

Water Seeks its Own Level.-Because water presses in all directions it runs through any available openings, and stops only when there is a resistance ahead of it equal to the force or weight behind it.

Our city water systems are based upon this law. The source of supply is a lake or river higher than the city, or, failing this, the water is pumped up to a reservoir

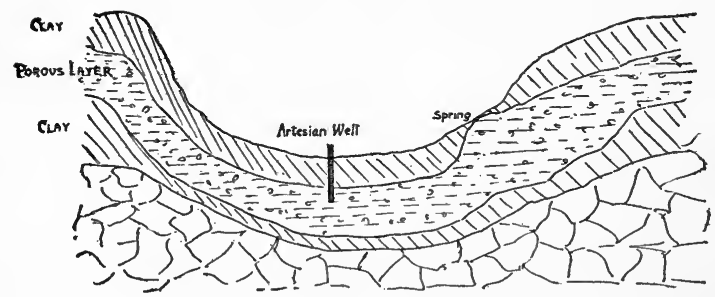

Fig. 25.-Diagram of artesian well.

or standpipe situated upon high ground. (The supply in this case may be a low river, a spring, a well, etc.) All water which is permitted to flow from this reservoir or source of supply attempts to rise as high as its origin. The great height of the large body of water gives us the desired pressure. Water coming from a hose used to sprinkle a lawn would rise to the top of the water in the reservoir from which it flows if it were not for other 
forces, the friction against the inside of the hose, the resistance of the air, and the action of gravity.

Artesian wells are produced by water trying to find its level. The source of the water is in the hills that are above the well; the water, soaking through the earth and running along an impervious layer of rock or clay, finds an opening and pushes up through it, or, more correctly, is pushed up through it by the body of water behind it. In some cases artesian wells spout high above the ground.

Buoyancy.-Push a block of wood under water and release it; it rises to the surface and floats with its bulk almost out of the water. This is due to the buoyancy (not of the wood, but) of the water, $i$. e., its tendency to raise all bodies to its surface. This is due to the facts already discussed, that pressure increases with depth and that it acts in all directions. This results in the pressure upward on the bottom of a submerged object being greater than the pressure downward upon its top. If the additional weight of the body itself is not more than this difference of pressure against top and bottom, the object floats.

Heavy substances, which displace less than their own weight of water, sink. Light substances, which displace more than their weight, float. The law of Archimedes-a floating body sinks until it displaces its own weight of liquid-is a summary of the above facts and other similar ones. 
Swimming.- The human body, partly because of the air in its tissues and in the lungs, is but slightly heavier than water, so that it floats just below the surface. With slight effort a portion of the head-mouth, nose, and eyes-can be kept above the water, making it possible for a person to swim. The balance is so nearly equal that it takes only a small quantity of water getting into the lungs and replacing the air to cause one to sink, i. e., drown. ${ }^{1}$

Experiment.-A fine needle, especially if dipped in oil, can be made to float on water if it is laid gently and evenly upon the surface. Its weight is not sufficient to overcome the force of the cohesion of the molecules of water.

Loss of Weight in Water.-On account of this quality of buoyancy, all objects weigh less in water than they do in air. The water pushes up or sustains a considerable portion of their weight. Experiments are easily made which prove this.

Hydrometers.-The hydrometer is a device used for ascertaining the specific gravity of liquids. It is based upon the law of Archimedes. It consists of a tube weighted at one end with the requisite amount of mercury, and marked with a scale. The point marked 0 is the point to which it sinks in water. Placed in a liquid

1 Bodies of drowned persons sometimes float after being in water a considerable length of time. This is because chemical changes have taken place, producing in the tissues gases that are lighter than water. 
heavier than water, it tends to float; in a liquid lighter than water, it sinks deeply. The scale is arranged so that it designates the specific

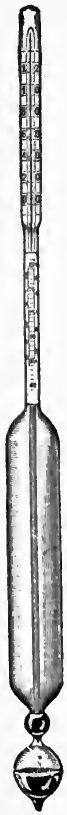

Fig. 26.-Hydrometers. gravity.

The urinometer and the cream tester are hydrometers. The urinometer is of importance because: (1) If urine is of low specific gravity, $i$. e., nearly that of water, it indicates that not enough solid matter is being eliminated from the body. (2) If it is of high specific gravity, there is too much solid matter, i.e., not enough fluid is being taken, or some abnormal condition is causing the elimination of materials that should remain in the body.

The specific gravity of normal milk is 1029. If the cream tester shows it lower than this, there is a suspicion that water may have been added. Excess of cream may change the test somewhat. 


\section{CAPILLARITY}

Capillarity, or capillary attraction, is the quality that causes liquids to adhere to solids in opposition to the force of gravity. Its action is most marked in fine tubes and in porous substances.

Experiments.-Hang a wick of gauze over the edge of a tumbler half full of water; water will soon be dripping from the outer end of the wick. Hang up a cloth so that its lower edge or corner dips into water; the whole cloth will gradually become wet. Dip the corner of a lump of sugar into coffee or cocoa; the whole lump very quickly becomes colored with the fluid. Place a white carnation or other white flower for a few hours in a bottle of red ink; the ink stains it, especially along the veins.

It is capillarity which causes the sap to rise in plants, since they have no circulatory system. It is this force which helps the small blood-vessels of the intestines, the lacteals, and the lymphatics, to absorb liquid nourishment from the intestinal contents. It is this which makes possible the capillary circulation and the flow of blood in the very small veins; the force of the heartbeat pushes the blood only part way through the smallest vessels, but capillarity assists and continues the process, especially when it is necessary for the blood to ascend, in opposition to gravity.

It is capillarity upon which we depend largely in our drainage of wounds. Gravity, of course, assists the process, but a gauze wick will drain even though the fluid to be removed must go upward. Drainage stops when the gauze becomes blocked with solid particles. 
Waterproofed cloth is that which has been treated with something which prevents capillary action.

\section{DIFFUSION}

- Diffusion is the force that makes fluids tend to mix when they are brought into contact.

Experiments.-Put some solution of blue vitriol in the bottom of a test-tube; tip the tube and with a medicine-dropper put carefully on top of it a layer of water; left undisturbed, they gradually mix, till the whole is blue. Put milk at the bottom of a test-tube and water on top; watch them mix.

Osmosis.-A similar process takes place through thin animal or vegetable membranes. It is called osmosis. It applies only to solutions of crystalline substances, however.

Experiment.-Procure a pig's bladder or other thin animal membrane; put some colored fluid into it-a solution of potassium permanganate is good-and hang it in or touching some water. The colored fluid will penetrate the membrane, and color the water, the latter exchanging places with it.

It is the combination of this force with capillarity which makes possible the absorption of stomach and intestinal contents. Osmosis occurs rapidly through the stomach wall. Note that the drinking of hot water causes diuresis within fifteen or twenty minutes, long before the fluid could have reached the intestines; it is absorbed directly from the stomach. Medicines given in hot water are quickly absorbed and an effect produced in a short time. Osmosis effects this by carrying the medication through the stomach wall into the circulation. 
When a saline cathartic is given, the saline matter absorbs much water from the tissues of the intestines, pulling it through the membrane of the intestinal wall; the excess of fluid so obtained produces a watery or very soft bowel movement.

Edema.-We find that osmosis takes place toward the more concentrated solution, and that saline substances increase it. When, therefore, in certain diseased conditions the kidneys fail to eliminate a sufficient quantity of saline material from the body and it accumulates in the tissues, it produces an osmosis of the body fluids and we have the condition which we call edema.

\section{SUMMARY}

Cohesion is not strong in liquids, therefore they are easily affected by gravity. Liquids are very slightly compressible.

It is the depth of water rather than the amount present which determines the pressure upon the bottom of the container. This law is illustrated by the ordinary hospital irrigator.

The pressure in a liquid is the same in all directions. This is illustrated by the fact that quality of pulse is the same in all parts of the body.

Water seeks its own level. City water systems, artesian wells, irrigators, etc., illustrate this law.

A floating body sinks until it displaces its own weight 
of the liquid. This law governs the use of the urinometer, etc., and explains ability to swim.

Capillarity is the property that causes liquids to rise in small tubes and other restricted places in opposition to the action of gravity. It is this force which aids the capillary circulation, absorption from the alimentary canal, the drainage of wounds, etc.

Waterproofing is the prevention of capillarity.

Diffusion is the property which causes liquids to mix when they are brought into contact. When it takes place through a membrane it is termed "osmosis."

Osmosis is especially active in saline solutions; it takes place toward the more concentrated solution. This explains the occurrence of edema when there is faulty elimination. 


\section{CHAPTER V}

\section{PNEUMATICS}

\section{LAWS RELATING TO GASES}

Properties of Gases.-In gases the molecules are considerably separated and have no cohesion; in fact, they are always trying to get farther apart and fail only because outside forces prevent them.

Experiment.-Produce dense smoke by burning sugar or setting fire to "touch-paper" (unsized paper soaked in a strong solution of saltpeter and dried). The smoke quickly becomes diffused through the room, even though there are no apparent currents of air.

The law of diffusion of gases corresponds to that of liquids. Gases which are in contact tend to mix. If it were not for this law we should, in a closed room, become quickly surrounded by a lake of impure air which we should be compelled to rebreathe; this is prevented by the rapid diffusion of gases, and by the fact that air is so readily disturbed, so that the opening of a door or the moving of an object in the room keeps the air "stirred up."

Elasticity of Gases.-Gases, because of the tendency of their molecules to get away from each other, are very elastic. Note the great elasticity of the air confined in an air-cushion, an automobile or bicycle tire. Observe 
the rapidity and force with which it escapes when even a small opening is made.

Compressibility of Gases.-All gases are compressible, most of them to a very marked degree. It is well known that a large quantity of oxygen, compressed air, carbon dioxid, etc., may be forced into a tank.

Illuminating gas is collected in very large iron tanks, the weight of which is sufficient to hold it in place. The tank is set in a deep cistern of water, through which the gas passes with great difficulty, and the tank rises or falls in it according to the amount of gas it contains. Pipes are laid from this tank; the weight of the tank and the elasticity of the gas itself force it through the pipes in every direction and with an even pressure.

Air is the Most Important Gas.- It is composed of a mixture (not a combination) of two gases, nitrogen (four-fifths) and oxygen (one-fifth). ${ }^{1}$ If it were not for the constant action of the law of diffusion of gases the air would be an irregular mixture, somewhat like marble cake, with spots and streaks of the two gases, causing endless inconvenience and danger.

The air surrounds the earth, but is not very deep over its surface, about 50 miles. There is probably some air as far up as 200 miles, but at a distance of 7 or 8 miles above the surface it is very rare, i. e., its molecules

1 There is also a small amount of carbon dioxid, watery vapor, and of various impurities in minute quantities. 
are far apart. Man has never been more than about 5 miles (25,000 feet) above sea-level.

Air has Weight.-Air is matter and all matter is attracted by the earth. In the case of air, the force with which the molecules try to get away from each other is slightly less than the attraction of gravity. The weight of air is 1.28 ounces per cubic foot.

Some gases are lighter than air, some heavier. A balloon rises in the air because it is filled with some gas lighter than air, usually hydrogen.

Air Pressure.-Air is like water in that the pressure increases with its depth. It is denser at the bottom, $i$. e., near the earth's surface, or, rather, at sea-level.

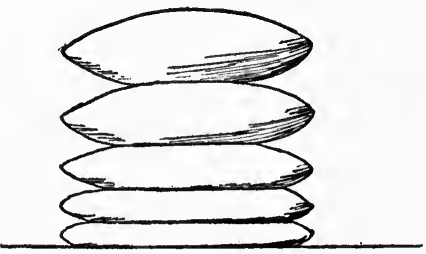

Fig. 27.-Diagram illustrating increase of pressure with depth.

Illustration.-Place several pillows in a pile; note that the lower one is much flattened, each successive one less so. This illustrates how the weight of the upper air compresses the lower portions and drives the molecules closer together.

The air pressure at any point equals the weight of the column of air which is above it, the height of this column being the distance that the atmosphere extends. 
It can be readily seen that this pressure is greater at sea-level than at an altitude.

Experiments.-Tie a piece of thin rubber (the wrist of an old rubber glove is suitable) over the mouth of a small funnel. Connect the funnel with a piece of rubber tubing. With your mouth withdraw some of the air in the funnel and clamp the tube. The rubber stretched over the funnel will bulge inward because of the external air pressure.

Remove the rubber, leave the tubing. Place the funnel against the cheek, if it is small enough to fit snugly; withdraw air by means of the tubing. The cheek will be pulled into the funnel, or, in reality, pushed in by the air in the tissues and the cavity of the mouth pressing outward. The blood in the small vessels is also forced in-shown by the redness which appears-because the blood-pressure from within remains the same while the air pressure from without is relieved. This is the principle of dry cupping, which is used to bring blood to the surface of a small area. The breast-pump works upon the same principle.
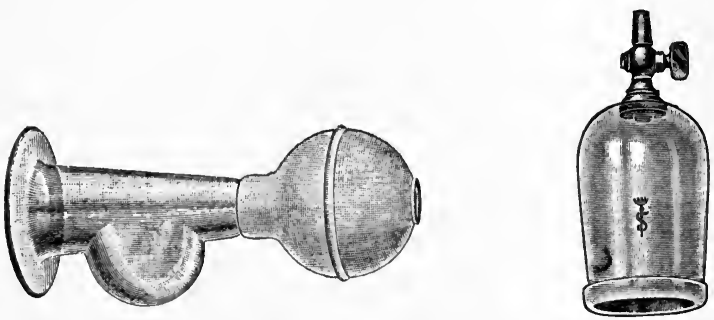

Fig. 28.-Breast-pump and cupping-glass.

The air pressure at sea-level is 14.7 pounds to the square inch. Our bodies, therefore, are constantly sustaining a weight of about 15 tons of air. We do not feel it (1) because the solid portions of the body are very resistant, (2) because the body fluids are not compressible, 
(3) but chiefly because the gases in the body are of the same density as the air and so equalize the pressure.

The feeling of pressure experienced by those who climb high mountains is due to the fact that the air in their tissues does not escape nor become thin as rapidly as that outside. The ear drum has been known to burst at a high altitude on account of the difference in air pressure on its two sides, especially if the eustachian tube be partly blocked.

Effects of Air Pressure.-Scientists of the old times formulated a law, "Nature abhors a vacuum." Later

- scientists explained this law by the discovery of the laws of air pressure. A vacuum is the term used to describe an enclosed space where there is little or no air. A perfect vacuum has never been obtained.

When we begin to expel the air from any space, more air tries to get in. If a possible opening is blocked by liquid or solid material, the external air will, if possible, push the liquid or solid in ahead of itself in its struggle to enter. In using a medicine-dropper we press the air out of the rubber bulb and dip the glass point into a liquid; since the air outside, pressing on all the liquid in the container, is kept away from the entrance to the tube by it, it forces the fluid into the tube.

Experiments.-Push an empty tumbler mouth downward into water. "Note that the water rises only a very little way into the glass, being kept out by the air which is there. Note the shape of the surface of the water inside the glass. Push a large cork into the water and release it under the tumbler. What occurs, and why? 
Fill a glass tube with water, close the upper end with the finger, and dip the lower end in water. The water remains in the tube because of the pressure of the air upon the surface of the water in

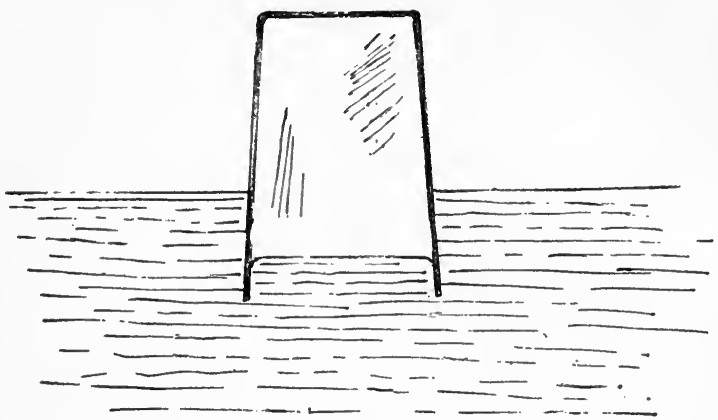

Fig. 29.-Tumbler inverted in water, showing how the air prevents the water from entering. (Note shape of water surface.)

the vessel. When the finger is removed from the top of the tube, the air pressure comes directly upon the water in the tube and causes it to fall.

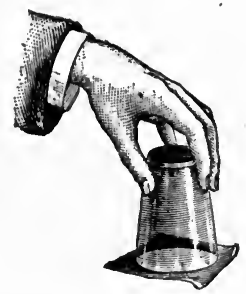

Fig. 30.-Upward pressure of the air (Butler, "Household Physics").

Fill a small tumbler brimful of water; press a smooth piece of paper on top; holding the paper tightly, turn the tumbler upside down; remove the hand which holds the paper in place. The paper 
remains. The water also remains in the tumbler. Both are held in place by the air pressure from below upward, the glass preventing the air pressure from above from acting upon the water. (Gravity is also partly overcome by the adhesion between the wet paper and the edge of the tumbler.)

Vacuum Fountain (Fountain in Vacuo).-Have a quart flask fitted with a tight cork, through which is a

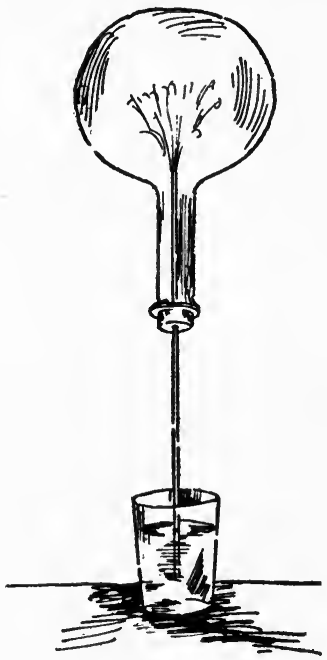

Fig. 31.-Fountain in vacuo.

small glass tube reaching halfway to the bottom. Exhaust as much air as possible from the flask by suction upon the tube, put the finger tightly over the end of the tube, dip the end in water, and release the finger. The 
water will rush into the flask with force enough to produce a fountain.

Hero's Fountain.-Put some water into the flask, well above the end of the tube. Blow through the tube until the air inside is compressed as much as possible.

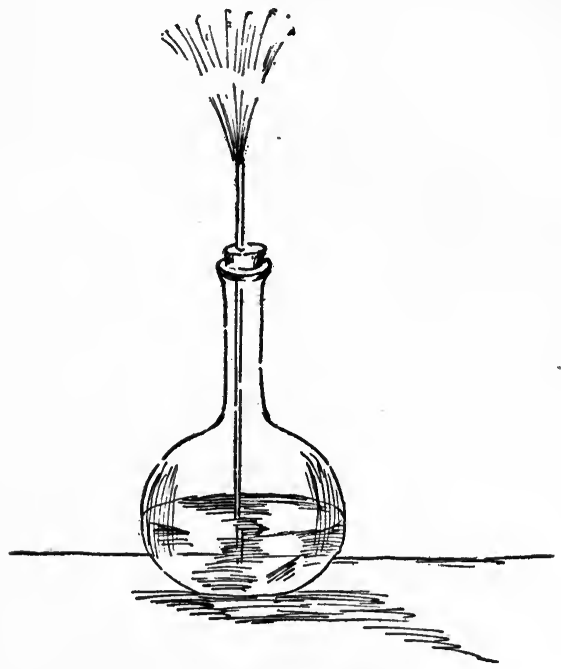

Fig. 32.-Hero's fountain.

Place the finger over the end of the tube to keep the compressed air from escaping. Release it suddenly, and the confined air will force water out through the tube like a fountain.

Applications of the Laws of Air Pressure.-Hypodermic or dressing syringes to work well must have pistons 
that are air-tight. When the end of the syringe is dipped in fluid and the piston drawn back in an attempt to create a vacuum, the pressure of the outside air forces the fluid up into the syringe and so fills it. Any air remaining in the syringe will force the fluid out ahead of it, so long as the syringe is held with its needle pointing down. If we wish to get the air all out of the syringe, we must hold it with the needle pointing directly up, so that the lighter air may make its exit through the needle before the heavier fluid. (In injecting under the skin, we force the liquid, by means of the piston and our fingers, into the resisting tissues.)

The atomizer is dependent upon the principles of air pressure. A stream of air from the bulb is forced over the top of the upright tube which dips into the

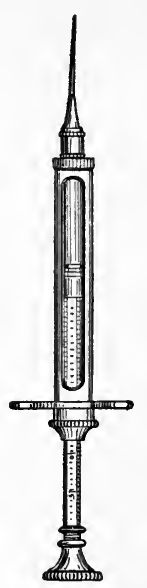

Fig. 33.-Нypodermic syringe (Morrow). reservoir of liquid; this reduces the external air pressure upon the contents of this tube. The pressure upon the surface of the body of fluid in the reservoir pushes the fluid up this tube in consequence. The jet of air from the bulb at the same time blows the liquid away in the form of a fine spray.

The siphon is a tube bent into a $U$ shape, open at both ends, one arm being longer than the other. Fill the entire 
tube with water, and holding a finger over the end to prevent its escape, dip the short arm into a container of water, dropping the longer arm outside. Release the

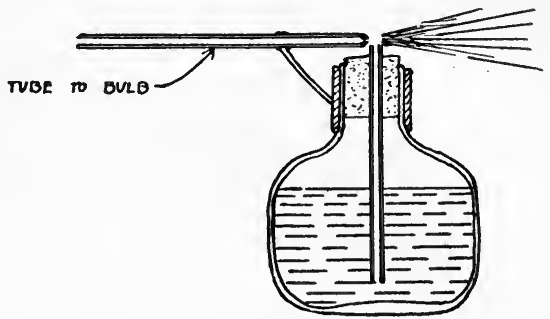

Fig. 34.-Diagram of atomizer.

finger and the water will run out through the siphon so long as the short arm dips into the water in the container. The explanation is as follows: The pressure upon the fluid in either arm is the atmosphere minus the weight

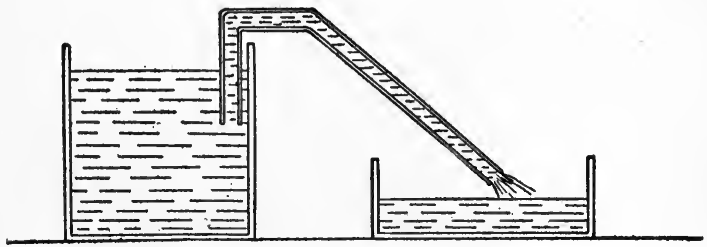

Fig. 35.-The siphon.

of the water in that arm. This makes the pressure greater in the short arm and less in the long arm; the fluid moves in the direction of least resistance. 
The stomach-tube is a siphon. The short arm is inside the stomach, the long arm outside. Water poured into the container (the stomach) will run out again when the long arm is lowered, providing the tube remains filled with water while the change in the position of the long arm is being made. If all the fluid in the tube is allowed to run into the stomach before reversing, there will be no siphon action. ${ }^{1}$ The bulb which is placed on some of the stomach-tubes is a variety of pump (see Chapter VI) which can be used instead of the siphon.

\section{SUMMARY}

In gases the molecules have no cohesion, but tend to flee from each other.

Gases are very elastic and very compressible.

Whenever gases are brought into contact, they diffuse as liquids do, but more rapidly. Upon this fact depends our ability to ventilate rooms and buildings.

Air is the most important gas. It is a mixture of four-fifths nitrogen, one-fifth oxygen, a little carbon dioxid, watery vapor, and other materials. It covers the earth's surface 7 or 8 miles deep, being more dense at sea-level because of the weight of the upper layers. Air pressure increases with depth.

The air pressure at sea-level is 14.7 pounds to the square inch. We do not feel it because the solid por-

${ }^{1}$ It is wise to have this actually illustrated in class, using a pitcher or other container in place of the stomach. 
tions of our bodies are very resistant, because the body fluids are not compressible, and because the body contains considerable air and so equalizes the pressure outward and inward.

The breast-pump, the hypodermic, the dressing syringe, cupping-glasses, the stomach-tube, etc., are based upon the laws of air pressure. Explain the working of each of them. 


\section{CHAPTER VI}

\section{PNEUMATICS (Continued)}

\section{LAWS RELATING TO GASES}

Pumps are machines for lifting and transferring fluids from one place to another. Their action depends upon air pressure. They are of two sorts-lifting and forcepumps.

The lifting pump has a tube which dips into water or other fluid, at its lower end, where there is placed a valve that opens only inward. High above this, attached to the pump handle, there is a "sucker," a tight-fitting piston pierced by a valve that opens only upward. When the sucker is raised by means of the handle (a lever), air pressure is taken off the surface of the small body of water in the tube; the air pressure upon the surface of the water in the well forces it up the tube. (See Laws and Experiments in Chapter V.) When by the action of the pump handle the sucker is lowered, the weight of the water in the tube closes the valve at its lower end and prevents the contents from running back into the well. By repeating the process, more and more water accumulates in the tube until it is high enough to run out of the spout near the top.

The force-pump has a one-way valve at the lower 
end of the tube the same as in the lifting pump, but its piston is solid. The second valve is at the side of the tube, and opens only outward, emptying into a tube which forms the spout. When the piston is raised, the

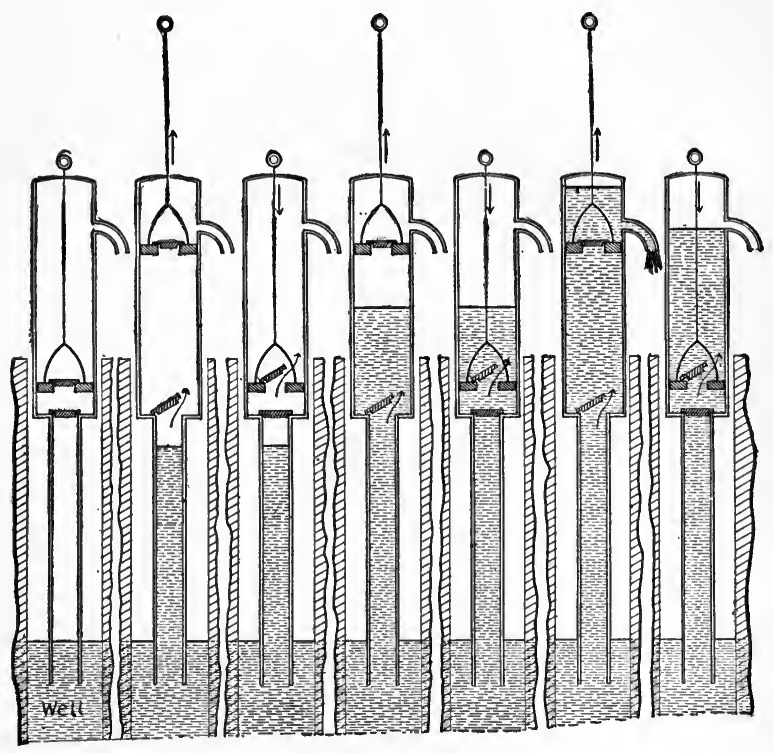

Fig. 36.--Lifting pump (Butler, "Household Physics").

main tube partly fills with water, exactly as in the lifting pump; when it is lowered, the weight of the water closes the valve at the bottom. The movement being 
repeated, continued pressure forces the side valve open and the water up the side tube and out at the spout.

A Davidson (or bulb) syringe is a variety of forcepump, at least so far as the action of the valves is concerned. Pressing the bulb while the end of the tube dips into water tends to create a vacuum, and when the pressure is released, water runs up into the tube and

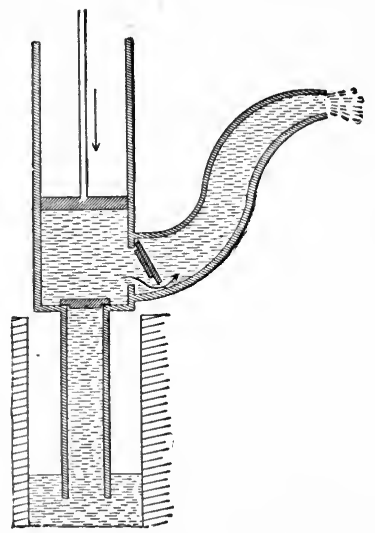

Fig. 37.-Force-pump (Butler, "Household Physics").

bulb. A second pressure forces the water in the tube against the valve at its lower end and closes it, at the same time pushing it against the outward-opening valve of the rectal or delivery tube and forcing the water out through it.

The bulb of a stomach-tube works exactly as does that of a Davidson syringe. 
The heart is a force-pump. The hollow organ resembles the bulb of a syringe, except that the force which contracts it is furnished by the heart muscle itself, situated in the wall. There is no piston, but the expansion and relaxation makes the cavity alternately larger and smaller. When the auricles contract, the oneway valves (the bicuspid and tricuspid) are forced open and the blood runs into the ventricles. When the
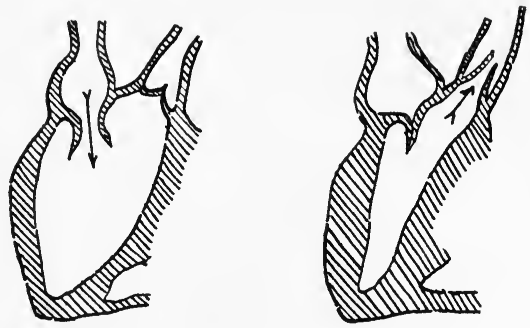

Fig. 38.-Dilation and contraction of ventricles of the heart.

ventricles contract, these valves are forced shut by the weight of the blood against them, and the semilunar valves are pushed open; the blood is thus forced out into the vessels, from the right ventricle to the lungs for purification, and from the left ventricle into the aorta, and so through the body. The impulse of the heartbeat as it forces the blood out through the arteries is transmitted to the very ends of the vessels and starts the blood on its way through the capillaries.

In the return venous circulation the flow is largely 
due to the pressure of fluid back of it and to muscular action. In the large veins of the lower limbs, however, this pressure is not enough to overcome the action of gravity. One-way valves are, therefore, introduced, which hold the blood in place until additional force from behind pushes them open and makes the blood rise. The action is much like that of the lifting pump.

The sphygmograph, or sphygmomanometer, is a machine which records the force of the heart-beat. A button is fastened over some artery that comes conveniently near the surface, and a series of levers transmit the impulse against it to a fine needle which traces the record of its rise and fall upon a specially prepared paper. Any irregularities or lack of force are noted by this tracing.

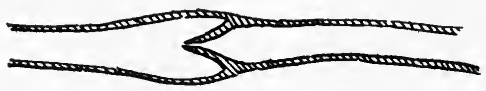

Fig. 39.-Valves in vein.

Steam Apparatus.-Steam is a gas. It occupies about 1700 times as much space as the water from which it is made. When confined within a boiler or other container and kept hot (i.e., in a gaseous state) it struggles to escape. This attempt to escape is used to produce motion, work of various sorts. (In many steam appliances the heat is an important factor. See Chapter VII.) In the steam engine the steam, in its effort to escape, drives before it with considerable force the piston, a solid body. The piston is attached to a wheel by one or more levers, and the wheel moves with the movement of the piston. The motion thus gained is 
transferred by one mechanism or another to whatever machinery it is desired to drive.

Respiration.-The act of breathing involves the laws of pneumatics. When the chest wall is pulled outward by the action of the chest muscles, and the diaphragm is lowered, the external air rushes in to fill what would otherwise be a vacuum. When the chest muscles relax and let the chest wall fall inward and the diaphragm

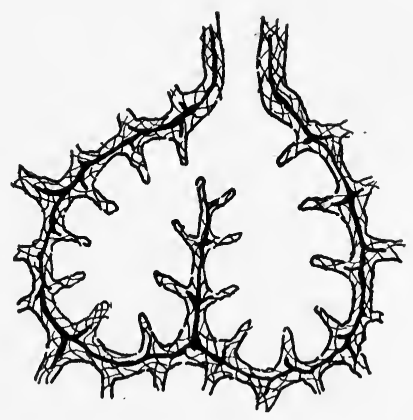

Fig. 40.-Diagram of air-cell of lung.

rise, making the space smaller, the air in the chest is forced out. This alternate intake and expulsion of air we call inspiration and expiration. About 30 cubic inches of air enter and are expelled with each respiration.

The muscular action takes air into the lungs as far as the smaller bronchi. Then the law of diffusion of gases comes into action, and an interchange takes place between the incoming oxygen and the carbon dioxid in 
the blood-stream in the lungs. This carbon dioxid, one of the important waste materials of the body, is a gas carried by the venous blood into all the capillaries of the lungs. The very thin membrane between the capillaries and the air cells of the lungs permits it to escape, by osmosis, into the air cells, and at the same time allows the oxygen which has come in to pass, by the same force, into the blood-stream. (Note that air is a mixture, not a compound; its oxygen is, therefore, free and ready to exchange places with the carbon dioxid.) The membrane lining the air-cells is just strong enough to prevent the fluid blood from passing. If it is weakened by disease, we have hemorrhage from the lungs.

\section{VENTILATION}

Principles of Ventilation.-If we open a window on a warm, perfectly still day, we presently feel the outside air coming in. This is due to the law of diffusion of gases. A certain amount of such exchange of outdoor and indoor air also takes place constantly through the cracks in our dwellings and even through the walls themselves, which are more or less porous. The phenomenon is more evident when a larger opening, like a window or door, is provided.

Diffusion of gases takes place more rapidly when there is wind to drive the molecules forward. It is also increased by marked difference in temperature.

Heat pushes the molecules of air farther apart, so 
that warm air always struggles more vigorously to get away than does cold air. Upon opening the window in very cold weather, you can feel the warm air going out for some time before the cold air appears to come in.

Warm air, because its molecules are farther apart, is lighter than cold air. In a closed room warm air rises, partly because of its lighter weight and partly because of the pressure of the cooler air which remains at the bottom. Hang two thermometers in a closed room, one near the floor and one near the ceiling. There will be a number of degrees variation in their readings, especially in a room which is artifically heated.

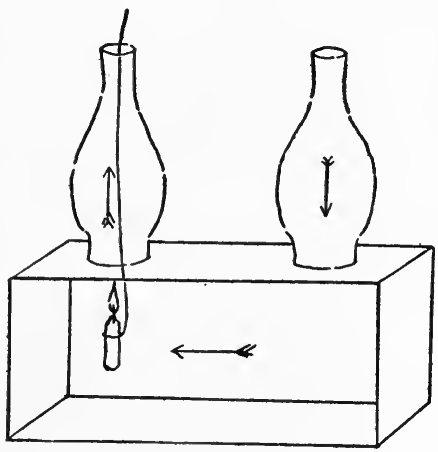

Fig. 4I.- How the draft in a chimney is produced.

The Draft in a Chimney.-Warm air, produced by a fire, rises because the cold air, which is heavier, pushes it up from the bottom. We say that a chimney draws, 
but the word is incorrect, since the draft is due to the push of the cold air from the room below, not to any pull of warm air from above. The effect is the same, but our mode of expression creates confusion in our minds.

Experiment.-Prepare an air-tight box with two holes in the lid; over each hole set a lamp-chimney and make the joint airtight. Lower a bit of lighted candle into one of the chimneys; the air thus heated rises, and fresh, cool air passes down through the other chimney to take its place. Show the draft thus produced by burning touch paper or something which smokes freely over the cool chimney. This method of introducing fresh air into a room is called gravity ventilation.

The above simple principles are the basis of our heating and ventilating systems, no matter how complicated they may seem.

To heat a room economically, the warmth should come from near the floor, because warm air always rises.

To ventilate a room we must have somewhere openings of sufficient size to permit diffusion of gases to take place as rapidly as is required by the number of occupants; 1000 cubic feet of air space for each person (a space 10 feet square by 10 feet high) is estimated to be the minimum requirement in a closed room. Ventilation must be rapid and thorough to keep this air properly oxygenated. If the openings provided for the entrance of warmed air and the escape of impure air are not properly located, diffusion will not be satisfactorily accomplished. Figure 42 shows the possibilities in such cases.

In the so-called "natural" ventilation-i. e., by open- 
ing the windows - one should open them at both top and bottom, so as to provide for proper circulation of air.
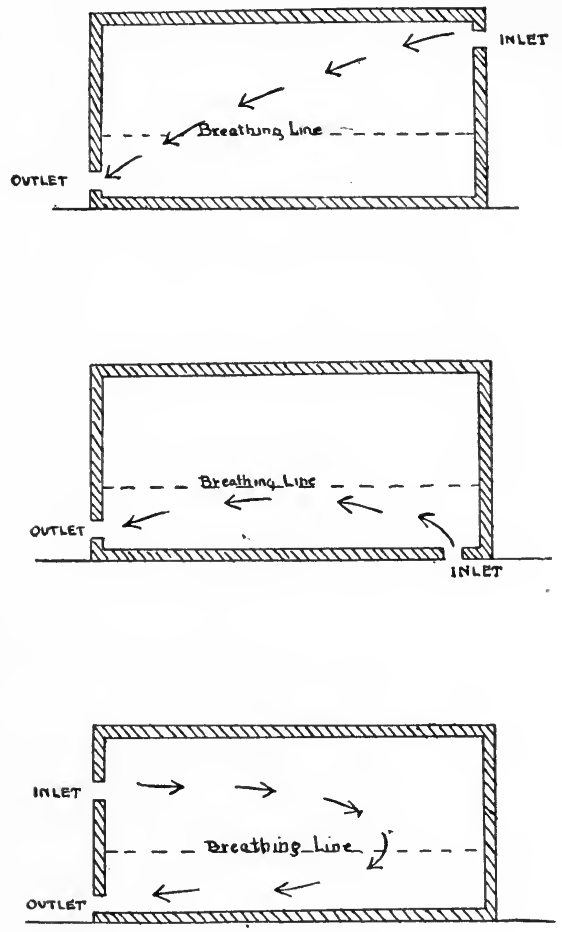

Fig. 42.-Air circulation in forced ventilation systems.

Ventilating Systems.- "Natural" ventilation is un- 
satisfactory in very hot or very cold weather; in very warm weather the diffusion of air takes place too slowly; in cold weather, too rapidly.

Artificial ventilation is a combination of heating with ventilation. Some systems embody the theory that fresh warmed air goes to the ceiling, while foul air drops to the floor; but authorities do not agree in this matter.

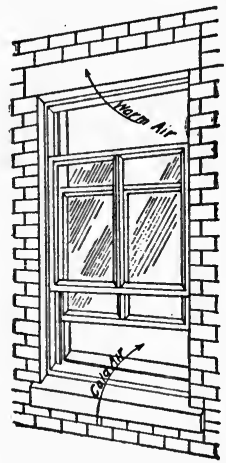

Fig. 43.-Natural ventilation (Butler, "Household Physics").

The correct and efficient method is to arrange the location of inlets and outlets so that the air in every room must be thoroughly stirred by the draft from the heating system; just what these locations are is still under discussion.

There are two sorts of heating-ventilating systems in use. One is the vacuum, in which the air is drawn out of the rooms by suction. The other is the plenum, in 
which air is forced into the room, usually by means of a fan driven by a motor. Neither system works well in combination with open windows.

An objection to all forced ventilating systems is that they stir up dust and bacteria. This is overcome in some cases by using a "washed air" system, in which dust and bacteria are removed from the air before it enters the room. This is only partially successful, because it does not take care of the dust and bacteria which originate in the room.

\section{SUMMARY}

Pumps are machines for transferring fluids from one place, or one level, to another.

Lifting and force-pumps are similar in their action. Each has a piston working in a tube which dips into the water or other fluid. Each has a one-way valve at the lower end of the tube, which permits the fluid to enter, but not to return. The lifting pump has a valve in the piston; the force-pump, one at the side of the tube. In each form of machine the repeated action of the pumphandle transferred to the piston lifts a portion of the liquid into the tube, until a sufficient quantity accumulates to run or be forced out of the spout.

The bulb syringe and the bulb of the stomach-tube are force-pumps.

The action of the human heart is like that of a forcepump, the power being the muscle in its wall. 
In the steam engine the piston is driven by the force of steam trying to escape its bounds. The motion thus produced is transferred by an appropriate mechanism to any desired machine.

Respiration is carried on in accordance with the laws of pneumatics. The actual exchange of oxygen and carbon dioxid is due to osmosis.

The ventilation of rooms and buildings involves the law of diffusion of gases, and the law that heated gases rise and cold ones fall.

Natural ventilation is satisfactory only in moderate weather. Artificial heating and ventilating systems work better in very cold weather; they are of two principal sorts, one in which the air is drawn out of the rooms by suction, the other in which it is forced in by a fan. All artificial ventilation stirs up dust and, therefore, bacteria.

Authorities disagree in regard to both theories and methods of ventilation. 


\section{CHAPTER VII}

\section{HEAT}

Heat is motion. We have learned that the molecules of all substances, however dense, are separated from each other, no one touching another. We have now to learn that these molecules are always in motion. (The motion is probably vibratory.) This molecular motion is heat.

Intensity of Heat.-A substance whose molecules are moving very slowly is cold. One in which they are moving more rapidly is warm. One in which they move with great rapidity is hot. When we heat an object, we stimulate its molecules to more rapid motion. When we cool it, we quiet their movements.

Heat may be transferred from one body to another just as motion or other sorts of energy may, by obedience to the laws that govern the transfer.

Sources of Heat.-Directly or indirectly nearly all of our heat comes from the sun. Coal is indirectly the energy of the sun stored up ages ago; petroleum likewise.

Heat may be produced by (1) friction; (2) percussion; (3) chemical action, and (4) electric action.

Experiment.-Rub a smooth metal button rapidly back and forth on a rough woolen cloth. The button becomes quite warm, an example of heat produced by friction. 
Friction is arrested motion, i. e., motion converted into heat, merely a different manifestation of the same force.

Because of this, we must often take means to get rid of friction when it is producing heat which we do not want (see page 56). For example, unless the bearings of wheels are kept oiled-the two portions of metal separated by means of the oil-the friction caused by their rapid movement makes them become hot and may even cause fire. A "hot box" on a railway car is the result of friction.

Experiment.-Strike a coin or other bit of metal hard and rapidly with a hammer. Both hammer and coin become warm, the heat being produced by percussion. Here again we have heat as the result of arrested motion.

Add sulphuric acid to a small quantity of cold water. Test with a thermometer. The liquid and the container become hot, an example of heat produced by chemical action.

The incandescent electric light, the electric flat-iron, and the electric cooker are examples of heat produced by electric action. (See Chapter XI.)

Bodily heat is produced by muscular action, by the chemical changes which take place in the process of nutrition, by the circulation, etc. Bodily heat is lost by conduction, radiation, and evaporation (see pages 107, 115, and 125). The heat loss and production are regulated by certain centers in the brain. Normal temperature is the result of a perfect balance between the heat-producing and the heat-losing processes. Fever is the result of either overproduction or poor elimination of heat; 
usually the latter. Subnormal temperature is usually due to lack of heat production, very occasionally to excessive loss of heat.

Burning is a chemical process, in which the oxygen of the air combines actively with the material of the fuel, changing it into an entirely different substance. The products are smoke, gases, and ashes, with the incidental products of heat and light.

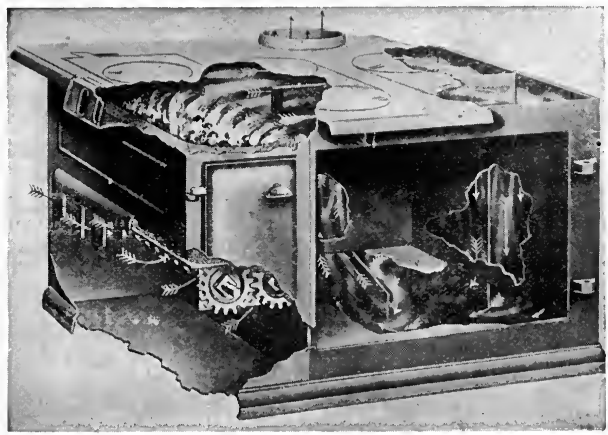

Fig. 44.-Drafts in a kitchen stove (Butler, "Household Physics").

If we wish a fire to burn well we must provide for the admission to it of plenty of oxygen; we do this by openings in our stoves and heaters which we call drafts or dampers. Closing a stove draft shuts off the supply of oxygen, therefore checks the process of combustion.

In a kitchen stove there are usually four drafts or dampers which regulate the activity of the fire and 
determine the direction in which the heat is to be thrown. When the under damper at the fire-box is open there is a draft of air through the fire, making it burn better. If this is closed and the upper one is opened the draft passes over the fire and it burns more slowly. The damper in the smoke pipe is an additional check upon the draft, slowing the fire still more. The oven damper directs the hot gases around the oven instead of over it.

Temperature is the degree of heat in an object or substance. It is not the amount of heat, or large bodies would always be hotter than small ones.

We use the term "warm" for things which are of a temperature about that of the human body $\left(98 \frac{1}{2}^{\circ} \mathrm{F}\right.$.). We say things are hot or cold when they are considerably above or below that temperature. Our statements in this respect are only relative, since twe call tea cold when it has a temperature of $105^{\circ} \mathrm{F}$, while a bath at $105^{\circ} \mathrm{F}$. is considered hot.

Our own sensations are not sufficiently accurate to enable us to judge heat by them, as they are dependent upon so many factors. A blindfolded person cannot be sure whether a substance is very cold or very hot, since the sensation is almost exactly the same in each case.

Experiment.-Have three containers, one of hot water, one of cold, and one of lukewarm. Put the fingers of one hand into the cold water while those of the other hand are in the hot. After a moment put both hands into the lukewarm water. It will feel cool to the hand from the hot water and warm to the hand from the cool water. 
Effect of Heat.-Heat produces the following effects:

1. Rise in temperature.

2. Increase in volume (the molecules being driven farther apart, the substance requires more room.)

3. Increase of pressure upon the container. This is due to the increased volume.

4. Change in physical state, as melting, vaporization, etc.

5. Change in character, as in burning or other chemical process.

Expansion and Contraction.-Since heat is motion, and increased motion tends to drive the molecules of a substance farther apart, it is easy to understand that heat increases the volume of a substance, i. e., expands it. Absence or lessening of heat causes the opposite effect, contraction. We have, therefore, the law, Heat expands and cold contracts. ${ }^{1}$

Experiment.-Use the flask with a bent tube through the cork. Place the end of this tube in water. Heat the empty flask. Bubbles of air will be seen pushing their way through the water because the heat expands the air in the flask. Without removing the end of the tube from the water, cool the flask by pouring cold water over it. Water will be forced up into the tube on account of the lessened air pressure in the flask.

Uneven expansion or contraction may encounter resistance at some point and a crack or breakage result, if the material is brittle. This is observed in glassware,

1 We are familiar with the fact that gloves and shoes fit more snugly when the hands and feet are very warm. This is almost entirely due to the above law. 
which is almost sure to crack if either heat or cold is suddenly applied to one portion; this portion expands or contracts, as the case may be, while the rest of the utensil remains unaffected. It is this uneven expansion or contraction which causes the breakage.

Water is the one great exception to the rule of contraction upon cooling. It acts like ordinary materials and contracts while cooling until a temperature of $4^{\circ} \mathrm{C}$. is reached, when it begins to expand. Ice occupies more space than did the water from which it was made. To this fact is due the bursting of water-pipes when frozen.

Measurement of Heat.-In order to accurately measure heat the thermometer has been devised. Its bulb contains some fluid which is especially sensitive to heat and readily expands when warmed. The tube provides an outlet for the expanding fluid. The scale records the amount of expansion or contraction.

Mercury is used in thermometers because it is sensitive to heat, easy to see, etc. Colored alcohol is also used, especially in thermometers for use in very cold regions where mercury would freeze. (Mercury freezes at $40^{\circ} \mathrm{F}$. below zero.)

If a thermometer bulb is placed in contact with anything hotter than is provided for by the length of its tube, the force of the expansion of the mercury will burst the tube. (We all know the unfortunate probationer who washes a thermometer in hot water.) 
If a thermometer bulb is placed in contact with anything colder than the tube provides for, the mercury goes into the bulb and we cannot register it.

The clinical thermometer is provided with a contraction in the tube at a point below the scale. This interferes with the free return of the mercury when cooling takes place, and so keeps in place what has run up the tube until it is shaken down, i. e., urged back into the bulb or toward it.

A thermometer must be very accurately made, scaled, and tested to be of value.

There are two sorts of thermometers in use, those having the Fahrenheit and those the Centigrade scale. ${ }^{1}$ In the Fahrenheit scale, $32^{\circ}$ is the freezing-point of water and $212^{\circ}$ its boiling-point. In the Centigrade scale (Centigrade means "one hundred steps") zero is the freezing-point of water and $100^{\circ}$ its boiling-point.

A calorie is the standard of measurement for chemical heat. It is the amount of heat required to raise the temperature of 1 pound of water 4 degrees Centigrade.

Boiling.-Liquids are said to boil when their temperature is raised to the point where they begin to change into vapor. When water is heated to $100^{\circ} \mathrm{C}$. bubbles of steam are formed, which, being lighter than the water, push their way to the surface and discharge into the air. This gives the appearance which we call boiling.

1 The Réaumur scale is not much used. 
The temperature of water to which heat is being applied rises gradually until full boiling-point is reached, when it remains stationary. After a liquid is once boiling, it cannot be made any hotter, though heat is still going into it. (See Latent Heat, page 127.) Test with a thermometer, and see if there is a difference in temperature between water that is boiling gently and that boiling vigorously.

Variation in Boiling-point.-All liquids do not boil at the same temperature. Alcohol boils at $78^{\circ} \mathrm{C}$., and ether at $37^{\circ} \mathrm{C}$. Mercury (a liquid metal) requires a temperature of $357^{\circ} \mathrm{C}$. to make it boil.

Raising the Boiling-point of Water.-When a liquid has a solid substance dissolved in it the boiling-point becomes higher. A familiar example is found in the fact that vegetables cook more rapidly in salted water, because its boiling-point is higher and more heat is being used.

Experiment.-Put water into two containers of the same size. Dissolve 2 or 3 teaspoonfuls of salt in one of them. Heat both until they boil. Test the temperature of each with a thermometer that has a scale above $212^{\circ} \mathrm{F}$. The salted water will be found several degrees hotter than the unsalted.

Air Pressure and Boiling.-The boiling-point of a liquid is changed when the air pressure upon it is changed. The boiling-point of water is $212^{\circ} \mathrm{F}$. at sea-level. As one goes to a higher altitude it becomes less, the difference being 1 degree Fahrenheit for every 500 feet of alti- 
tude. In Denver, 1 mile above sea-level, water boils ar $202^{\circ} \mathrm{F}$; ; on the top of Pike's Peak (14,000 feet) it boils at $184^{\circ} \mathrm{F}$; at the latter place it is impossible to cook eggs hard, because there is not enough heat in boiling water to coagulate the albumen. Even at 1 mile above sea-level it takes appreciably longer to cook vegetables, etc., because boiling water is not as hot as at sea-level.

Experiment.-Put some water into a flask and heat it to the boiling-point. Remove from the fire and at once cork tightly. Turn the flask upside down and pour cold water over it. The cold condenses the steam which is in the flask and thus removes its pressure from the surface of the water. The water begins to boil again from the release of pressure. When it again stops boiling, test the temperature. It will be found considerably less than $212^{\circ} \mathrm{F}$.

This phenomenon is utilized in a practical way in the vacuum kettle. Condensed milk, for example, is made by evaporating the moisture from milk at a temperature below $212^{\circ} \mathrm{F}$, $i$. e., boiling it in a kettle from which a portion of the air has been pumped, so that the pressure on the surface of the liquid is much less and the boilingpoint considerably lowered.

Steam Pressure Apparatus.-Conversely, if we increase the pressure upon the surface of a liquid, we raise its boiling-point. "Pressure cookers" and sterilizing apparatus take advantage of the fact that steam under pressure is hotter than that which is in contact with the air. Cookers of this sort are made steam tight and strong enough to resist several pounds' pressure. They 
cook their contents at a temperature higher than $212^{\circ} \mathrm{F}$, therefore more rapidly and thoroughly. (They also keep in the flavors which would otherwise escape with the steam. ${ }^{1}$ )

In a dressing sterilizer 15 or more pounds of pressure are used to raise the steam to a temperature of $240^{\circ} \mathrm{F}$. or more. We call this "superheated" steam, and find that it remains dry, that is, uncondensed. This makes the sterilizing process more sure because of the higher temperature to which possible germs are subjected. The pressure also serves to force the steam in among the dressings, so that it may reach every portion of the materials to be sterilized. The dryness of the steam is an additional advantage. Such sterilizers must, of course, be fitted with safety-valves, so that the pressure may not run so high as to endanger the apparatus.

(Water sterilizers ordinarily are devices for boiling water under normal air pressure, and afterward either keeping it hot or cooling it. They may be arranged to sterilize under pressure at a higher temperature. Utensil and instrument sterilizers are merely pans in which the boiling is accomplished by gas, steam, or electric heat.)

Evaporation is the process of changing a liquid into a gas. When a liquid, especially if warm, is left exposed to the air the molecules on its surface are constantly

${ }^{1}$ The action of heat in cooking food is largely due to the chemical changes which it produces. 
leaving and going into the air. With time, all the liquid goes into the air in this way and disappears. It has become vapor-evaporated. The process is, as we know, hastened by heat, and by a draft of air or wind, which enable the molecules to detach themselves more easily; the current also carries them away, making room for more to rise. Evaporation also takes place more rapidly from a large surface, since there are a greater number of molecules exposed to the air and ready to take flight.

Applications of these principles are familiar. We heat a liquid when we wish it to evaporate quickly. We hang wet clothing in a breeze to dry it: We spread out damp materials when we wish them to dry. We use a large open pan when we wish its contents to evaporate or dry out, and a smaller one with a tight cover when we wish to keep materials moist.

Evaporation Cools.-Experiments.-Pour a little alcohol or ether upon the hand. It feels cool, $i$. e., it cools the hand as it evaporates. Hang two thermometers side by side. Cover the bulb of one with a bit of gauze, the end of which dips into water. Fan them vigorously. The wet-bulb thermometer shows a considerably lower temperature than the other. ${ }^{1}$

The evaporation of perspiration from the surface of the body cools it. Fanning cools a person who is perspiring by hastening evaporation. Since there is a constant "insensible" perspiration going on even in cool weather (the amount is 20 to 30 ounces in twenty-

1 The Mexican ollo, a porous water-jar, hung in a draft, keeps water cool in hot weather by evaporation. 
four hours), its evaporation produces a considerable cooling of the body. Profuse perspiration causes a very marked cooling. On a damp day the evaporation of perspiration takes place slowly, and we do not get the cooling action to any extent; we therefore "feel the heat."

The fan bath which is given to reduce temperature constitutes a method of causing moisture to evaporate rapidly from the surface of the body, thus extracting heat from the patient. For a similar reason a tepid bath often reduces temperature as well as a cold one.

A cold compress should always be thin, so that evaporation may prolong and add to the cooling process, and obviate frequent changing. (Conversely, a hot compress should always be thick and covered well, in order to prevent both evaporation and radiation of heat.)

Condensation is the opposite of evaporation, and is produced in an opposite way. If a warm vapor is cooled, it condenses, $i$. e., becomes a liquid again. This is the cause of rain; the heat of the sun vaporizes water from the sea, lakes, etc., and it is stored, still warm, in the form of clouds. When these clouds are struck by a cold wind or come into a cooler layer of air, the vapor of which they are composed condenses into drops and we have rain.

(Snow is frozen-crystallized-water vapor. Dew is caused by the moisture in the air condensing upon a surface which is colder than the air. The earth, grass, plants, etc., radiate their heat readily, therefore soon become cooler than the air. Frost is frozen-crystallized-dew.) 
Distillation is the process whereby a liquid is vaporized by heat and the vapor collected and cooled, making it into a liquid again. It is commonly done by boiling the liquid in a closed vessel, letting the vapor escape through a long tube which runs through cold water; the large surface presented to the cooling process makes the vapor condense rapidly; it drips from the end of the tube into a container.

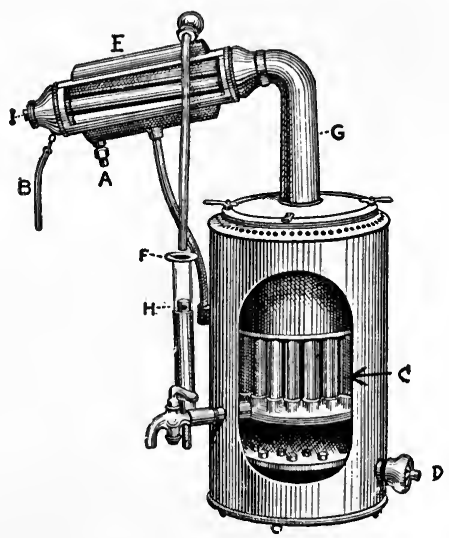

Fig. 45.-Water still: $A$ and $B$, Inlet and outlet for water to cool it; $C$, boiler for water; $D$, inlet for heating gas; $E$, condenser; $G$, collecting pipe for steam; $I$, outlet for distilled water.

The so-called "dry" or destructive distillation consists of heating solid substances in tightly closed vessels, $i$. e., in the absence of air. It is a chemical process, 
the substance being broken up and other substances formed.

Distillation is used to free a liquid from some substance dissolved in it, since the liquid alone vaporizes, the solid matter needing a much greater degree of heat to drive its molecules apart.

When a mixture of liquids or a solution of solid matter in one or more liquids is heated, the most volatile (that is, the one which boils at the lowest temperature) is naturally the first to be vaporized. For example, if a mixture of ether and water be heated, the ether will be evaporated and disappear long before the water begins to boil. In this way liquids that have different boiling-points may be separated and purified by distillation. ${ }^{1}$

Distilled water is absolutely pure, since it has by the process undergone been freed from any matter dissolved in it. Water from a well, a river, or a lake may be pure in the sense that it has no harmful matter in it, but since it usually has in solution some mineral or other matter, it is not pure in the chemical or scientific sense. Stills are sometimes attached to water sterilizers so that the water may be distilled, and so freed from all mineral as well as vegetable or animal impurities.

\section{SUMMARY}

Heat is molecular motion, probably a species of vibration. When the molecules are moving very rapidly, the substance is said to be hot; when less rapidly, warm; when still less rapidly, cool or cold.

${ }^{1}$ An interesting example of this occurs in the manufacture of petroleum products. Benzine, being very volatile, is the first to be collected in the process of distillation, then gasoline, then kerosene, and so on. 
The chief source of heat is the sun. Heat is also produced by friction, by percussion, by chemical and by electric action. Bodily heat is the result of the chemical processes occurring in nutrition, of muscular action, the circulation, etc. It is lost by radiation and evaporation.

Normal temperature is the condition of balance between production and loss of heat. High temperature is the result of overproduction or insufficient elimination or radiation of heat. Subnormal temperature is usually due to underproduction of heat.

Burning is a chemical process in which matter changes not merely its form, but its actual composition and hence its identity.

Temperature is degree of heat. The terms "warm" and "cold" are relative, and our sensations are not sufficiently accurate to judge of them.

Heat produces five general effects: rise in temperature, increase in volume, increase of pressure, in the container, change in state, or change in character.

Heat expands substances. Cold contracts them. Water is the marked exception to this rule, in that it expands upon freezing.

Uneven expansion or contraction causes breakage in brittle substances.

The thermometer is a device for the accurate measurement of the degree of heat. The clinical thermometer is made with a contraction in the tube which prevents 
the mercury from returning to the bulb unless shaken back.

In the Centigrade scale zero is freezing-point, $100^{\circ}$ boiling-point.

A calorie is the amount of heat required to raise 1 pound of water 4 degrees Centigrade in temperature.

In boiling; portions of water are successively vaporized, the light steam rising in bubbles, which break at the surface. The temperature at which liquids boil varies greatly. Water is taken as the standard.

Dissolving a substance in water raises the boilingpoint of the water. Increase in the air pressure upon the surface of water raises its boiling-point. Decrease in the pressure lowers its boiling-point.

Dressing sterilizers employ superheated (dry) steam under a pressure of 15 or more pounds; this forces its way into the materials and the higher temperature obtained makes the bactericidal action more certain. Water sterilizers boil the water to render it germ free, then cool or reheat it as desired. Utensil and instrument sterilizers are merely vessels arranged conveniently for boiling.

By evaporation liquids are changed into gases and diffused into the air.

Evaporation cools. In bathing or other procedures to reduce temperature as much evaporation as possible should be obtained. The evaporation of the perspiration cools the body under normal circumstances. 
Condensation is the opposite of evaporation.

Distillation is the process of vaporizing a liquid, collecting the vapor and recondensing it. Distillation is used to free liquids from impurities or to separate liquids that have different boiling-points. Only the liquid vaporizes, any solid substance in solution being left behind. Distilled water is chemically pure.

Dry distillation is a chemical process. 


\section{CHAPTER VIII}

\section{HEAT (Continued)}

\section{TRANSMISSION OF HEAT}

SINCE heat is motion, we can easily understand how it may be transmitted from one thing to another. There are three methods by which this occurs: conduction, convection, and radiation. Conduction refers to solids; convection, to liquids and gases.

Conduction.-When one portion of a solid body is heated, its molecules transmit their motion to those next them, and the heat travels throughout the whole body. In other words, the heat is conducted from one portion to another.

Substances differ greatly in their power of conducting heat. Upon this fact many of the conveniences of life depend, temperature being a very large factor in our comfort.

Metals are, as a rule, good conductors of heat. Cloth and most porous materials are poor conductors.

Experiments.-Put the end of a short iron wire into a flame; note how soon the end held by the fingers becomes hot. Put the end of a sliver of wood or a straw into a flame; it burns close to the fingers before any heat is observed in the straw itself. 
Flat-iron handles, tea-pot handles, etc., are made of wood because it is a poor conductor of heat. ${ }^{1}$ A kitchen "holder" is merely a substance that is a poor conductor of heat.

Wool is a poorer conductor of heat than cotton, cotton poorer than linen. Linen clothing and bedding tend to cool the body by conducting heat away from it. Wool keeps the bodily heat to a great extent where it is. Cotton conducts it away but slowly. Asbestos, which is a very poor conductor of heat, is used for covering steam-pipes when we wish to keep their heat from escaping.

Wool is used for fomentation cloths because it is a poor conductor of heat and so retains it for a long time. Cotton fomentation cloths give up their heat quickly and so are not satisfactory.

Water is a poor conductor of heat.

Experiment.-Hold a test-tube nearly filled with water by its bottom and heat the top of the water in a flame; the top will boil while the bottom is barely warmed.

Large bodies of water tend to keep the temperature of the air in their vicinity even. Towns built near a large body of water are not as likely to be hot in summer as corresponding inland towns, while in winter they are often warmer. Farmers on the shores of the great lakes

1 The so-called "cold handle," though made of metal, is arranged so that heat must travel a long way; the handle becomes "air-cooled" in the process. 
find that the lake keeps away frost by preventing sudden drops in temperature. . (Other factors, of course, modify this general rule.)

Air and all gases are poor conductors of heat because their molecules are so far apart that they do not readily convey their motion to their neighbors. Much practical use is made of this fact.

It is well known that loose clothing keeps the body warmer than tight clothing, not only because the circulation is less impeded, but because it encloses a considerable quantity of air which does not conduct the bodily heat away. Several layers of light clothing are warmer than few heavier ones because of the layers of air between them.

If a house be built with a double wall, having an air space between the two parts, it will be warmer in winter and cooler in summer than one built with a. solid wall twice as thick. Double windows keep heat in because of the air enclosed between them.

Refrigerators are devices for keeping out heat as well as for retaining cold. (Cold is merely absence of heat.) Their walls are made of materials which are poor conductors of heat, as wood, paper, cork, sawdust, air. It is the number and thickness as well as the particular material of these layers that makes a refrigerator a good one. In choosing a refrigerator, one with thick walls is pretty certain to be better than one with thin walls. In ice-houses the walls usually have large 
"dead air" spaces, since air which cannot be disturbed prevents the passage of heat very effectively.

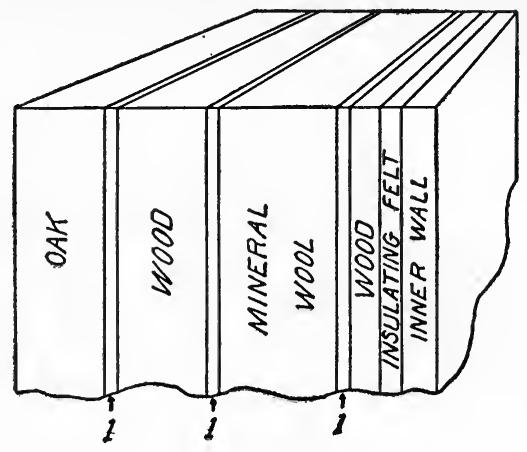

\section{Insulating Sheathing.}

Fig. 46.--Section of a refrigerator wall (Butler, "Household Physics").

(There should be circulation of air in the interior of a refrigerator. The ice is always placed at the top; it cools the air there, which drops because of its weight and because it is pushed aside by the lighter, warmer air below. This warmer air, in turn, becomes cool and drops; thus a circulation is maintained, keeping the food cold. Any food having a pronounced odor should be kept in a separate tight compartment, or any food like butter or milk which readily absorbs odors.)

One can keep ice for a considerable length of time by wrapping it in a woolen cloth and hanging it in the air. In the refrigerator, however, the object is not to keep the ice, but to cool the food. Ice in a refrigerator should, therefore, be left uncovered. 
Capacity for Heat.- If a substance is a poor conductor of heat, it follows that it holds or retains heat for a longer time than does a substance which is a good conductor of heat. Hot-water bottles are of advantage because the water retains its heat so well. Bricks or stones hold heat well. Stove-lids or other metal articles impart their heat quickly to objects that are in contact with them, and so become cool themselves. The best
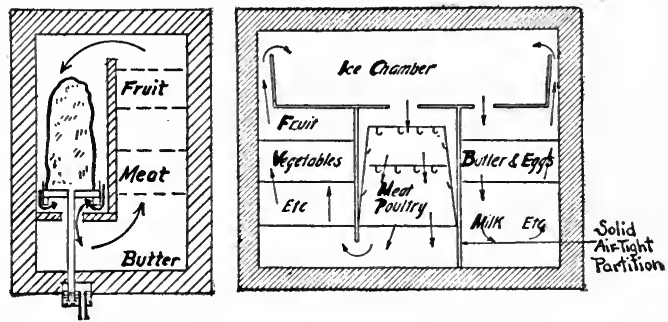

Fig. 47.-Circulation of air in a refrigerator (Butler, "Household Physics").

heater is a stone jug of water, because both water and stone are poor conductors of heat, i. e., retain heat well.

The fireless cooker is a device that makes use of substances which are poor conductors of heat, such as asbestos, felt, dead air, hay, etc., to prevent heat from escaping from the contents of a vessel which has been heated to boiling-point. The apparatus keeps the food at a temperature somewhat less than boiling-point, but sufficiently high to continue the cooking process. 
If, in addition, heated soapstone disks are laid over the food containers, still more heat is retained and further cooking made possible.

The vacuum bottle has a space in its wall from which some of the air has been withdrawn, leaving a partial vacuum; this leaves so few molecules of air in the confined space that (in addition to the fact that they are

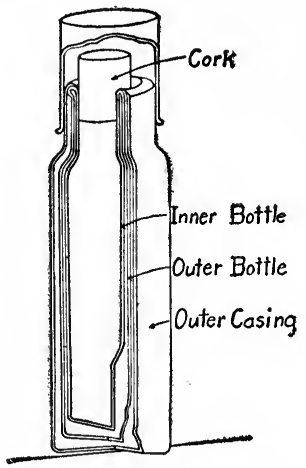

Fig. 48.-Section of vacuum bottle (Butler, "Household Physics").

confined) they do not transmit their motion to one another nor to their surroundings except with the greatest difficulty. By this means heat within the bottle is kept in; or if it is desired to keep the contents cold, the outside heat is prevented from getting in.

Convection is the movement of liquids or gases by means of which heat is distributed through them. Air 
or water heated at the bottom starts rapid currents of convection, because the heated portion is lighter and so rises, stirring the whole mass. We have seen that water may be heated to boiling at the top without marked effect upon that below; boiling would be almost impossible if we applied heat only at the top.

Experiments.-Water: Put a small quantity of sawdust into water; apply heat to the bottom of the container and watch the convection currents. Air: Repeat the experiment given on page 92. This illustrates the convection of gases.
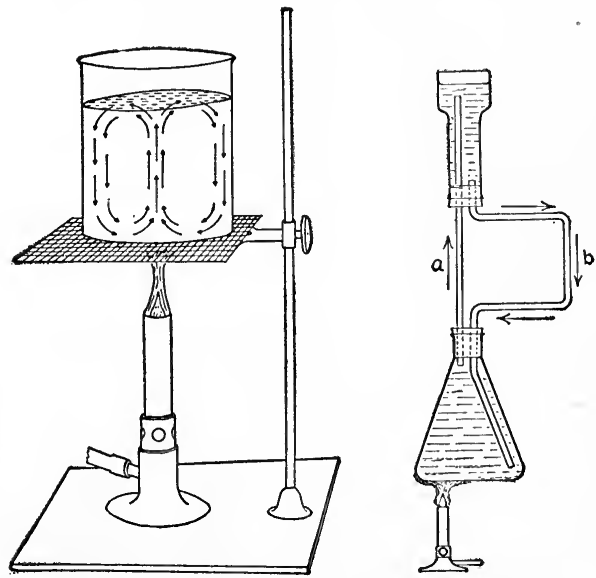

Fig. 49.-Convection currents in water (Butler, "Household Physics").

Plumbing and Heating.-The principle of convection in liquids and gases underlies most of our arrangements for plumbing and heating. 
Hot water, being lighter, always rises. When we use the kitchen range for supplying hot water the arrangement is as follows: The cold water enters the "waterback" of the range (a flat thin tank set next to the fire so as to expose a large surface to be heated) from the bottom of the tank in the kitchen. ${ }^{1}$ As it becomes

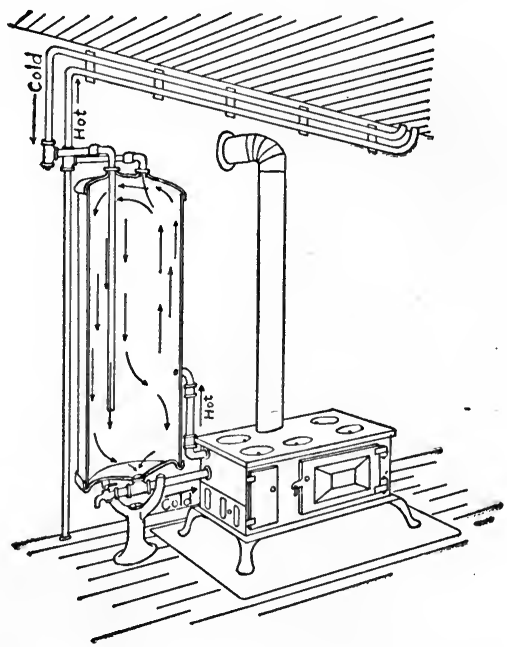

Fig. 50.-Heating water with kitchen range (Butler, "Household Physics").

heated, it rises through the pipe which discharges near the middle of the tank. From here it continues to rise, the hottest water always being at the top of the tank.

1 This tank is incorrectly called a boiler. 
It circulates by means of a pipe branching to all the

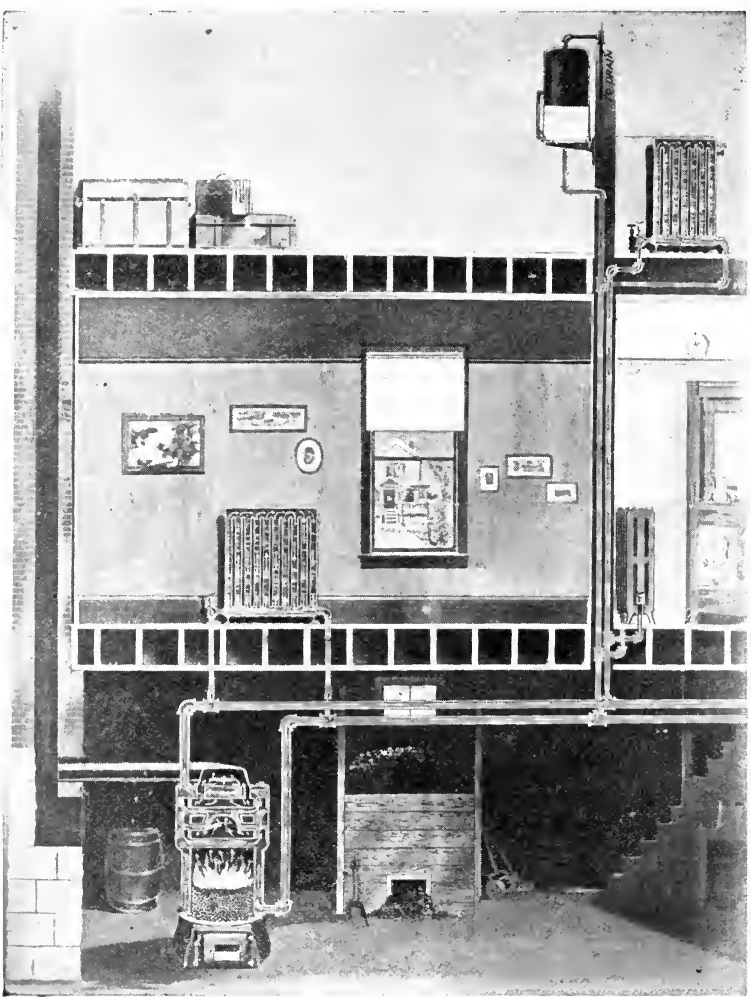

Fig. 51,-Hot-water heating system (Butler, "Household Physics"). fixtures in the house, where it is drawn off at the faucets. 
The supply is kept renewed by the entrance of cold water into the tank.

When hot water is supplied from a tank connected with the heating system and heated by it, the principle of convection is the same.

A hot-water heating system is arranged so that water heated in a boiler in the basement rises through pipes and circulates in radiators placed in the various rooms. As it cools in the radiators it falls, and so returns to the heater. Since hot water expands so greatly, such a system must be provided with an expansion tank at its highest point (usually in the attic) into which the excess of hot water runs. If the pipes were not provided with this outlet they would burst when the water was heated.

Steam heating systems take advantage of the law of expansion of gases. Steam set free from a boiler in the basement rises and struggles to escape. It forces its way through the pipes provided for it into the radiators. There it gives up its heat, cools, and in consequence condenses, falling to the bottom and dripping through the "return" pipe back to the basement. It re-enters the boiler as cold water, coming in at the bottom, and again ascending as it is heated and changed into steam.

(It can be readily seen that the heat from steam is much more intense than that from hot water; to this is due the almost universal overheating of buildings where the former is used.) 
Radiation of Heat.-A heated body starts in the air about it molecular movements which radiate or move in all directions; by this means it loses its heat, transmitting it to the air and thence to surrounding objects. The heat of a fire literally strikes your face or body when you are near it.

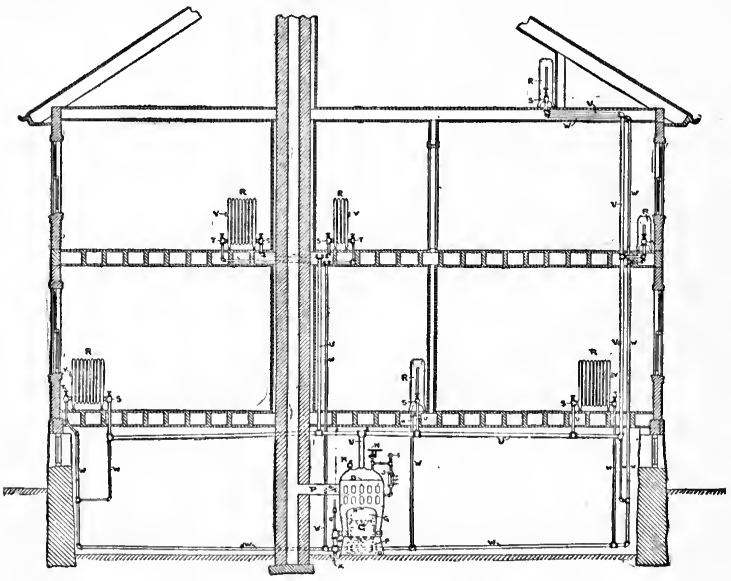

Fig. 52.-Steam heating system (Butler, "Household Physics").

Hold your hand between your face and a fire, and the heat is shut off from your face. Why? Because you have intercepted the waves of molecular motion which were coming from the fire.

Radiation takes place slowly from smooth surfaces, more rapidly from rough ones. Is it for this reason 
that objects which we wish to have retain their heat are made smooth (as the tea-kettle, hot-water bottle, etc.), while those which we wish to give up their heat rapidly are rough (as stoves, steam radiators, etc.).

Steam or hot-water radiators are exactly what their name implies. They are hot bodies which start heat movements in the air about them. The larger their surface, the more heat they radiate or give off; this is the reason for making them in the usual form, with many pipes, thus presenting a large surface which is in contact with the air. If they were flat boxes they would need to be very much larger in order to present the same amount of radiating surface. Hospital engineers object to having the radiators in an operating room covered with sheets, because it makes them in effect a flat box and reduces the actual radiating surface so greatly that it becomes impossible to heat the room.

Radiators are commonly placed at the bottom of the room and in its coldest part, i. e., next the windows, so that they may start convection currents of -warm air in the portion where it is most needed and the room be heated more evenly.

The human body is of a higher temperature than the air which usually surrounds it. It therefore radiates its heat. If heat were not constantly being produced in the body ${ }^{1}$ we should become cold from the mere fact of radiation. Other conditions being equal, small

1 Much of the bodily heat is produced by chemical action. 
persons-presenting a larger surface in proportion for radiation-tend to lose their heat more rapidly than do large persons; for this reason it is necessary to protect babies from sudden cooling.

Clothing, especially that made of materials which are poor conductors of heat (as wool), prevents radiation of bodily heat, and so keeps the body warm. On the other hand, thin clothing, or that made of materials which are good conductors of heat (as linen), allows the bodily heat to radiate and so be lost. Thin clothing also permits rapid evaporation of perspiration, which assists the cooling process.

Sunstroke occurs as follows: The high temperature of the surrounding air practically abolishes both radiation and conduction of heat. If, in addition, there be high humidity, so that evaporation from the skin is also stopped, while heat production in the body continues, excessive elevation of bodily temperature takes place, and sunstroke is the result.

\section{LATENT HEAT}

When heat goes into a substance, yet does not change its temperature, it is called latent (hidden) heat.

Experiments.-(a) Put cracked ice into a sniall vessel, set a thermometer in it (keeping the bulb of the thermometer off the bottom), and apply heat. The thermometer registers the same temperature, just above freezing-point, until all the ice is melted. (b) Boil water for ten minutes, testing with the thermometer. The water is changed to steam, yet gets no hotter than $212^{\circ} \mathrm{F}$. In each case we are sure that heat is entering the vessel and contents, yet we find no record of it. 
Latent heat is that which disappears when a substance changes its form.

The explanation is as follows: The molecules in either solids or liquids, being held together by cohesion, take considerable force, or energy, to separate them. The heat energy which we put into them in the process of heating is used in overcoming this cohesion and enabling them to change their form.

Artificial Cold.--It should be, and is, possible to recover this lost energy. It is done by reversing the process of liquefaction or evaporation. Water under normal conditions freezes very slowly because it takes time to get rid of the latent heat or energy which it acquired upon liquefying. If we wish to make ice artificially and rapidly, we hasten the process by rapidly vaporizing some volatile liquid, such as ammonia or compressed carbon dioxid; it extracts heat for this change from water which is placed adjoining it; the water, therefore, freezes.

In freezing ice-cream, the salt hastens the melting of the ice, causing it to extract heat from any nearby object, which in this case happens to be the cream.

\section{SUMMARY}

Solids conduct or radiate heat. Liquids or gases convey it by currents. Conduction, convection, and radiation are all modes of transference of molecular motion.

Metals are, as a rule, good conductors of heat. Wood, 
wool, etc., are poor conductors. Water is not a good conductor of heat, nor is air. We choose our clothing, and utensils, build our homes, etc., with reference to these qualities in materials. The hot-water bottle, fomentation flannels, double windows, the fireless cooker, the vacuum bottle, refrigerators, etc., are examples of the practical application of the principles of heat conduction and radiation.

Objects which conduct heat poorly hold it well, and vice versa.

Convection of heat by currents of water or air is the underlying principle of our heating, ventilating, and hot-water supply systems.

Objects give off heat by radiation from their surface. Rough surfaces radiate better than smooth ones.

The human body loses heat by radiation. Clothing tends to prevent this loss.

Sunstroke is due to lack of heat radiation and evaporation of the perspiration, coupled with excessive heat production.

During boiling and melting no change in temperature takes place, even though heat is constantly entering the substance under observation. This heat which is apparently lost and produces no effect is called latent heat. It may be recovered by reversing the processes. 


\section{CHAPTER IX}

\section{SOUND}

What Sound Is.-Drop a pebble into a pool of still water. It starts small waves or movements which travel in all directions and which strike the shore or rim with a definite force.

We live in what is practically a lake of air. Any disturbance in the air creates waves which travel considerable distances, until their force expends itself. The sort of air disturbance with which we are most familiar is sound. There has always been much discussion as to whether sound was the air wave itself or the effect produced by it upon the ear and brain; the latter is now regarded as correct.

Production of Sound.-Sound is produced by the vibration of bodies. Such bodies may be strings, membranes, thin plates, etc. The vibration may be produced by a current of air, a blow, etc. In some instances the vibrations may be felt or seen. Place your hand lightly against a large bell that has just been rung; note that the sound ceases when your hand checks the vibration.

Sound waves travel outward in every direction, not only on a plane, as those in water do, but up and down 
also, along all possible radii of a sphere whose center is the spot where the vibrations are produced. Each wave-like vibration compresses the air ahead of it, press-

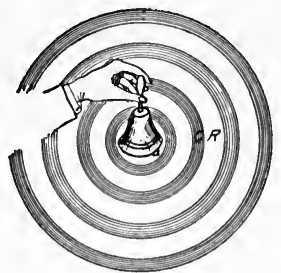

Fig. 53.-Sound wave movement (Butler, "Household Physics").

ing the molecules closer together; these rebound, coming wider apart; the rebound produces pressure, the pressure a rebound, and so on; thus the vibratory movement consists of an alternate condensation and rarefaction of the sound medium. The molecules of air do not travel in carrying a sound, but merely vibrate to and fro.

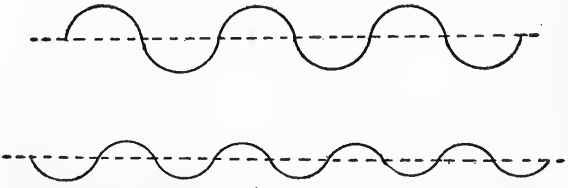

Fig. 54.-Diagram of sound waves.

Upon the amplitude of such vibrations depends the intensity and pitch of the sound. 
The Human Voice is produced by the vibrations of the vocal cords. The vocal cords of the human throat resemble strings or bands. They are pulled together or separated, tightened or loosened, by muscular action

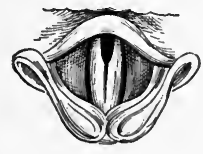

A

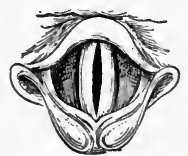

$B$

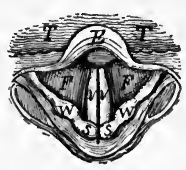

C

Fig. 55-Top view of larynx: $A$, small or highest register; $B$, upper thin or middle register; $C$, lower thin or middle register.

(voluntary). Air from the lungs is forced across them, between them, making them vibrate. Low tones are produced by relaxation of the muscles which control them; high tones, by tightening.

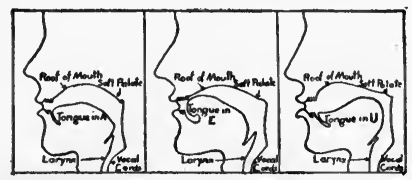

Fig. 56.-How voice is modified (Butler, "Household Physics").

The voice is modified by the movements of the cords themselves, the tongue, lips, and cavity of the mouth, as well as by the size and shape of the nasal cavity, and changes in the shape of the throat. The whole process is very complicated and takes much practice to get perfect results. To a certain extent quality of voice de- 
pends upon inborn characteristics, but it is largely the result of training. Perfect control of breath, vocal cords, and the muscles of throat and mouth is necessary for excellence in speaking or singing.

Organs of Hearing.-Our ears are the organs which collect a portion of the sound waves and transmit the impression gained therefrom to the brain. The sound waves, collected by the external ear, cause the tightly

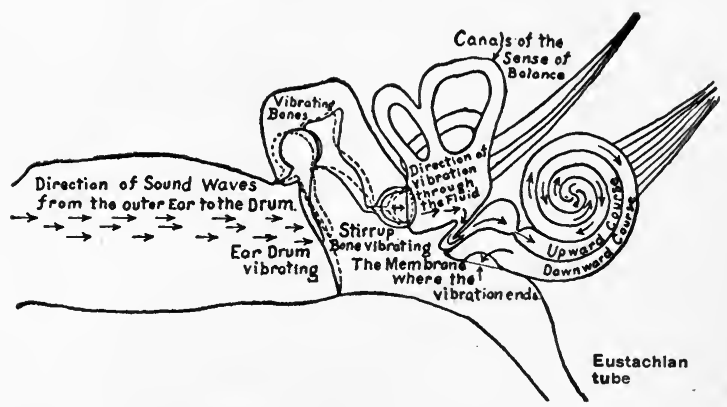

Fig. 57.-Transmission of sound by mechanism of ear (Butler, "Household Physics").

stretched ear drum to vibrate. This vibration is taken up by the chain of tiny bones in the middle ear and transmitted to the fluid and otoliths of the inner ear. These, in turn, stimulate the tiny fibers of the endings of the auditory nerve, which conducts the impulse to the brain where its meaning is interpreted. The eustachian tube equalizes the air pressure between the middle ear and the outside world. 
Ability to distinguish between sounds and to know their meaning is the result of a long process of education and practice.

Diseased conditions, temporary or permanent, inflammatory processes which cause swelling, pus, etc., interfere greatly with the transmission of sound by the ear mechanism, or even stop it altogether. The ear drum may be tightened or relaxed by disease, the chain of ossicles stiffened, the eustachian tube blocked so that there is not a proper adjustment of air pressure, or the inner ear or auditory nerve may be effected; any of these cause partial or complete deafness.

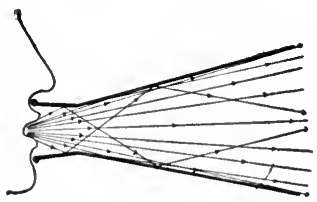

Fig. 58.-Megaphone, showing reflection of sound (Butler, "Household Physics").

Artificial Aids to Hearing.-Ear trumpets or conversation tubes are merely instruments which collect a quantity of the waves of sound, intensify them (usually by reflection) and convey them to the ear, thus producing a greater vibration of the ear drum than would the few waves which come in ordinary circumstances. ${ }^{1}$ The

${ }^{1}$ Other devices for the deaf are in the form of telephones. (See Chapter XI.) 
megaphone is similar; it not only collects, but greatly reflects and intensifies the waves of sound.

Speed of Sound.--Sound waves move through the air at a rate of 1125 feet per second. The rate varies slightly with the temperature of the air, with its humidity, density, etc.

Sound travels much more slowly than does light. Witness the well-known facts that you see a gun fired long before you hear its report, or that you see a workman at a distance strike a blow long before you hear it, or that lightning and thunder-which are practically simultaneous-sometimes appear to be far apart.

Conduction of Sound.-Sound waves are transmitted more readily by other substances than by air. They move through water four times as fast as through air, through wood ten times as fast, through steel fifteen times as fast.

Water, the earth, wood, metal, etc., are, therefore, better conductors of sound than is air.

Experiments.-Place the ear at one end of a long table or board and listen for the tick of a watch at the other end; it can be heard at a considerably greater distance than it can through the air. Scratch with the finger or a pin on a table to which the ear is applied; the sound is much louder than when it comes through the air. Listen to approaching footsteps or wheels by placing your ear to the ground; they will be heard long before it is possible to detect them through the air.

The stethoscope takes advantage of this. It collects, by means of a wide tube and a vibrating membrane, 
the waves of sound made by the action of heart or lungs, conducting them to the ears by means of tubes and ear-pieces. The phonendoscope magnifies or increases the intensity of the sounds it transmits, and is therefore sometimes preferred in making delicate distinctions.

Intensity of Sound.-Sounds differ greatly in intensity because of the great variation in the force of the vibration that produces them. Intensity is influenced by the medium of transmission, the nearness of the hearer, the action of reflectors, concentrators, etc.

Pitch.-Sounds differ in pitch, being high, low, or medium. Difference in pitch is due to a difference in the number of vibrations per second produced by the object which makes the sound. High pitch is due to rapid vibration; low pitch, to slower vibration. Also, small cords or objects give tones of high pitch; large ones, tones of low pitch. Also, tightly stretched strings give higher tones than loose ones. (These facts may be verified by examining the strings of a piano while they are being struck.) The human ear is able to distinguish sounds having from 16 to 32,500 vibrations per second. ${ }^{1}$

This is the reason that women and children have high-pitched voices, because their vocal cords are small and light, and readily drawn tight.

${ }^{1}$ We are told that there are sounds of such extremely high pitch that the human ear cannot respond to them. Animals and insects undoubtedly hear sounds outside of the range of our ears, because of the different or more delicate construction of their auditory ap. paratus, 
Hoarseness is due to a swelling of the vocal cords or a gathering of mucus between or upon them.

Reflection of Sound.-Sound waves are reflected from any surface which they strike (see Fig. 58), but not noticeably from small or rough surfaces, nor those composed of soft or porous materials. If the surface is broad, flat, and smooth, the reflection is more perfect. This reflection, or echo, coming from a large surface situated at an exact distance is often very clear. In an ordinary room there is this same reflection of sound, from walls and ceiling, but it comes so quickly after the sound itself that we hear them as one. In large rooms it may be very annoying. Fireproof hospital buildings are often troublesome because of their resonance; being built of hard, smooth materials (metals, hard plaster, etc.) they reflect sound and often even magnify it.

Interference with Sound.-To prevent sound waves from traveling we block their way by interposing a different medium. A closed door reflects sounds rather than transmits it, and only a few waves go through the cracks around it.

One hears more easily indoors because the walls keep the sound waves in, besides collecting and reflect-. ing them, so retaining or increasing their intensity. Out of doors, they go off in all directions.

Sound waves lose their force in passing a corner, so that their greatest strength is evident when the recipient is directly in front of the object or person producing the 
sound. For this reason a nurse should stand or sit as nearly as possible in front of a patient to whom she is speaking, so that he may hear her without effort.

Music and Noise.-We distinguish between noise and music as it chances to be pleasing or displeasing to us personally. It is agreed, however, that musical sounds are those in which the vibrations are uniform and regular, while noise is a succession of confused and irregular vibrations.

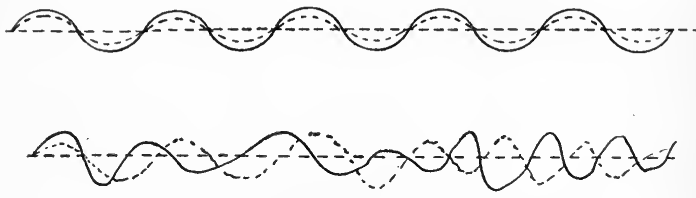

Fig. 59.-Sound waves of music and of noise.

Heart and Lung Sounds.-The sounds made by the normal heart in its contraction and relaxation resemble "Lubb, dup." If, for any reason, the valves do not close properly, blood gurgles back through them, producing a characteristic sound. If the valve edges are rough, or the valve stiffened by disease, the sound is modified. By long practice and experience physicians learn to recognize each slight change in sound and to know its exact meaning.

The normal sound made by the air passing in and out of the lungs is like that of a steady, gentle breeze. Bronchial secretion in excess may cause a rattling sound; 
tough mucus, the sound called "râles," a sort of whistling; fluid in the air cells, a gurgling or crackling sound; pleurisy may give a rubbing sound, the "friction murmur." Absence of sound where it should be found indicates consolidation of lung tissue.

\section{SUMMARY}

Sound is vibration which stimulates the auditory nerve. This vibration, due to whatever cause, produces waves which travel outward in every direction. Upon their size and shape depend the quality of the sound produced.

The human voice is produced by the vibration of the vocal cords. It is modified by the muscles of the larynx, throat, and mouth, and by the size and shape of the mouth and nasal cavities. Abnormal or diseased conditions also alter its quality.

The external ear collects sound waves, which cause the ear drum to vibrate. The vibration is transmitted by the mechanism of the middle and inner ear to the auditory nerve, thence to the brain, which, after training, acts as interpreter.

Devices for the aid of the deaf collect, reflect, and increase the force of sounds.

Sound waves travel about 1125 feet per second through the air, and much more rapidly through water or solid materials.

Sound waves are reflected, especially from hard, 
smooth surfaces. A perfect reflection is called an echo. Indoors reflection of sound assists us in hearing, because it increases the force of sounds; but it may, in a large room, tend to confuse sounds.

Sound waves may be stopped by interposing some different material. Sound cannot travel around a corner without considerable loss.

Intensity of sound is due to the character of the force that produces it.

Pitch is due to the number of vibrations per second, the size of the vibrating object, etc.

Music is regular vibration; noise, irregular.

Heart and lung sounds are indicative of the condition of these organs, but it takes experience to interpret them correctly. Changes in or stiffening of the valves of the heart produce certain definite abnormal sounds. The presence of secretion or tissue changes in the lungs produce sounds that are of diagnostic value. 


\section{CHAPTER X}

\section{LIGHT}

What Light Is.-Until about one hundred years ago it was thought that light was a material substance which came from the object seen. Now it has been discovered that light is similar to heat and sound, in that it is made up of waves.

Light waves are about $\frac{1}{30000}$ inch in length, and they move much more rapidly than do the waves of heat or of sound. Light waves may be changed into heat waves. ${ }^{1}$

Transmission of Light.-Light waves are transmitted not through air nor through liquids, but through what - for want of a better term-we call the ether. We do not know what the ether is, but we know that everywhere, pervading all liquids and solids, filling every space in the world, and all the spaces between the worlds and stars and suns, there is something which transmits light waves.

Light waves travel at the rate of about 185,000 miles per second. It can be judged from this that air is too coarse a material to transmit them.

${ }^{1}$ Glass transmits light readily, heat with some difficulty. In a cold frame, the light of the sun, passing easily through the glass, is absorbed by the earth and the plants and turned into heat. This heat is retained by the glass and so accumulates. 
Sir Oliver Lodge, one of the world's greatest scientists, considers that light waves may be electric waves. An important point in support of his opinion is that light and electricity travel at the same rate of speed. .

Direction of Light.- Light waves always travel in straight lines. They cannot turn a corner. We therefore call the direction of light waves rays, and think of light as straight rays sent out in every direction from the luminous or illuminated object.

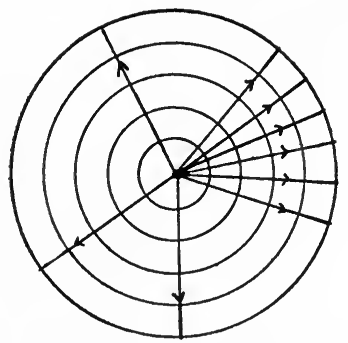

Fig. 60.-Direction of light waves. Light rays.

We see an object, however, in the direction in which its light rays enter our eyes. For example, when we look at an object reflected in a mirror we seem to see it behind the mirror, though we know that it is in front. Figure 61 explains this.

Intensity of Light.-We know that light becomes dimmer as it travels away from its source. Figure 62 explains why. $O$ is a source of light. At the distance 
$A$ a certain number of rays fall on a certain surface; at the distance $B$, four times as large, only the same

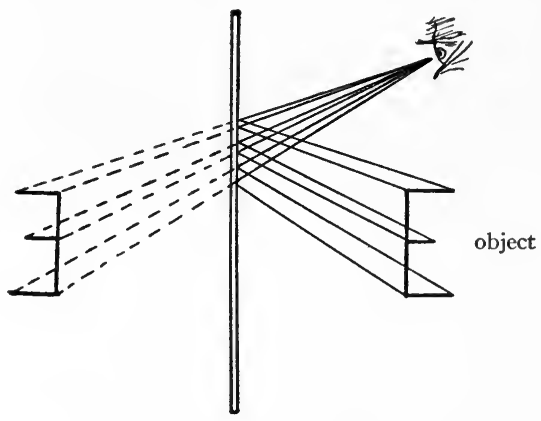

Fig. 6r.-Reflection in mirror.

number of rays fall. At $C$, a surface much greater, the illumination is very much less.

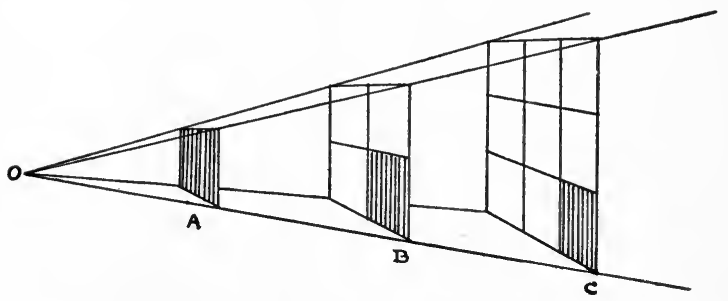

Fig. 62.-Intensity of light according to distance.

How Materials Affect Light.-Light cannot pass through some sorts of material at all, but is absorbed by them; such materials we call opaque. Material which 
transmits light easily is called transparent. Materials which transmit a portion of the light which comes to them, reflecting the rest, are translucent. Other materials reflect all the light which comes to them.

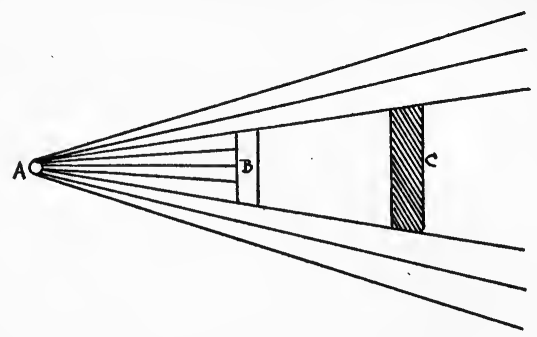

Fig. 63.-Formation of a shadow: $A$, Source of light; $B$, object; , umbra or shadow.

Shadows.-When rays of light strike an opaque body, a shadow is formed behind it. (The technical name is umbra.) If the source of light is small in com-

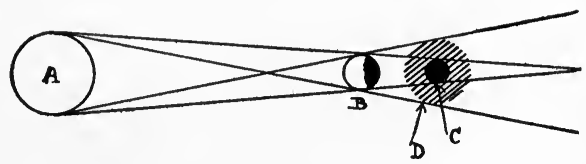

Fig. 64.-Formation of penumbra: $A$, Source of light; $B$, object; $C$, umbra; $D$, penumbra.

parison with the size of the object, the edge of the shadow is sharp. If the source of light is large in comparison, the edge is blurred. There may be a distinct band which is dimly lit, called the penumbra (Fig. 64). 
How We See.-Light waves enter the eye, and pass through the cornea, the pupil, the lens, and the vitreous humor, being modified by each of them. They strike the retina, which is the sensitive portion that receives the image. The retina transfers the sensation to the optic nerve, which sends it on to the brain for interpretation.

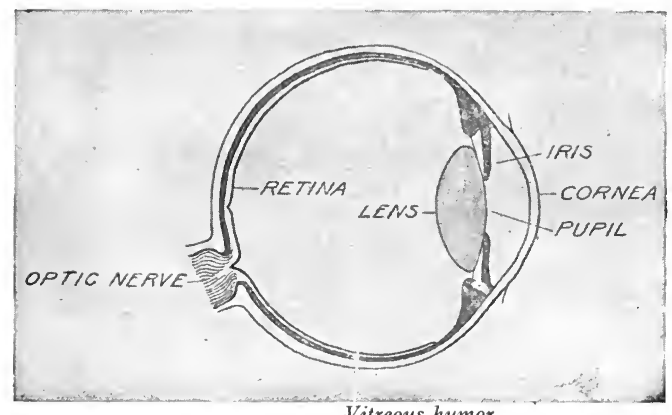

\section{Vitreous humor}

Fig. 65.-Section of the eye (Butler, "Household Physics").

What We See.-We see only those objects from which light comes to us. This light may be given out by the object itself or reflected by it.

A body that gives out light is called luminous. The sun, a fire, an electric light, a red-hot or white-hot piece of metal, etc., are luminous. That is, they send out waves of light. When these waves enter the eye, we see the object.

Most objects are seen, however, by reflected light. 
Light from a luminous object, usually the sun or an artificial light, falls on the object and is reflected, just as sound is, or as a rubber ball bounds back when thrown against a wall. When we see an object by the light that it reflects we say that it is illuminated.

Reflection of Light.-All surfaces reflect light to some extent, but in most cases it is hardly noticeable. Smooth surfaces reflect light better than rough. Silvered glass, forming a mirror, is one of the best.

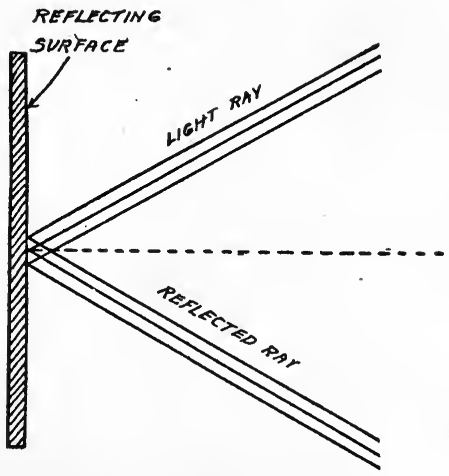

Fig. 66.-Reflection of light.

Figure 66 shows how reflection of light occurs. If the light strikes the reflecting surface at an angle, it is thrown off or reflected at an exactly corresponding angle. Only when light strikes a reflecting surface at a right angle does it come back in exactly the same direction from which it came. This law of reflection enables us to 
illuminate objects in positions where we cannot throw a direct light upon them.

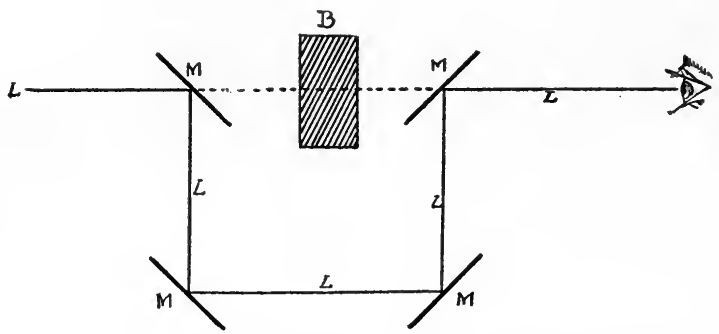

Fig. 67.-Seeing through a brick: $B$, Brick or other object; $M, M$, $M, M$, mirrors; $L, L, L$, light ray.

Rays of light may be reflected two or more times, and if the material of the reflecting surface is of the requisite quality, it may not lose much in the transfer.

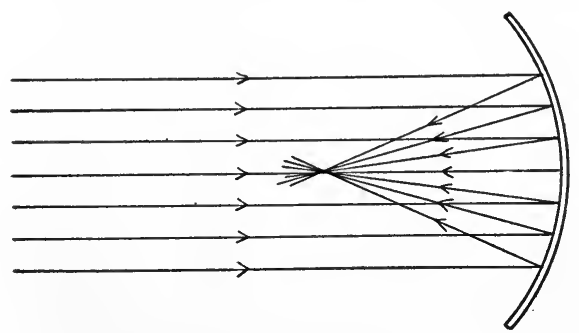

Fig. 68.-Concave reflector.

Figure 67 shows how, by means of reflecting mirrors, we may "see through a brick." 
Reflectors placed behind lights are made smooth and concave, so that they not only collect and reflect the light, but intensify it.

\section{REFRACTION}

Whenever a ray of light passes obliquely from one transparent substance to another, it is bent in its course. This bending we call refraction.

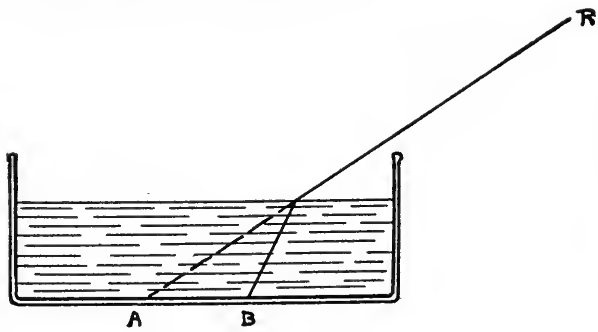

Fig. 69.-Refraction of light by water: $R$, Ray of light; $R-A$, line of sight; $R-B$, refracted ray.

Experiments.-Thrust a stick into a dish of water at an angle, and look at it from one side. It appears bent. Place a coin in a dish in such a position that it is just hidden by the rim; have some one pour water into the dish; the coin will be seen. In each instance the surface of the water refracts or bends the rays of light coming from the object.

When light enters a thick plate of glass, it is bent (refracted) by the first surface which it encounters; as it passes through and leaves the glass from the other side, it is bent again, always in the same direction, providing both surfaces of the glass are parallel. 
Experiments.-Look at a pencil obliquely through a thick piece of glass; it appears in a different position from what it is known to occupy. Look at a candle flame through a square bottle filled with water and held diagonally; the flame appears to be much higher than it really is.

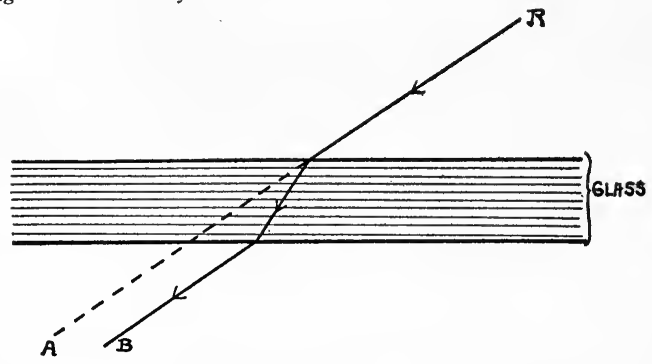

Fig. 7o.-Refraction of light by glass: $R$, Ray of light; $R-A$, line of sight; $R-B$, refracted ray.

Lenses are pieces of glass used for bending light rays. Their surfaces are usually curved, so that light passing

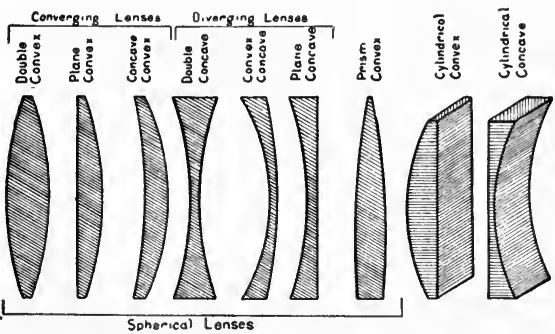

Fig. 71.-Types of lenses (Butler, "Household Physics").

through them may be distributed or concentrated, as the case may require. They may be concave or convex, 
a combination of the two, or combined with a plane surface. Figure 71 gives some of the common forms of lenses.

Convex lenses refract rays of light so as to cause them to come together.

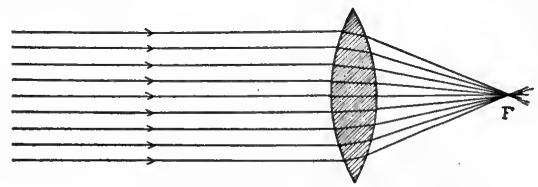

Fig. 72.- Refractions of light by convex lens.

Experiment.-Hold a strong reading glass (a "burning glass" so called, if it can be obtained) over a sheet of white paper. Find the distance at which it gives the most concentrated light. The glare is almost blinding, and the illuminated spot upon the paper may scorch, smoke, or even take fire. The same effect can be had with a piece of ice carefully molded.

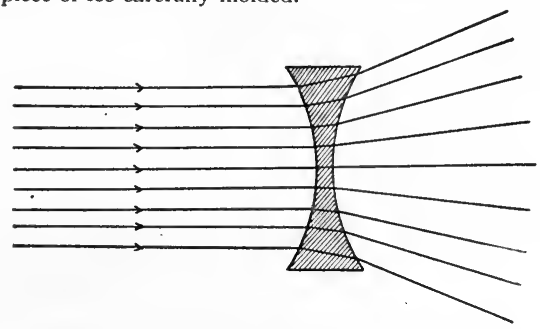

Fig. 73.-Refractions of light by concave lens.

Concave lenses refract rays of light so as to cause them to be distributed.

Focus.-A convex lens whose curves are perfectly even on all sides brings the rays of light together at a 
point. This point is called the focus (see Fig. 72). If we are looking through the lens, it is at this point that the image of the object which we are observing appears distinct and clear cut.

Polarization.-Light is said to be polarized when its vibrations are made to take place in one direction, and its rays become parallel. Polarization occurs by reflection from a mirror, or by refraction. Certain transparent materials polarize light in a special way, turning the rays always toward the right or toward the left, as the case may be. Tourmaline is one of these.

Solutions of glucose (grape-sugar) polarize light, turning the ray always to the right; the degree of rotation is in proportion to the amount of glucose present in the solution. Levulose (also called fructose) also polarizes light, turning the ray to the left. These phenomema are made use of in urinalysis to determine the character and amount of sugar present.

\section{THE EYE}

The cornea of the eye is a convex lens which bends the rays if light that enter it, bringing them closer together. The lens of the eye, situated a little behind the cornea, is a double convex lens which bends them twice more, bringing them still further together. It is by means of this arrangement that our eyes are able to "take in" so much at one time.

The normal eye is so constructed that its focus, the 
point where the refracted rays meet evenly and exactly, and the image of an object is distinct, is exactly on the

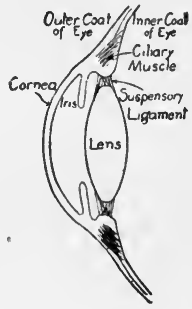

Fig. 74.-Detail of eye (Butler, "Household Physics").

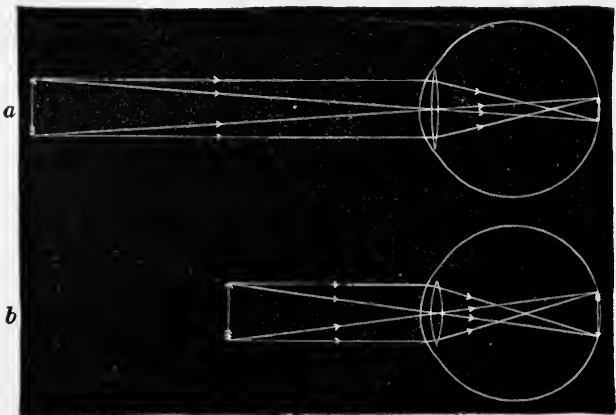

Fig. 75- -Accommodation of eye for distance: $a$, For distant objects; $b$, for near objects. (Butler, "Household Physics.")

retina. The muscles of accommodation, acting upon the lens, flatten or thicken it, and change the focal point as objects are near or far away. 
In eyes which are not normal the focal point falls too far in front of or behind the retina, and the image formed there is blurred. In the case of near-by objects we may

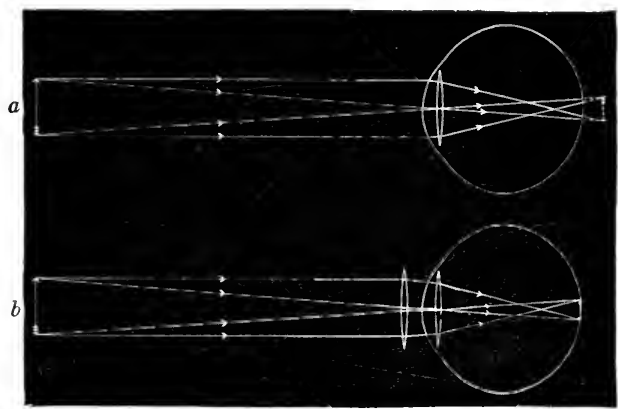

Fig. 76.-Correction for far-sighted eye by glasses: $a$, Far-sighted eye; $b$, correction. (Butler, "Household Physics.")

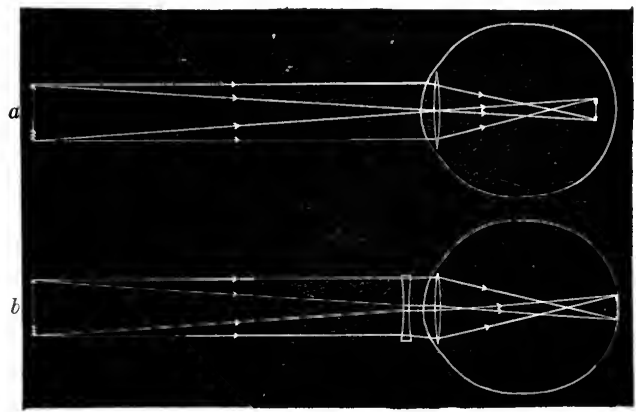

Fig. 77.-Correction for near-sighted eye by glasses: $a$, Near-sighted eye; $b$, correction. (Butler, "Household Physics.") 
remedy this somewhat by changing their distance from the eye; as when we see a "far-sighted" person hold a book at arm's length in order to read it easily, while a "near-sighted" person holds it within a few inches of the eye.

Defects in the structure of the eye may be congenital or acquired. They are overcome by the use of glasses, which are lenses of shapes varied to suit the needs of the particular eye in question. They are so constructed as to bring the focal point exactly on the retina. Correct fitting of the frames or mountings is also important, so that the focal point may remain in its proper position.

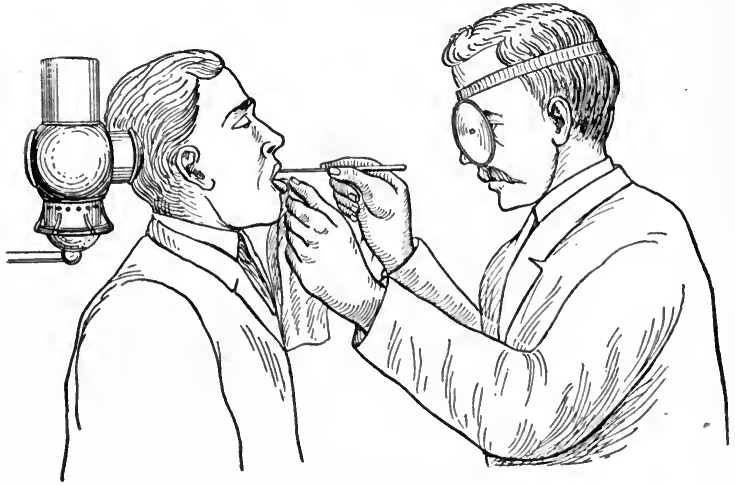

Fig. 78.-Head-mirror (Morrow).

\section{OPTICAL INSTRUMENTS}

The head-mirror used by physicians has a concave reflecting surface designed to concentrate light in order 
to throw in into a cavity, thereby illuminating it. The hole at the center enables the operator to see the spot upon which the light is thrown, while the dark back of the mirror shades his eyes from the glare.
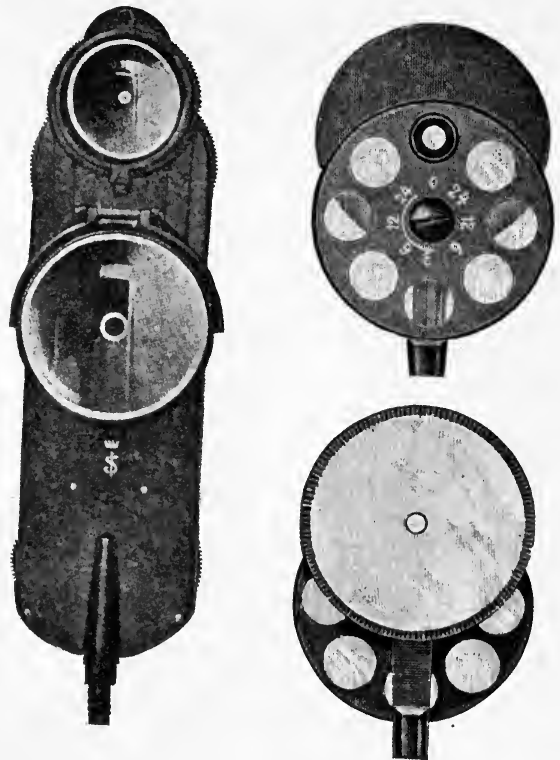

Fig. 79.-Ophthalmoscopes.

The ophthalmoscope is similar to the head-mirror. It sends into the interior of the eyeball, through the pupil, light which is reflected from a lamp placed back of and at one side of the patient's head. The rays re- 
flected from the retina through the pupil come back to the mirror, through the hole in which the operator may observe, and so get a picture of the interior of the eye.

The laryngoscope uses a concave reflecting mirror or an electric light to throw light into the throat, whence it is reflected downward by a flat mirror placed at such an
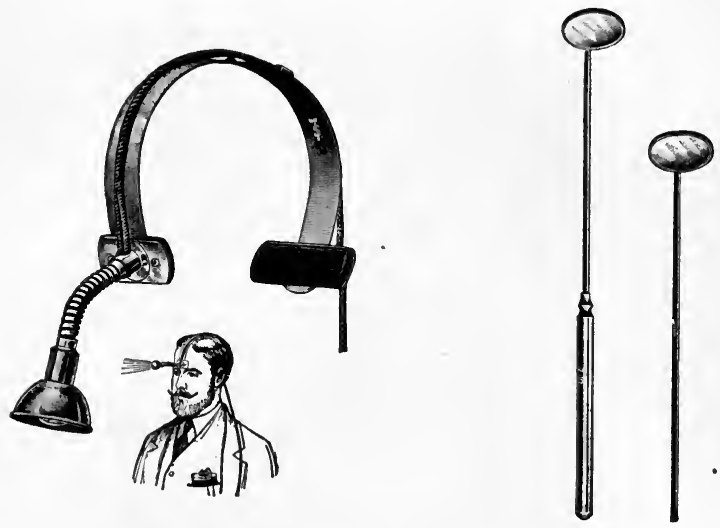

Fig. 80.- Laryngoscope and throat mirrors.

angle that it will throw the light into the larynx. This mirror serves the double purpose of a reflector for the light going into the larynx and for the image of the condition existing there which goes back to the observer's eye.

The camera is an artificial eye. It has a double convex lens which acts exactly as does the lens of the human eye. The accommodation, or change for objects at different 
distances, is made by changing the position of the lens itself. Instead of the retina there is the sensitized plate or film, which gives us a permanent record of the object.

The microscope lens refracts the rays of light coming from a very small object, so that the lens of the eye can

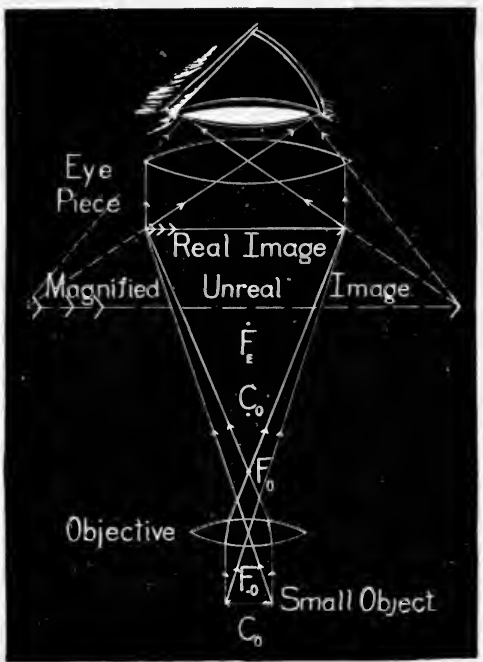

Fig. 81.-Image in the compound microscope (Butler, "Household Physics").

make use of them. As the eye follows those rays out, it sees the object larger than it really is. The compound microscope has a double set of lenses, usually five or more 
in all, thereby greatly increasing its refraction and consequent magnifying power.
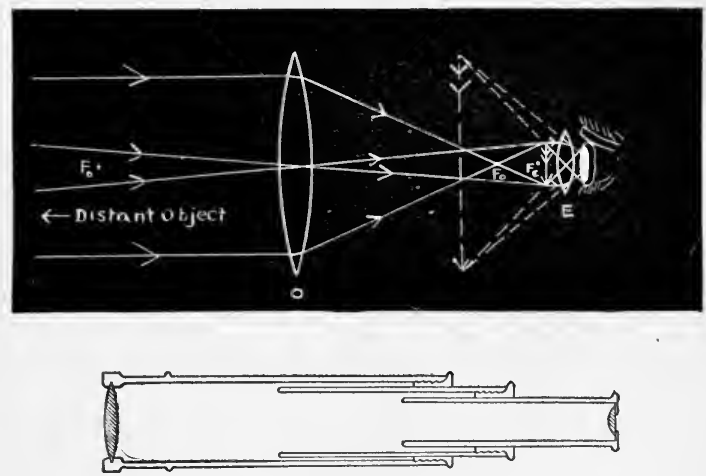

Fig. 82.-Telescope (Butler, "Household Physics").

The telescope is constructed upon principles similar to those involved in the microscope. The larger telescopes make use of reflection as well as refraction.

\section{COLOR}

A prism is a piece of glass or other transparent substance having two of its sides set at an angle to each other. It may be used to refract light so as to break it up into its component parts.

Experiment.-Pass sunlight through a glass prism. We get a band of rainbow-colored light.

By this means we discover that white light is composed of seven "primary" colors-violet, indigo, blue, 
green, yellow, orange, and red. Scientists have found that the red rays are those that vibrate most slowly, while the violet rays, at the other end of the spectrum, vibrate the most rapidly. Correspondingly, the red waves are longest, the violet waves shortest. ${ }^{1}$

The Finsen light is a lamp which gives out ultraviolet rays, that is, rays which vibrate more rapidly

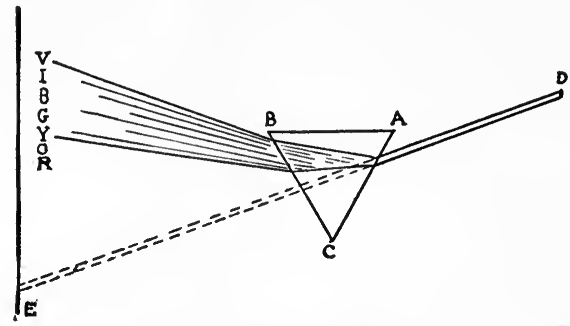

Fig. 83.-Prismatic spectrum.

than even the violet ones. These rays produce chemical changes in the tissues which are exposed to them.

Color is the impression given to the eye by light of varied rates of vibration.

A body is colored when it reflects only a portion of the white light that comes to it from the sun. An object or substance is white when it reflects all the sunlight. It appears black when it reflects almost no light, but, on the contrary, absorbs it.

${ }^{1}$ Red waves are about .0007 millimeter in length, violet waves about .0004 millimeter. 
Artificial lights have different wave lengths from sunlight and are therefore colored. Their color mingles with that reflected from objects or substances which they illuminate, making these objects appear of a different color from what they do in daylight. It is for this reason that matching of colors is impossible except in daylight.

\section{SUMMARY}

Light is made up of waves, as are heat and sound. Light waves are very short (about $\frac{1}{30000}$ inch) and travel very rapidly (about 185,000 miles per second).

Light is transmitted by the ether, a material which pervades the whole universe.

Light travels in all directions from its source. For convenience we refer to rays of light, since the direction is always perfectly straight.

Light waves may be absorbed by a substance or object, transmitted by it, reflected, or refracted by it.

When light is stopped by an opaque body, a shadow is produced on its farther side. This shadow has a sharp edge if the light is small, blurred if it is large.

We see only objects from which light comes to us. They may be luminous, i.e., giving out light, or they may reflect light which comes to them from another source. Most objects are seen by reflected light.

Light is reflected in the opposite direction from that of its approach, and at exactly the same angle. If it 
comes from the right, it is reflected to the left, and vice versa.

Light rays may be refracted or bent in passing from one substance to another. This is done artificially by means of lenses. Convex lenses concentrate light rays, concave lenses distribute them.

A focus is the point at which converging rays of light come together and produce a distinct, clear-cut image.

Light is polarized by making it vibrate in one direction only, in parallel rays. The direction and amount of refraction caused by a substance or a solution which polarizes light may be used as a test for determining its presence.

Light enters the eye, is refracted by the cornea, passes through the pupil, and is twice refracted and concentrated by the lens. Normally the focal point is exactly on the retina, adjustment for near or far-away objects being made by the ciliary muscle. The pupil regulates the amount of light which enters the eye. The image formed on the retina is transferred to the brain by the optic nerve.

Eye defects may be overcome by means of glasses whose lenses change the focal point or make other needed adjustments.

The various optical instruments are combinations of lenses, reflectors, or both. They may reduce or magnify the apparent size of an object, illuminate cavities, and reflect their contents, etc. 
Sunlight is white light. It may be broken up into its seven primary colors. Some colors are formed by rapid vibrations, some by slower vibrations.

An object appears colored when it reflects only part of the light which comes to it from the sun. Black objects absorb light instead of reflecting it; white ones reflect all the light coming to them.

Artificial lights are themselves colored, therefore they change the apparent color of objects which they illuminate. 


\section{CHAPTER XI}

\section{ELECTRICITY}

What We Know About It.-Electricity is a force the nature of which we do not know. We know how to produce it, how to control it, and we make constant use of it; but no one has been able to define it nor find out what it is.

Magnetism is a species of electricity. Magnetic iron is a natural product, but magnets are also made artificially.

Experiments.-Show how a magnet attracts iron filings, tacks, etc. Hold it outside a glass of water containing small tacks; it will be found that its power is exerted through the glass and through the water.

In a bar magnet, straight or curved, it is found that the drawing force is exerted most strongly at the ends. These are called the poles.

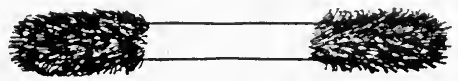

Fig. 84.-Iron filings clinging to pole of magnet (Butler, "Household Physics").

The compass needle is a magnet freely suspended. One end of such a magnet will always be found seeking 
the magnetic pole of the earth, which is approximately north. If two suspended magnets are brought near each other, the north-seeking ends repel each other, but a north- and a south-seeking end attract each other. Thus we find that the poles of a magnet are of two sorts, positive and negative. We also find that unlike poles attract and like poles repel each other.

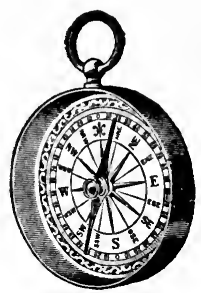

Fig. 85.-Mariner's compass (Butler, "Household Physics").

Electricity may be produced in three ways: (1) by friction, (2) by chemical action, and (3) by means of $a$ dynamo. We recognize, therefore, three varieties of electricity, yet it is likely that they are merely different manifestations of the same force.

Frictional Electricity.-Many different materials produce electricity when rubbed briskly under favorable conditions. In dry, cold weather, the rubbing of the feet on a carpet, the stroking of a cat's fur, the rubbing of a piece of hard rubber with flannel, or a glass rod with silk, etc., produce electricity. One can often see the 
sparks caused by its discharge or escape. When frictional electricity is produced by a machine it is done by the rapid revolution of metal brushes against glass plates; the electricity so produced is stored in Leyden jars and is allowed to escape at the pleasure of the operator. When the machine is in motion, a prickling

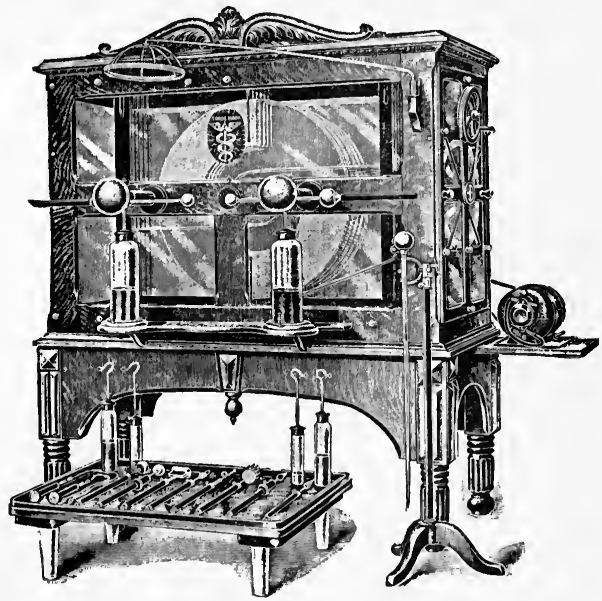

Fig. 86.-Holtz's static machine.

sensation (due to the small sparks which come through the air) is felt by a person standing in its vicinity, there is a peculiar metallic odor due to the chemical effect, the air is slightly heated, etc. This form of electricity is called static (from the Greek statikos, brought to a standstill), because it may be stored. 
Electricity by Chemical Means.-In producing electricity by chemical action we use a combination of materials which we call a cell. Two or more cells connected are termed a battery. ${ }^{1}$

The usual "wet" cell is composed of a piece of zinc and another of carbon set into a solution of sal ammoniac, and connected at their dry ends by a wire, usually of copper. The chemical action of the solution upon the

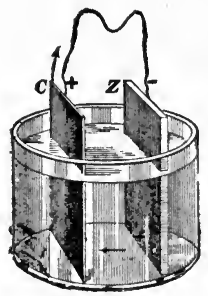

Fig. 87. -Wet cell (Butler, "Household Physics").

elements (the zinc and carbon) starts a current, which flows through the wire. The carbon is the negative element, the zinc the positive; the current always flows from the positive to the negative.

A "dry" cell is similar, except that the sal ammoniac is merely damp instead of being wet, the moisture being kept in by a tightly sealed container. Dry cells do not last as long as wet ones, and are more expensive in proportion to their size, but require less attention.

1 These terms are often confused. 
The wires connected with the elements of a cell complete what is called the electrical circuit. When the wire is continuous, the circuit is closed, and the current flows. When the wire is broken, cut, or removed, the circuit is open, and the current stops.

(It is possible, however, for electric current to leap across a short break in the circuit, producing a spark.)

In the wiring for electric lights, the switch or button makes the connection between the two open ends of

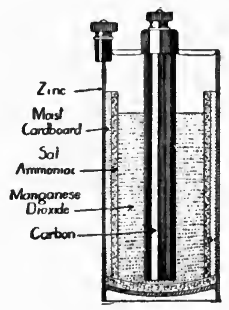

Fig. 88.-Dry cell (Butler, "Household Physics").

the circuit and allows the current to flow. The light burns so long as the connection is maintained. When the circuit is broken by turning the button or switch, the light goes out because of the interruption of the current.

Electricity by Dynamo.-If a coil of wire be moved in the immediate vicinity of a magnet, a current of electricity is set up in the wire. A machine which thus converts motion into electric energy is called a dynamo. 
Its essential parts are the rotating coil or armature, and the large magnet, called the field magnet.

Motors.-Conversely, machines have been made which will convert electric energy into motion. Such machines are called motors.

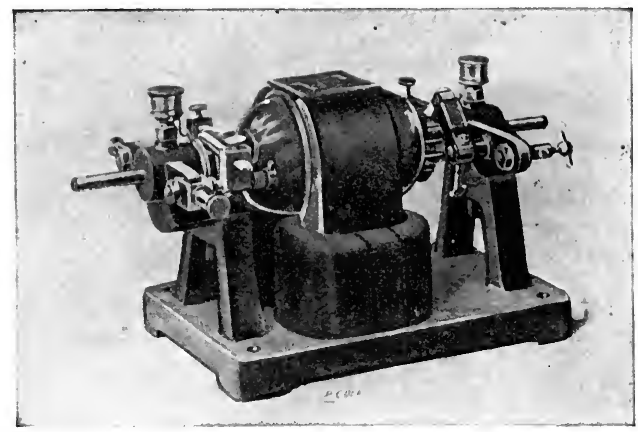

Fig. 89.-Electric motor ('Tousey).

Electric Heating.-When a strong electric current is passed through a wire which is too small to carry it properly, the wire becomes heated. ${ }^{1}$ Wires large enough to carry the current do not become hot.

Electric heaters are made with fine wires, which are also of a material which does not conduct electricity well; these resist the passage of the current and so become heated. The electric flat-iron, the electric toaster, electric stove, electric heating pad, etc., have their

${ }^{1}$ This may be the cause of some of the fires due to "defective wiring." 
"heating elements" made of fine wire surrounded by or embedded in some substance which insulates it from the

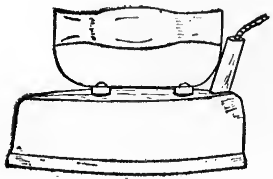

$a$

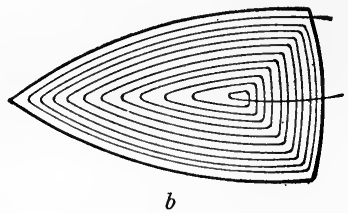

Fig. 90.-Wiring in electric flatiron: $a$, Electric flatiron; $b$, wire grid. (Butler, "Household Physics.")

surrounding objects, but permits the heat to be given off in any desired direction. The electric cautery is

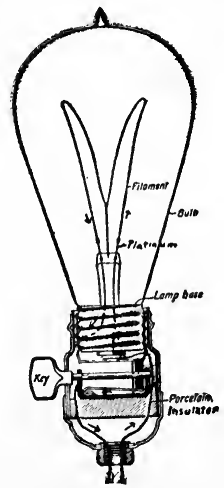

Fig. 9I.-Incandescent electric lamp (Butler, "Household Physics").

constructed upon the same principles; its advantage is that the degree of heat can be controlled, so that a high 
or low temperature may be employed. (This is done by means of special apparatus.)

If from any cause these appliances get too hot, they "burn out," i. e., the wire is destroyed and must be replaced before they can be used.

Electric Lights.--If a finer wire or a stronger current is used than is employed in heating apparatus, the wire may become white hot, so that it gives out light. This is the principle underlying the incandescent electric $b u l b$, in which a strong current is passed through a very fine filament. The thin glass which encloses it has had the air pumped out of it and is sealed tightly, so that no oxygen can get in to support combustion and cause the filament to burn up.

The arc light is made with two sticks of carbon, a substance which melts or burns up with difficulty. These sticks are arranged so that the current has to leap across a small space between them; in so doing, it heats them white hot, producing a brilliant light.

The fuse in an electric lighting system is a bit of metal which fuses or melts at a low temperature. If for any reason the current becomes too strong, the fuse by melting breaks the connection; in this way the lighting system is protected against sudden increase of current from trouble at the power-house, influence of electric storms, etc. Telephones have similar arrangements at the central station; when these fuses burn out (melt) because of wires being struck by lightning, or from any 
other cause, they can readily be renewed and the connection re-established.

Electromagnet.-If a bar of soft iron be wound with wire and an electric current passed through the wire, the

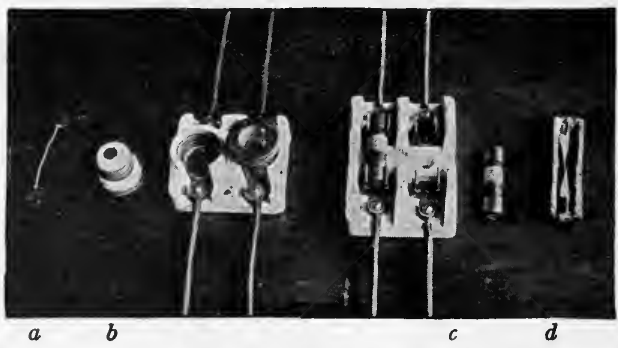

$$
\mathbf{I}
$$

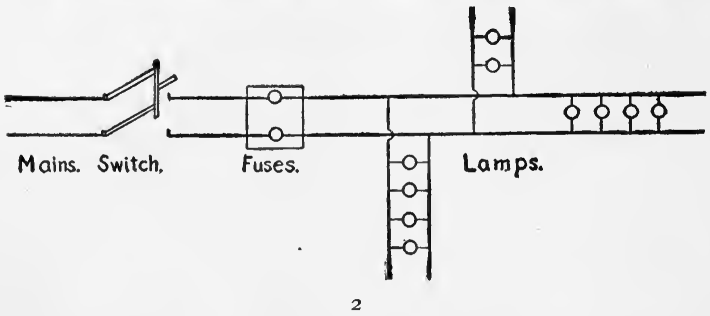

Fig. 92.- I, Fuses and their action: $a$, Link fuse; $b$, screw inclosed fuse and base; $c$, cartridge fuse and base; $d$, cartridge fuse cut open, exposing fuse metal. 2, Lamps in house grouped in parallel. (Butler, "Household Physics.")

iron becomes a magnet. It remains magnetized so long as the current flows. This is called an electromagnet. 
An electromagnet is much stronger than any other sort of magnet. Its power depends upon the strength of the current flowing through the wire and upon the number of turns of wire. Examine the coil in an electric machine and you will find that there are a vast number of turns of very fine wire.

The eye magnet, used to extract pieces of metal from the eye or other portions of the body, is a strong electro-

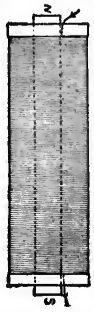

$a$

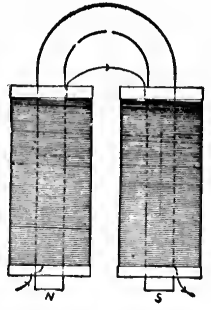

$b$

Fig. 93.- $a$, Straight bar electromagnet; $b$, horseshoe electromagnet. (Butler, "Household Physics.")

magnet. If large enough, it will pull out a needle which is embedded $\frac{1}{2}$ inch in the flesh.

The so-called "vibreur," or electromagnetic vibrator, is used to locate metallic foreign bodies. They are first located approximately by means of the $x$-ray; then, if not too deeply embedded, they are found with great accuracy by applying the vibrating magnet. The patient's sensations aid in the operation.

In the electric telegraph an electromagnet pulls down 
an iron lever; this makes a mark upon or a puncture in a moving paper ribbon, the result being a dot or a dash, according to the length of time that the lever is held down. The operator makes and breaks the circuit which induces the power in the magnet, thus producing a series of dots, dashes, and spaces; these constitute the Morse alphabet.
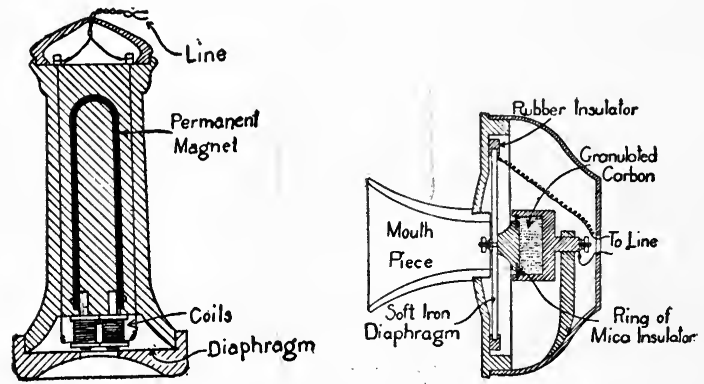

Fig. 94.-Telephone receiver and transmitter (Butler, "Household Physics").

In the telephone the voice striking against a thin iron disk sets it vibrating. These vibrations make and break the current induced in an electromagnet which is in the receiver. The wire transmits the vibrations in all their peculiar quality, and a similar instrument at the other end reproduces them.

In the electric bell the push of the button makes the connection between two ends of wire which complete the circuit. When the circuit is closed, current passes 
through a small electromagnet which pulls the clapper back, making it strike the bell. There is in the mechanism an arrangement for a rapid making and breaking of the circuit, producing the intermittent, buzzing ring.

When an electric bell does not work, one of several things may be the difficulty. Nearly all of them may be remedied by very simple measures. A new dry cell

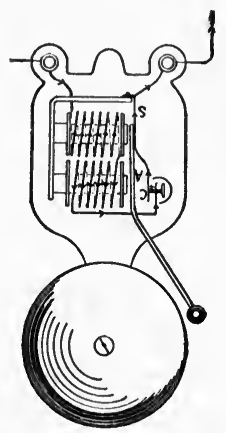

Fig. 95.-Electric bell (Butler, "Household Physics").

may be needed for the battery; more water or fresh solution, if it is a wet cell. The commonest trouble occurs at the push-button, where the connection may fail to be made because a wire has slipped or been worn through. Frayed ends of wire cause the current to be conducted to other things and so be useless. Accumulation of dust on the electromagnet may prevent its working properly. Only very occasionally is there trouble in the wire itself. 
If a bell rings continuously, the difficulty is usually in the push-button, or possibly in the wires. A simple inspection of the interior of the button reveals the trouble in most cases, and it is quickly remedied. The mere stopping of the sound of the bell (by pushing something between it and the clapper) is not advisable, since in this case the battery or cell "runs down," $i$. e., is worn out, very rapidly.

Rate of Speed.-Electricity travels at the same rate of speed that light does, 185,000 miles per second.

Electric Measures.-A volt is the measure of electric pressure or force.

An ohm is the measure of electric resistance.

An ampere is the measure of electric current.

When a force of 1 volt overcomes a resistance of 1 ohm, a current of 1 ampere results.

A watt is the measure of amount of electricity.

Conductors of Electricity.-Some substance are good conductors of electricity, other are not. Cotton, linen, water, the human body, etc., are neutral, being neither very good nor very poor. The most satisfactory conductor of electricity and the one in most common use is copper wire. Most metals are good conductors, though they vary in degree. Acids are likewise good.

Poor conductors of electricity are called insulators. They are used to interrupt or ward off electric current. Such substances are hard rubber, glass, wood, etc.

Electric Treatments.-Electricity is used in the treat- 
ment of disease, usually in order to stimulate some portion of the body to a proper performance of its function, or to help the process of nutrition or metabolism.

Static electricity is produced in the so-called static machine (see page 165) by friction. It is used to regulate functional processes, circulation, secretion, nutrition, etc. It is also of value in some inflammatory conditions and paralyses.

Galvanic electricity is produced by a cell or battery, and gives a vibration. It is used in the diagnosis and treatment of nervous disorders and in some forms of paralysis.

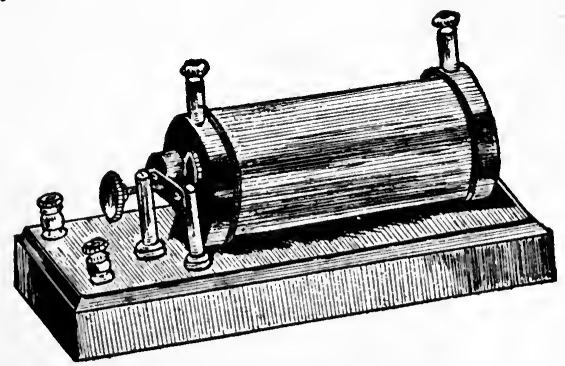

Fig. 96.-Induction coil.

Faradic electricity is produced by an induction coil, and is felt as vibration. It is used as a tonic, is employed in rheumatism, in eczema, and in nervous conditions, etc.

High-frequency current is used to promote elimination, reduce blood-pressure, relieve pain, etc. 


\section{SUMMARY}

Electricity is a force the nature of which we do not know, though we use it commonly, can produce and control it.

Magnetism, a species of electricity, occurs in nature or may be produced artificially. The mariner's compass has a magnetic needle one of whose ends or poles always seeks the north.

Electricity may be produced by friction, by chemical action, or by a dynamo.

Many different materials may be used to make frictional electricity. In the static machine it is produced by revolving metal brushes against plates of glass, and is stored in Leyden jars.

Electricity is produced through chemical action by means of certain combinations of materials called a cell. The essential parts of a cell are its two elements (usually metals), the solution, and the connecting wire. When complete, it forms an electric circuit, through which a current flows. This circuit may be closed or opened (made or broken) at will by means of a switch or other device. When electricity leaps across a break in a circuit, it produces a spark.

The essential parts of a dynamo are the field magnet and the armature (a rotating coil of wire). The magnet induces an electric current in the wire.

Motors are machines which convert electric energy into motion. 
When an electric current is forced through a wire too small to carry it, heat is produced. The various electric appliances in domestic and hospital use are constructed in accordance with this law.

Electric lighting comes under the same law. A still smaller wire is used, or some substance, as carbon, which fuses with great difficulty. The filaments of incandescent lights are enclosed in vacuum globes so as to cut off oxygen and so prevent their combustion.

A fuse is a piece of metal which melts at a low temperature. It is used to protect electric light or telephone systems from a sudden increase of current which would cause them to burn out.

An electromagnet is a bar of soft iron wound with wire through which an electric current is passed; the iron becomes strongly magnetized. The electromagnet is a vital part of the mechanism of the telegraph, telephone, electric bell, etc.

When an electric bell does not work, it is usually due to some simple trouble which can be revealed by inspection and easily remedied.

Electricity travels at the rate of 185,000 miles per second.

The volt, the ohm, the ampere, and the watt are electric measures.

Metals, acids, etc., are good conductors of electricity. Wood, glass, rubber, etc., are poor conductors, and are used to insulate against electricity. The human body 
is neutral, neither good nor bad, as a conductor of electricity.

Static electricity (frictional), galvanic electricity (chemical), faradic electricity (from an induction coil), and the high-frequency current are used in medical treatment. 


\section{CHAPTER XII \\ THE $x$-RAY. RADIUM \\ THE ROENTGEN OR $x$-RAYS}

History of the $x$-Ray.- It has long been known that an electric spark would pass more readily, leap farther, through rarefied air than through ordinary air. Late in the nineteenth century Sir William Crookes worked out a special vacuum tube, in which the air was so rarefied that there was but one-millionth as much as in a

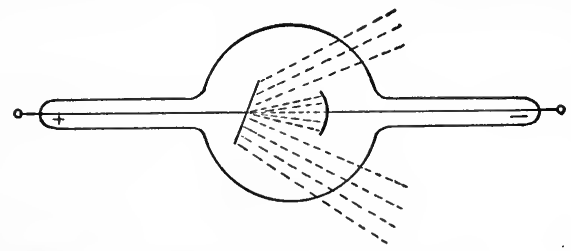

Fig. 97.-A Crookes tube, showing reflected " $x$-rays."

corresponding space in the atmosphere. He connected this "high" vacuum tube between the terminals or poles of a machine that produced the correct sort of electric current. It was so arranged that the discharge or spark took place between the two electrodes (metal conductors which introduce and withdraw the current) in the tube. ${ }^{1}$

${ }^{1}$ In the Crookes tube of high vacuum the electric force causes the glass of the tube to become phosphorescent. 
It was found that in the Crookes tube connected with an electric machine which was set in motion something radiated in straight lines from the negative electrode or terminal. This something was named the cathode ray. Later Conrad Roentgen found that if the cathode rays were reflected from the walls of the tube or from a special reflector or obstacle placed in the tube, a new sort of rays with special powers were produced. These he named $x$-rays, $x$ in algebra signifying an unknown quantity. They are also called Roentgen rays.

Characteristics of the $x$-Ray.-We know very little of the nature of $x$-rays, but we make use of them in some very definite ways.

They act upon a photographic plate exactly as daylight does (the action is chemical), and produce a picture of whatever is in front of the plate.

So far as we know, $x$-rays cannot be reflected nor refracted, nor in other ways manipulated as light rays are. They have very little effect upon the human eye.

At present we know of no means of bringing $x$-rays to a focus; photographs taken by their means must always be close to the object and, therefore, life size.

The most striking characteristic of the $x$-ray is that it passes through substances which light will not penetrate, such as wood, clothing, cardboard, flesh, etc. Most metals stop it, aluminum being the chief exception. Surgical dressings of gauze and cotton do not interfere with the passage of the $x$-ray; but iodoform, 
plaster casts, adhesive plaster, and wood splints are said to cast shadows. If there is a metallic foreign body to be located, these things do not interfere materially with the process; but if the soft tissues are to be carefully

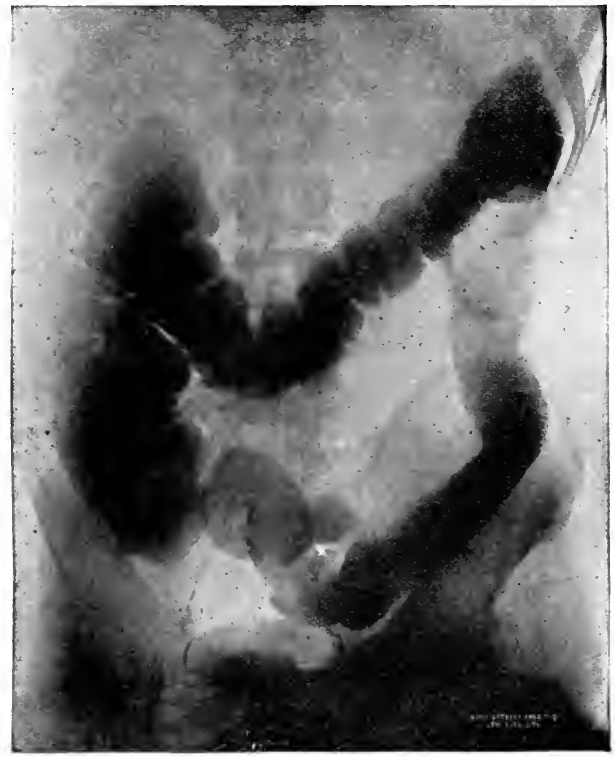

Fig. 98.- $x$-Ray of intestine (Gant).

examined, it is wisest to remove any of the above dressing materials.

Bismuth is quite opaque under the $x$-ray. Taken 
internally, bismuth coats the stomach and intestines, making it possible to see very clearly their outlines under the $x$-ray. Bismuth "meals" or enemata are, therefore, used to aid in the diagnosis of conditions existing in the alimentary canal.

The Fluoroscope.-It was found that certain substances, fluorescent materials, such as calcium tungstate, barium cyanid, etc., become luminous under the $x$-ray.

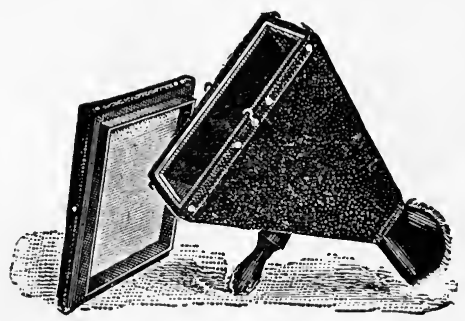

Fig. 99.-Fluoroscope.

The fluoroscope was, therefore, constructed so that the $x$-ray shadow picture falls on a screen of fluorescent material, which illuminates it, causing it to be distinctly seen. It is used in making $x$-ray examinations.

Uses of the $x$-Ray. - The $x$-ray is used in medicine and surgery to

(1) Locate foreign bodies.

(2) Locate fractures of the bones.

(3) Discover diseased conditions. These can be seen when the tissue change involved is considerable. 
(4) In stomach and intestinal work, to discover displacements, strictures, ulcers, etc., and to note the rapidity of functional processes.

(5) Produce permanent photographs of the findings.

(6) The $x$-ray has been used with some success in the treatment of lupus, exophthalmic goiter, ulcers, etc.

$x$-Ray Burns.-For some years after the $x$-ray came into use it was found that too long or too frequent

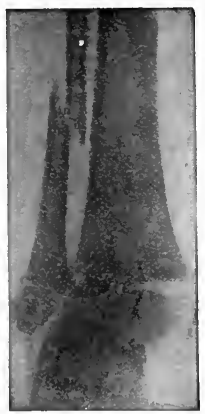

Fig. 100.- $x$-Ray of fractured fibula (Scudder).

exposure to it produced burns ${ }^{1}$ which were very difficult to heal, and which were followed in some cases by cancer or some malignant growth.

Protection against such burns is now had by the use of sheets of lead as screens, by rubber gloves containing lead, by lead glass (glass into which lead is incor-

${ }^{1}$ It is now also believed that the burns were sometimes due to tubes in which the vacuum was poor, 
porated), etc. In consequence, these burns are now very rare.

\section{RADIOM}

History and Characteristics.-Radium is a very mysterious substance, with some remarkable properties. It was discovered and isolated in 1898 by Madame Curie of France.

Radium is one of a group of substances (uranium, helium, etc.) which give out energy at a very rapid rate. They also emit rays, which affect a photographic plate, produce phosphorescence, discharge electrified bodies, and traverse bodies that are opaque to ordinary light. Shenstone, in "The New Phỳsics," sums it up as follows: "Radium gives off plentifully certain radiations which exhibit wonderful powers of generating light and heat, renders various minerals phosphorescent, and causes the air to conduct electricity. It also emits an emanation.

"It does these things for long periods, without any perceptible diminution of its powers, and will, it is calculated, continue to do them for thousands of years before it is exhausted."

Theories in Regard to Radium.-Nearly one hundred years ago Faraday classified matter into four groups, instead of the usual three. He called these groups solid, liquid, gaseous, and radiant matter. $\mathrm{He}$ held that while in solids the molecules were held firmly in place by cohesion, in liquids less firmly, and while in gases 
they were struggling gently to get away from each other, in radiant matter they were fleeing from one another with great force.

The present theory is that the atoms of a "radioactive" substance are continually subject to a disintegration (breaking up) that takes place violently, throwing off particles which constitute the "emanation," $i$. e., radium gas. The wreck of the old atom gives rise to a new atom, which may, in turn, go through a similar disintegration. The process goes on till only stable atoms are formed.

It is estimated that radium disintegrates one-half in two thousand years.

Radium compounds, or "salts," also apparently undergo a spontaneous and continuous disintegration, or tearing apart. In this rapid and violent disintegration energy is released to a remarkable degree. It amounts to 100,000 times as much energy as is given off in any known chemical change. There is doubtless a limit to this radio-activity, but it has not yet been found.

Radium compounds are found to be always two degrees hotter than their surroundings, a fact suggestive but unexplained.

Production of Light and Heat.-Radium and all its compounds evolve heat and light. Radium itself is luminous. It burns the skin when exposed for any length of time, or when exposed frequently for short periods. Those who work with radium invariably have the 
papillæ of the skin of their finger-ends burnt off, the nails cracked and split, etc. Whether this is harmful or not has not been determined.

Radium Rays.-There are three distinct kinds of rays given off by radium: the alpha ( $\alpha)$, beta ( $\beta)$, and gamma $(\gamma)$ rays. The alpha rays can be stopped by a sheet of paper; the beta rays penetrate thin aluminum; the gamma rays affect a photographic plate as $x$-rays do, and can be stopped only by thick plates of lead. The beta and gamma rays penetrate the tissues of the human body.

Uses of Radium.-Treatment of disease with radium is still in the experimental stage. It is being used with apparent success in cancer (epithelioma, sarcoma, and carcinoma), in exophthalmic goiter, in removing keloid, and some sorts of scar, etc. It is used both internally and externally.

Only a minute quantity is needed to produce a marked effect.

Radium emanation (the gas) is also used in treatment. It is given off from both radium and the compounds. This gas remains radio-active for about four days, then disintegrates and loses its power. The so-called radium waters or solutions are, for this reason, usually ineffective.

The whole amount of radium in the world at the present time is but a few ounces, but its remarkable energy makes this in effect a very large quantity. 


\section{SUMMARY}

The $x$-ray is produced by the discharge of an electric current in a special sort of vacuum tube.

It penetrates many materials which are opaque to light, such as flesh, clothing, surgical dressings, etc., and to a lesser degree wood, plaster casts, and adhesive plaster, etc. It cannot be refracted nor brought to a focus. It does not impress the human eye, but acts upon a photographic plate as light does.

The $x$-ray is used in locating foreign matter in the human body, or fractures of bones, in discovering diseased conditions, organic displacements, etc. Photographs of the conditions found are taken by means of it.

It has been used with some success in the treatment of external troubles.

The fluoroscope is a screen of some material which becomes luminous under the $x$-ray. It is used in making examinations.

$x$-Ray burns, due to long or frequent exposures, were formerly common and dangerous. They are now prevented by screens of lead or lead glass.

Radium is a mysterious substance, similar to uranium and helium, which is radio-active, $i$. $e$., generates heat and light, causes phosphorescence, emits rays similar to the $x$-ray, etc. It was discovered in 1898 by Madame Curie.

It is thought that the atoms of radium are constantly and violently disintegrating, thus releasing an enormous 
amount of energy. Its compounds and gas are similar in action to the element itself.

Three sorts of rays are given off by radium, the alpha rays being feeble, the beta and gamma more active. The two latter penetrate the human body and cause tissue changes therein. The gamma rays affect a photographic plate.

Radium and its compounds are being used with apparent success in the treatment of cancer and some external conditions.

Radium emanation (the gas) remains active only a comparatively short time.

There are but a few ounces of manufactured radium in the world at the present time. 


\section{CHAPTER XIII}

\section{QUESTIONS FOR REVIEW OF PRINCIPLES AND ORIGINAL THINKING}

1. ARE the following substances organic or inorganic? Coal, wood, tile, marble, cork, a tumbler, absorbent cotton, gauze, drainage-tubing, cement flooring, baking powder, salt, corn flour, acetanilid, tincture of digitalis, castor oil, antidiphtheric serum, bismuth subnitrate, ichthyol, bichlorid of mercury.

2. Are the following physical or chemical processes? Rising of cream, rising of bread, making salt solution, toasting bread, melting butter, freezing ice-cream, ringing an electric bell, purging by castor oil, sterilizing instruments, disinfection of linen by carbolic solution, production of the rainbow, making $x$-ray pictures.

3. Why does an automobile skid when turning a corner?

4. Why is a passenger thrown backward or forward when a car suddenly starts or stops?

5. Why is dancing easier than walking?

6. Why does stamping remove snow or mud from one's shoes?

7. Why does beating remove dust from a rug?

8. Why do rubber heels make walking more comfortable? 
9. Why is the arch of the foot an advantage?

10. What is a crystalloid substance? A colloid substance?

11. Why is it harder to carry a load upstairs than on a level?

12. Why can a person crawl over thin ice when it would give way were he walking?

13. Why is it dangerous to stand up in a small boat?

14. Why are ink bottles made with thick bottoms?

15. Upon what principle is the laundry extractor made?

16. Why must sewing machines be frequently oiled?

17. Why do we put sand on icy sidewalks?

18. Why do knots stay tied?

19. How do chains prevent a motor car from skidding?

20. Why can a heavy piece of furniture be best moved by pushing low down on it?

21. What sort of a machine is the coffee mill? The claw of a hammer? Grass clippers? A retractor? A nasal speculum? A needle? A curling iron? A door knob?

22. Why does cream rise?

23. Explain the use of a life-preserver.

24. Why do we hang the container high in giving hypodermoclysis? Why low in giving a Murphy drip?

25. Explain the action of a blotter, or of absorbent cotton.

26. Why is a new towel inefficient for drying purposes? 
27. Discuss the drainage of wounds from the standpoint of physics.

28. Why does paint or varnish preserve wood?

29. Why do we wear rubbers?

30. What happens when one of the valves of the heart fails to act?

31. What is a trap in plumbing?

32. What would you do if a kitchen "boiler" leaked? A hot-water pipe? A cold-water pipe?

33. What happens when the chest wall is punctured. an opening made through into the lung?

34. How does a pneumatic door-check work?

35. Explain how a medicine-dropper works?

36. Explain the draft in a chimney.

37. Why does a fireplace ventilate a room?

38. Why do we place the ice in the top of a refrigerator rather than the bottom?

39. Why does a furnace sometimes fail to heat a certain room?

40. Why do stoves sometimes smoke when a fire is first started?

41. What is the best way to air a room? Why?

42. Why can a room be aired more quickly in winter than in summer?

43. Why are heaters always placed in the basement?

44. Why may one sometimes be more comfortable on a day when the thermometer stands at 90 degrees, than on a day when it is 82 degrees? 
45. How can you loosen a glass stopper which sticks? Why?

46. Why is water not used in a thermometer?

47 . Why is the bulb of a clinical thermometer made so long? Why is the bore made so small?

48. Why are the grates of stoves and furnaces fitted loosely and not fastened?

49. Why do water pipes burst when they freeze?

50. Why is the amount of ice-cream produced by a, freezer greater than the amount of liquid put in?

51. Why does a lamp chimney crack when a drop of water falls on it?

52. Why are thin tumblers less likely to crack than thick ones when placed in hot water?

53. Why is a cotton comfortable warmer than a wool blanket?

54. Why is a vacuum bottle silvered?

55. Why does bread or cake rise when being baked?

56. Of what advantage is the fireless cooker?

57. Why are stone houses cooler than wooden ones in summer?

58. Why are heating pipes or steam pipes sometimes covered with asbestos or felt?

59. How does a tea-cosy keep the tea warm?

60. Why does a hot-water bag remain warm so long?

61. Why are soapstones used in a fireless cooker rather than plates of iron?

62. Why do we cover an ice-cream freezer with a 
blanket after the freezing has been accomplished? Why do we not empty the melted ice from around the can?

63. Why is a wooden tub better than a metal one for the outside of a freezer?

64. Why should we not wrap the ice that is put into a refrigerator?

65. Why is ice better than ice water for cooling a refrigerator?

66. Why must a laundry dry room have a fan in order to do rapid work?

67. Which will dry more rapidly, gloves washed with water or with gasoline? Why?

68. Why do we cover utensils in cooking?

69. How may potatoes be cooked in ter minutes?

70. Explain why we use a double boiler.

71. Why does water evaporate faster from a pan than from a bottle?

72. Why is it a waste of gas to keep water boiling violently in cooking?

73. Why does a tea-kettle have a large bottom?

74. Why does a person feel chilly in damp clothing?

75. Why does ethyl chlorid freeze the tissues?

76. Why do we "see our breath" when it is cold? Why not when it is warm?

77. Why do one's glasses become covered with mist on coming from the cold into a warm room?

78. Why do opinions differ as to whether a room is warm or cold? 
79. What principles of physics are involved in the use of the cold tub and the cold sponge in reducing temperature?

80. Why is the thunder-clap not heard till some time after its lightning flash is seen?

81. Why are sounds heard better across water?

82. Why does a person hear better by placing the hand behind the ear?

83. Explain the use of the ear-trumpet.

84. Why is a grand piano used in preference to an upright for concerts, etc.?

85. Explain the difference between men's and women's voices.

86. What are some of the conditions that may produce deafness?

87. Why does the size of the pupil of the eye change?

88. Must a person be nearer the camera or farther away for a full-length portrait than for the head only?

89. Explain the intense heat produced by a "burning glass."

90. Why are ground-glass globes used on gas or electric lights?

91. Why do the eyes become tired from close work or reading more quickly than from looking at a distance?

92. Why do people have two pairs of glasses, or those with double lenses?

93. Why should very near-sighted persons wear glasses for reading? 
94. Why is prismatic glass used in doors or windows opening into dark corridors?

95. Why should colors be matched only in daylight?

96. How does an electric light switch work?

97. Why does not an electric bell ring unless the button is pushed?

98. What precautions must one take in using an electric heating pad?

99. Where would you look for trouble if a patient's bell failed to ring?

100. If an electric light suddenly went out, to what causes might it be due? 


\section{INDEX}

Accommodation in the human Block of pulley, 50 eye, 152

Adhesion, 24

Affinity, chemical, 24

Air cells in lung, 90

composition of, 74

pressure, 75 et seq.

and boiling, 105

washing systems, 96

weight of, 75

Altitude and the boiling-point, 105,106

Ampere, 175

Apparatus for experiments, 17, 18

Appliances, electric, 168 et seq.

Arc light, 170

Armature, 168

Artery clamp, 42

Artesian well, 65, 66

Artificial aids to hearing, 134

cold, 128

light, 160

Atomic theory, 22

Atoms, 22, 23

Attraction, capillary, 69

Axis-traction forceps, 54

BALL bearings, 56

Baths to reduce temperature, 109

Battery, electric, 166

Bell, electric, 173, 174

Bismuth in $x$-ray work, 183

Bodily heat, production of, 99

radiation of, 126

Boiling, 104 et seq.

Boiling-points, 105

Bottle, vacuum, 120

Bread mixer, 49

Breast pump, 76

Bulb syringe, 87

Buoyancy, 66

Burning, 100

Burns from $x$-ray, 184

CAlorie, 104

Camera, 156

Capillarity, 69

Cathartics, saline, action of, 71

Cathode rays, 181

Cell, electric, 166

Center of gravity, 33

Centigrade thermometer, 104

Centrifugal force, 38

Centrifuge, 38

Chemical action productive of heat, 99

affinity, 24

changes, 23, 24

Chemistry defined, 21

Chimney draft, 92

Circuit, electric, 167

Circulation in hot-water systems,

122,124

of blood, 88 
City water systems, 65

Clinical thermometer, 104

Clothing, 127

Cohesion, 24 in liquids, 60

Cold compress, 109 frame, 141

Color, 158 et seq. waves, 159

Compass, mariner's, 164

Compressibility of gases, 74 of liquids, 60

Condensation of liquids, 109

Conduction of electricity, 175 of heat, 115 et seq. of sound, 135

Conservation of energy, 36

Contraction due to cold, 102

Convection of heat, $115,120 \mathrm{et}$ seq.

Cooker, fireless, 119

Cooking under pressure, 106

Cooling, artificial, 128 by evaporation, 108, 109

Corpuscles, 41

Cracking, cause of, 102

Crank and axle, 49

Cream separator, 37 tester, 68

Crookes' tubes, 180

Crystallization, 28

Crystalloid substances, 29

Cupping glasses, 76

Current, electric, 166 high-frequency, 176

Defective sight, 153, 154

Dew, 109

Dialysis, 29

Diffusion, 29, 70 of gases, 73, 91

Dilator, uterine, 43,44
Distillation, 110, 111 destructive, 110

Distilled water, 111

Divers, deep sea, 62

Draft in a chimney, 92 in a stove, 100, 101

Drainage of wounds, 69

Dressing sterilizer, 107

Drops, size of, 60

Drowning, 67

Dry cells, electric, 166

Ductility, 27

Dynamo, 167

EAR, mechanism of, 133

Edema, 71

Elasticity, 27 of gases, 73

Electric action productive of heat, 99 appliances, 168 et seq.

battery, 166 bell, 173, 174 cell, 166 circuit, 167 current, high-frequency, 176 flat-iron, 169 fuse, 170 heating, 168 lamp, 169 lighting, 170 motor, 168 switch, 167 telegraph, 172 et seq. treatments, 176 wiring, 167, 168

Electricity, 163 et seq. and light, 142 chemically produced, 166 conductors of, 175 faradic, 176 frictional, 164 
Electricity, galvanic, 176

how produced, 164

produced by dynamo, 167

rate of travel, 175

static, 165,176

Electromagnet,.171, 172

Electron theory, 23

Emanation, radium, 186, 187

Energy, 35, 36

Equilibrium, stable and unstable, 34

Evaporation, 107 et seq.

Expansion by heat, 102

Extension apparatus, 50

Eye defects, 154

magnet, 172

the human, 151, 152

FAHRENHEIT thermometer, 104

Fan bath, 109

Faradic electricity, 176

Fever, 99

Field magnet, 168

Finsen light, 159

Fireless cooker, 119

Fireproof buildings, sound in, 137

Flat-iron, electric, 169

Fluoroscope, 183

Focus of light, 151

of the eye, 152 et seq.

Force, centrifugal, 38

driving, 39

pump, 86

the heart a, 88

Forceps, artery, 42 obstetric, 54

Forms of matter, 28

Fountain, Hero's, 80 vacuum, 79

Freezing of water, 103

Friction, 55 et seq., 98, 99

Frictional electricity, 164
Frost, 109

Fulcrum, 41, 45, 47

Fuse, electric, 170

Galvanic electricity, 176

Gas, illuminating, 74

Gases as conductors of heat, 117

diffusion of, 73, 91

properties of, 73

structure of, 28

Gravity, 32

center of, 33

specific, 33,60

HARDNESS, 27

Head mirror, 154

Hearing, aids to, 134

mechanism of, 133

Heart, action of, 88

sounds, 138

Heat, 98

bodily, 99, 126

effects of, 102

latent, 127

measurement of, 103

retention of, 119

sources of, 98

transmission of, 115 et seq.

Heating, electric, 168

systems, 121 et seq.

High-frequency" electric current, 176

Hoarseness, 137

Hot-water heating, 124

Human voice, 132

Hydraulics, 60

defined, 30

Hydrometer, 67

Hypodermic syringe, 81

ICE-CREAM freezer, 49,128

Illuminated objects, 146 
Illuminating gas, 74

Impenetrability, 35

Importance of physics, 19

Incandescent electric lights, 170

Inclined plane, 51

Induction coil, 176

Inertia, 26

Instruments, optical, 154 et seq.

Insulators, electric, 175

Interference with sound, 137

Irrigators, 62, 63

JoINTs, construction of human, 56,57

KITCheN range, drafts in, 100 , 101

for heating water, 122

LAMP, electric, 169

Laryngoscope, 156

Latent heat, 127, 128

Law, Newton's, 37

of Archimedes, 66

Pascal's, 64

Laws of air pressure, 80 et seq. of motion, 37

Lead in $x$-ray work, 184

Lens of the eye, 151 .

Lenses, 149, 150

Lever, 41 et seq.

Stanhope, 29

Levers in the human body, 44,47 , 48

of the first class, $41-44$

of the second class, 45,46

of the third class, 47

Leyden jar, 165

Lifting pump, 85

Light, 141 et seq.

arc, 170

artificial, 160
Light, direction of, 142

electric, 170

incandescent, 169,170

intensity of, 142, 143

rays of, 142

reflection of, 146,157

refraction of, 148

transmission of, 141, 144

waves, 141

Liquids, compressibility of, 60 pressure in, 61 et seq.

properties of, 60

structure of, 28

weight of, 61

Lubricants, 56

Luminous objects, 145

Lung sounds, 138

Lungs, action of, 90

Machine, the human, 39

Machines, 38 et seq.

classes of, 41

Magnetism, 163

Magnets, 163

electro-, 171, 172

eye, 172

field, 168

Malleability, 27

Matching colors, 160 ,

Matter, composition of, 21

forms of, 28

properties of, 24

Measurement of heat, 103, 104

Measures, electric, 175

Mechanics, 32 et seq.

defined, 30

of obstetrics, 52

Medical uses of electricity, 176

of radium, 187

of the $x$-ray, 184

Microscope, 157

adjustment of, 51 
Mirror, reflection in, 142, 143

Molecular motion, 98

Molecules, 22, 24

Motion, 25

laws of, 37,38

Motors, electric, 168

Muscles as levers, $44,47,48$

as pulleys, $\mathbf{5 1}$

Music, 136, 138

NoISE vs. music, 138

Normal temperature, 99

Obstetric forceps, 54

Obstetrics, mechanics of, 52, 64

Ohm, 175

Opacity, 27

Ophthalmoscope, 155

Optical instruments, 153 et seq.

Osmosis, 70, 71

Oxygen in combustion, 100

Particle, 22

Pascal's law, 64

Penumbra, 144

Perspiration, action of, 108, 109

Phonendoscope, 136

Photographs by $x$-ray, 181

Physical changes, 23, 24

Physics defined, 21

importance of, 19

Pitch of sounds, 136

Plane, inclined, 51

Plenum system of ventilation, 95

Pliers, 42

Plumbing in kitchen, $i 21$

Pneumatics, 30, 73 et seq.

Polarization of light, 151

Porosity, 26

Power in levers, 41 et seq.

in machinery, 39

Pressure in liquids, 64
Pressure in steam apparatus, 106 et seg.

of air, 75 et seq.

Primary colors, 158

Prism, 158

Properties of gases, 73

of liquids, 60

of matter, 24, 25, 27

Pulley, 50

Pumps, 85, 86

QuEstions for review, 190

RADIANT matter, 185

Radiation of heat, 125 et seq.

Radium, 185

compounds of, 186

emanation, 186, 187

history of, 185

uses of, 187

Rain, production of, 109

Rate of travel of electricity, 175

of light, 141

of sound, 135

Rays, radium, 187

$x$-, 180

Reaction, 38

Reflection of light, 146, 147

of sound, 137

Refraction of light, 148

Refrigerators, 117, 118

Respiration, 90, 91

Review questions, 190

Roentgen rays, 180 et seq.

Rolling friction, 56

SALINE cathartics, 71

Scissors, 42, 44

Screwdriver, 51

Separator for cream, 37

Sewing machine, 49

Shadows, formation of, 144 
Sheave, 50

Sight, 145, 151 et seq.

Siphon, 81, 82

Sliding friction, 55

Snow, how produced, 109

Solids, structure, 28

Sound, 130 et seq. conduction of, 135

interference with, 137 reflection of, 137

speed of, 135

Sounds of heart and lungs, 138

Spccific gravity, 33, 60, 68

Speculum, bivalve, 43

Sphygmomanometer, 89

Stability, 34

Standing, 34, 35

Stanhope lever, 49

Static electricity, 165

Steam apparatus, 89

engine, 89

heating system, 124

pressure apparatus, 106 et seq.

Sterilizers, 107

Stethoscope, 135

Stomach-tube, 83

Subnormal temperature, 100

Substances, simple and complex, 21

Sunstroke, 127

Supplies for experiments, 17

Swimming, 67

Switch, electric, 167

Synovial fluid, 57

Syringe, bulb, 87

hypodermic, 81

Systems of heating, 121 et seq. of ventilation, 94

Telegraph, 172 et seq.

Telephone, 173

Telescope, 158
Temperature, bodily, 99, 100 defined, 101 its relation to form, 28

Tenacity, 27

Tendency to crystallize, 28

Testing milk, 68

Theories in regard to radium, 185

Theory, atomic, 22

electron, 23

Thermometers, 103, 104

Transmission of light, 144

Transparency, 27

Treatments, electric, 176

with radium, 187

URINALYSIS, polarized light in, 151

Urine centrifuge, 38

pressure in bladder, 64

Urinometer, 68

Uterine dilators, 44,52

VACUUM, 77

bottle, 120

fountain, 79

kettle, 106

system of ventilation, 95

tube, 180

Valves in veins, 89

Venous circulation, 89

Ventilating systems, 94

Ventilation, 91 et seq.

Vibrations producing sound, 130 , 136

Vibreur, electric, 172

Voice, human, 132, 136

Volt, 175

WALKING, 34, 35

Washed air ventilating system, 96

Water as a conductor of heat, 110 bed, 64 
Water, distilled, 111 freezing of, 103

heating system, 122, 124 sterilizers, 107

systems, 65

Waterproofing, 70

Watt, 175

Wave movement of sounds, 131

Waves in colored light, 159 of light, 141

Wedge, 52

Weight, 33

of air, 75
Weight of liquids, 61

Weights moved with lever, 41 et seq.

Well, artesian, 65

Wheel and axle, 49

Wiring, electric, 167, 168

Work, 35, 36

Wounds, drainage of, 69

$x$-RAY, 180 et seq.

burns from, 184

characteristics of, 181

uses of, 183 





\section{SOUTHERN BRANCH UNIVERSITY OF CALIFORNIA LIBRARY LOS ANGELES, CALIF.}


